Adição e avaliação de estímulos sonoros como ferramenta de apoio à exploração visual de dados

Wagner José Franchin 



\title{
Adição e avaliação de estímulos sonoros como ferramenta de apoio à exploração visual de dados
}

\author{
Wagner José Franchin
}

Orientadora: Profa. Dra. Rosane Minghim

Dissertação apresentada ao Instituto de Ciências Matemáticas e de Computação - ICMC-USP, como parte dos requisitos para obtenção do título de Mestre em Ciências Ciências de Computação e Matemática Computacional. 



\section{Agradecimentos}

Primeiramente tenho que agradecer a Deus pela saúde, coragem e determinação em todos estes anos de vida. Certamente Ele é responsável direto por me guiar e ajudar a superar as diversas adversidades da vida.

Agradeço aos meus pais Vitório e Margarida pela educação, carinho e apoio. Aos meus irmãos Ivan e Silvana pelo companheirismo e pela força.

Agradeço aos meus Avôs (Antonio e José) e Avós (Santina e Aparecida), Tios (Carlos Roberto, Benedito, Paulo e Adão), Tias (Márcia, Maria, Dete e Maria de Lurdes), Primos (José Rodrigo, Eduardo, Fernando, Marcelo, Marco e Tiago) e primas (Nátia, Bianca, Márcia, Vivian e Bruna) pelo apoio.

Agradeço a minha orientadora de mestrado Rosane Minghim pela dedicação, comprometimento e profissionalismo apresentado durante estes dois anos e meio de trabalho.

Agradeço aos meus amigos da USP: Márcio de Almeida, Henderson Silva, Roberto Pinho, Fernando Paulovich, Lionis Watanabe, Delane Dias, Renato Rodrigues, demais amigos do ICMC e todos os alunos voluntários que colaboraram participando do experimento com usuários que realizei.

Agradeço a todos os professores e funcionários do ICMC que colaboraram para que este trabalho fosse possível.

Um agradecimento especial ao meu clube de coração Sociedade Esportiva Palmeiras pelos anos de conquistas e títulos.

Obrigado!! 

Visualização é o processo genérico que utiliza representações visuais e interativas para facilitar a análise e o entendimento de informações de conjunto de dados. A maioria das ferramentas de visualização existentes atualmente utiliza exclusivamente recursos visuais para representar informações e isto tem limitado a capacidade exploratória e a apresentação de dados. Vários estudos têm demonstrado que o uso do som como recurso alternativo para representação de dados (sonificação) pode ser útil na interpretação de informações e também pode apoiar o aumento da dimensionalidade da apresentação visual. A sonificação é o objeto de estudo deste trabalho.

Este trabalho implementa o novo módulo de sonificação de um sistema de exploração visual de dados, o Super Spider (Watanabe, 2007), que foi estendido com a implementação de recursos que auxiliam a exploração de dados por meio de sons. Um novo sistema, chamado Sonar 2D, também foi desenvolvimento de forma integrada ao Super Spider e apresenta uma nova técnica para sonificação de dados. Além disso, são apresentados resultados de testes com usuários aplicados para avaliar e validar os mapeamentos visuais e sonoros utilizados nos sistemas. 

Visualization is a generic process that uses visual and interactive representations to easy the analysis and the understanding of complex datasets. To this date, most of the visualization toolkits make use almost exclusively of visual aid to represent information, which has limited the capacity for data presentation and exploration. Many studies have shown that sound as an alternative data display tool (sonification) can be useful to support information interpretation and may also add dimensions to a visual display. Sonification is the object of study of this work.

This work implements the new sonification module for a recently developed visual exploration system, the Super Spider (Watanabe, 2007). It has been extended with the implementation of functionalities in order to support data exploration through sounds. A new system, called Sonar 2D, was also developed and integrated to Super Spider, including a new technique of data sonification. In addition, this work presents results user evaluation for validation of some of the visual and sound mappings employed in both systems. 

Resumo

$\begin{array}{lll}\text { Abstract } & \text { iii }\end{array}$

1 Introdução $\quad 1$

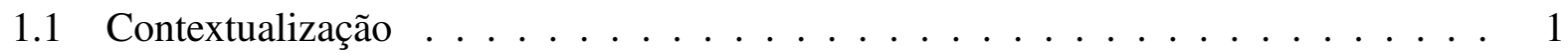

1.2 Motivação e objetivos . . . . . . . . . . . . . . . . . . . . 2

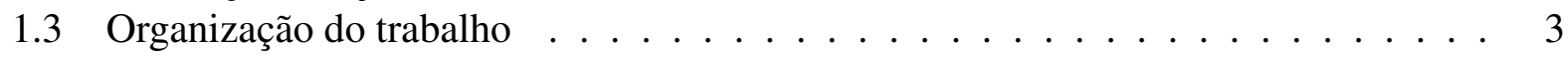

2 Percepção Sonora e Sonificação $\quad 5$

2.1 Considerações Iniciais . . . . . . . . . . . . . . . . . . . . . 5

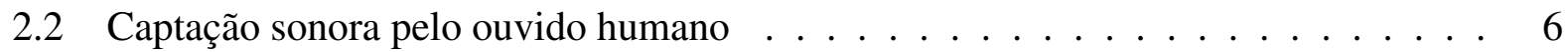

2.3 Percepção sonora . . . . . . . . . . . . . . . . . . . . . . 6

2.4 Funções do som . . . . . . . . . . . . . . . . . . . . . . . . . . . . . . .

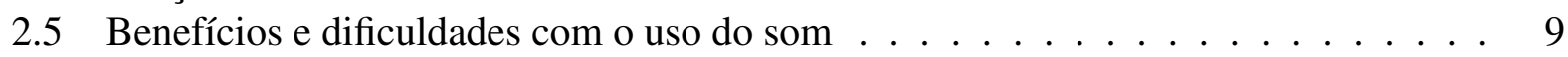

2.6 Sonificação . . . . . . . . . . . . . . . . . . . . 10

2.6.1 Áreas de pesquisa em sonificação . . . . . . . . . . . . . . . . . 11

2.6.2 Campos de aplicação de sonificação . . . . . . . . . . . . . . . . . . 12

2.6.3 Técnicas de sonificação . . . . . . . . . . . . . . . . . . . . . . . . . . . . . . . 13

2.7 Considerações Finais . . . . . . . . . . . . . . . . . . 18

3 Revisão Bibliográfica $\quad 21$

3.1 Considerações Iniciais . . . . . . . . . . . . . . . . . . . . . . 21

3.2 Revisão dos trabalhos de sonificação . . . . . . . . . . . . . . . . . . . . 21

3.3 Revisão dos trabalhos com experimentos em sonificação . . . . . . . . . . . . . 33

3.4 Considerações Finais . . . . . . . . . . . . . . . . . . . 37

4 Sistema de sonificação de dados $\quad 39$

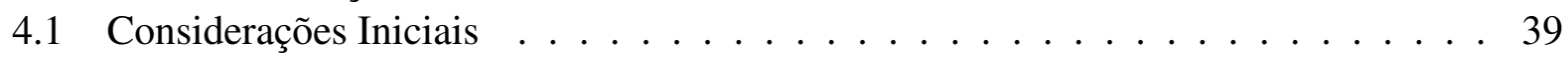

4.2 Spider Cursor . . . . . . . . . . . . . . . . . . . . . . . 39

4.2 .1 Principais funcionalidades . . . . . . . . . . . . . . 41

4.3 Super Spider . . . . . . . . . . . . . . . . . . . . 42

4.3.1 Módulo de sonificação . . . . . . . . . . . . . . . . . . . 43

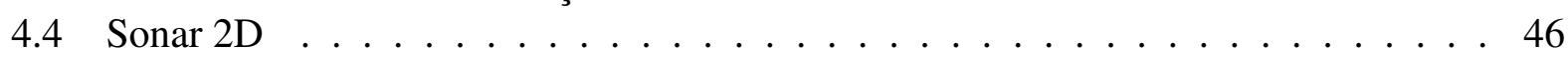

4.4.1 Interfaces visuais e inicialização do sistema . . . . . . . . . . . . 46 
4.4.2 Configuração dos itens sonoros . . . . . . . . . . . . . . . . . 48

4.4 .3 Mapeamento sonoro e execução . . . . . . . . . . . . . . . . . . 51

4.4.4 Analisando o conjunto de dados sonificado . . . . . . . . . . . . . 53

4.5 Considerações Finais . . . . . . . . . . . . . . . . . . . . . 54

5 Experimento com usuários $\quad 57$

5.1 Considerações Iniciais . . . . . . . . . . . . . . . . . . . 57

5.2 Definição e aplicação dos testes . . . . . . . . . . . . . . . . 57

5.2.1 Definição dos conjuntos de dados e mapeamento visual e sonoro . . . . . . 58

5.2 .2 Definição dos participantes . . . . . . . . . . . . . . 58

5.2 .3 Aplicação dos testes . . . . . . . . . . . . . . . . . . . . 59

5.2 .4 Definição das tarefas . . . . . . . . . . . . . . . . . . 60

5.3 Análise dos resultados . . . . . . . . . . . . . . . . . . . . 64

5.3.1 Tarefa de ordenação sonora por regiões . . . . . . . . . . . . . 65

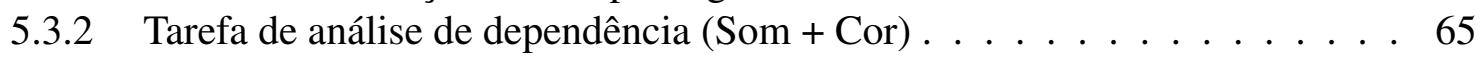

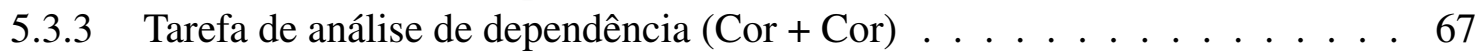

5.3 .4 Tarefa de análise de densidades . . . . . . . . . . . . . . . 68

5.4 Considerações Finais . . . . . . . . . . . . . . . . . . . . . 68

6 Conclusões $\quad \mathbf{7 1}$

6.1 Trabalhos Futuros . . . . . . . . . . . . . . . . . 72

$\begin{array}{ll}\text { Referências } & 83\end{array}$

$\begin{array}{lll}\text { A Resultados dos testes aplicados } & 85\end{array}$ 


\section{Lista de Figuras}

2.1 Ouvido externo, ouvido médio e ouvido interno (extraído de (corpohumano.hpg.ig.com.br, 2007)). . . . . . . . . . . . . . . . . . . 7

2.2 Fluxo de dados em sonificação (adaptado de (Hermann, 2002)) . . . . . . . . . . . 11

2.3 Passos da técnica de sonificação por audificação (adaptado de (Hermann, 2002)) . . 14

2.4 Passos da técnica de sonificação por mapeamento de parâmetros (adaptado de (Hermann, 2002)) . . . . . . . . . . . . . . . . . . 17

2.5 Representação da técnica de sonificação Model-Based Sonification (adaptado de

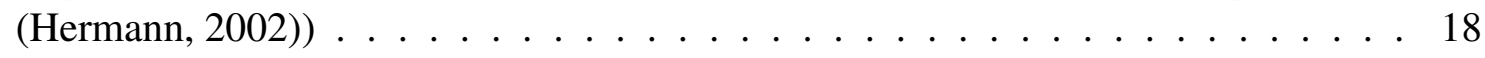

3.1 Interface visual do sistema MUSART (adaptado de (Joseph e Lodha, 2002)) . . . . 23

3.2 Duas formas de interação presente no DSVol (adaptado de (Salvador, 2003)). . . . 24

3.3 Sondagem de superfície (Plane Scan) em dois gráficos (adaptado de (Salvador, 2003)) . . . . . . . . . . . . . . . . . . 24

3.4 Gráfico de dispersão (scatter plot) dos dados e a curva principal (adaptado de (Hermann et al., 2000) ) . . . . . . . . . . . . . . . . 25

3.5 Interface do usuário para controle do modelo sonificação de dados por cristalização (adaptado de (Hermann et al., 2000)) . . . . . . . . . . . . . . 26

3.6 Tela do modelo de visualização do AVDisplay Visualization (adaptado de (Hermann et al., 2003b)) . . . . . . . . . . . . . . . . . 27

3.7 Tela de mapeamento sonoro do sistema Sonification Sandbox . . . . . . . . . . . 28

3.8 Tela principal do sistema Audio Abacus . . . . . . . . . . . . . . . . . . . 30

3.9 Diferentes figuras com suas opacidades controladas por parâmetros sonoros na interface gráfica do SonART (adaptado de (Yeo et al., 2004)) . . . . . . . . . . . . 30

3.10 Tela do teste de associação do som ao gráfico (adaptado de (Bonebright et al., 2001)) 33

3.11 Imagens do conjunto de dados Volume de Chuva (adaptado de (Salvador, 2003)). . 35

3.12 Imagens das telas do experimento (adaptado de (Pauletto e Hunt, 2005)). . . . . . . 35

3.13 Mapas com diferentes níveis de concentração de ozônio utilizados no experimento (adaptado de (Holmes, 2005)). . . . . . . . . . . . . . . . 36

3.14 Interface utilizada pelos participantes para descrever os sons (adaptado de (Brazil e Fernström, 2006)). . . . . . . . . . . . . . . . . . 37

4.1 Exploração do conjunto de dados com o cursor. . . . . . . . . . . . . . . . . . 40

4.2 Seqüência de operações do corte. . . . . . . . . . . . . . . . . . . 41

4.3 Visualização sendo explorada utilizando o 2D Spider Cursor e super-quádricas no sistema Super Spider. . . . . . . . . . . . . . . . . . . . . . . . . . . . . 43 
4.4 Super-quádricas disponíveis para a exploração dos dados. . . . . . . . . . . . . . . 43

4.5 Opções de configuração do módulo de sonificação. . . . . . . . . . . . . . . . . . . 44

4.6 Opções de controle da sonificação do caminho de corte. . . . . . . . . . . . . . . . 46

4.7 Tela principal do Sonar 2D . . . . . . . . . . . . . . . . . . 47

4.8 Definindo o ponto central do Sonar com o 2D Spider Cursor . . . . . . . . . . . . 48

4.9 Execução de mais de uma janela do Sonar 2D para conjunto de escalares distintos. 49

4.10 Tela principal com a opção File Info selecionada . . . . . . . . . . . . . . . . . 49

4.11 Sonar2D Display com a representação de novo ponto selecionado . . . . . . . . . . 50

4.12 Parâmetros: instrumento, valores dos escalares e cor do item sonoro . . . . . . . . 50

4.13 Parâmetros: intensidade, entoação e mapeamento inverso . . . . . . . . . . . . . 50

4.14 Tabela de itens sonoros e os botões para adicionar e remover itens. . . . . . . . . . 51

4.15 Execução do Sonar2D nos dois modos de execução. . . . . . . . . . . . . . . . . . 52 . . . . . 53

4.16 Tela de configurações do sistema. . . . . . . . . . . . . . . . . . 53

4.17 Gráficos gerados durante o mapeamento sonoro. . . . . . . . . . . . . . 53

5.1 Tela inicial do experimento. . . . . . . . . . . . . . . . . . . 60

5.2 Tela do teste de ordenação por regiões utilizando som. . . . . . . . . . . . . . 61

5.3 Tela da tarefa de análise de dependência (Som + Cor) na etapa 1. . . . . . . . . . 62

5.4 Tela da tarefa de análise de dependência (Som + Cor) na etapa 2 . . . . . . . . . . . 62

5.5 Tela da tarefa de análise de dependência (Cor + Cor) na etapa 1. . . . . . . . . . 63

5.6 Tela da tarefa de análise de dependência (Cor + Cor) na etapa 2. . . . . . . . . . 63

5.7 Tela do teste de análise de densidades de pontos. . . . . . . . . . . . . . . 64

5.8 Resultados obtidos na tarefa de ordenação (Bar Chart) . . . . . . . . . . . . . . . 66

5.9 Resultados obtidos na tarefa de análise de dependência som e cor. . . . . . . . . . . 66

5.10 Resultados obtidos na tarefa de análise de dependência utilizando cor. . . . . . . . 68

5.11 Resultados obtidos na tarefa de análise de densidades (Bar Chart) . . . . . . . . . . 69 


\section{Lista de Tabelas}

4.1 Valores das propriedades sonoras do ponto com valor escalar igual a 40. . . . . . . 45

4.2 Valores das propriedades sonoras do ponto com valor escalar igual a 90. . . . . . . 45

5.1 Informações sobre as duas etapas do experimento . . . . . . . . . . . . . . . 59

5.2 Tarefa de ordenação sonora por regiões. . . . . . . . . . . . . . . . . 65

5.3 Tarefa de análise de dependência som e cor (Etapa 1 e Etapa 2). . . . . . . . . . . 66

5.4 Intervalos com nível de confiança de $95 \% \ldots \ldots \ldots$. . . . . . . . . . . 67

5.5 Tarefa de análise de dependência utilizando cor (Etapa 1 e Etapa 2). . . . . . . . . 67

5.6 Intervalos com nível de confiança de $95 \% \ldots \ldots \ldots 7 . \ldots \ldots$

5.7 Tarefa de análise de densidade (maior densidade) . . . . . . . . . . . . . 68

5.8 Tarefa de análise de densidade (menor densidade) . . . . . . . . . . . . . . 68

A.1 Resultados de cada participante na tarefa de ordenação - Etapa 1 . . . . . . . . . . 86

A.2 Resultados da tarefa de análise (Som + Cor) e (Cor + Cor) - Etapa $1 \ldots$. . . . . . . 87

A.3 Resultados da tarefa de análise de densidades com o Sonar - Etapa 1 . . . . . . . . 88

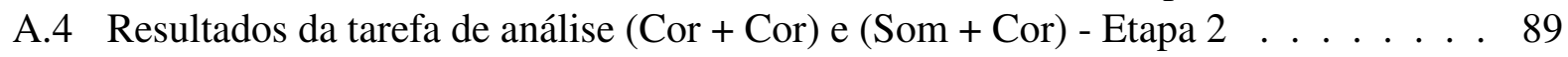





\subsection{Contextualização}

A geração e o armazenamento de grande quantidade de informações dos diversos campos do conhecimento humano nas últimas décadas têm sido beneficiados pela rápida evolução dos recursos computacionais de processamento e armazenamento de dados. $\mathrm{O}$ avanço do poder computacional também tem possibilitado a aquisição de conhecimento a partir de grandes conjuntos de dados, tornando possível a apresentação, interpretação e o entendimento das informações sob análise.

A área de Visualização Computacional (Minghim e Oliveira, 1997) surgiu como um instrumento para auxiliar cientistas e pesquisadores no desenvolvimento de ferramentas e outras aplicações computacionais que facilitem a análise de conjuntos de dados de alta dimensionalidade.

A Visualização Computacional conta com um aparato de técnicas de Computação Gráfica, Interação Usuário-Computador, Processamento de Sinais e Imagens e muitas outras com o propósito de apresentar informações de maneira clara e intuitiva, com aplicações nas mais variadas áreas como: financeira, metereológica, médica, biológica, empresarial e espacial.

Um problema que a visualização computacional enfrenta é a representação de grandes conjuntos de dados, muitas vezes multidimensionais. O principal motivo é que a tela de um computador possui recursos limitados tanto de espaçamento (tamanho da tela) quanto de capacidade de projeção espacial de gráficos de alta dimensão. Na tentativa de resolver ou minimizar esse problema, a utilização de estímulos sonoros (sonificação ${ }^{1}$ ) como alternativa para auxiliar na representação

\footnotetext{
${ }^{1}$ A palavra sonificação (sonification) tem sido usada para indicar o mapeamento sonoro de dados numéricos com a intenção de fornecer informações (Salvador, 2003).
} 
e exploração de dados multidimensionais tem sido sugerida e desenvolvida (Zhao et al., 2005) (Childs, 2005).

Neste contexto, o propósito deste trabalho é o de estudar, propor e implementar estratégias de adição de estímulos sonoros em sistemas de visualização.

\subsection{Motivação e objetivos}

Nos últimos anos, muito tem sido feito para aumentar a capacidade exploratória das ferramentas de análise de dados. A capacidade das técnicas de visualização de informação para gerenciar dados de alta dimensionalidade é reconhecida há varios anos. Embora as técnicas de visualização não estejam ainda exauridas, existem limitações para a habilidade das pessoas em interpretar e reconhecer informações visualmente (Smith et al., 1994). Por isso é crescente a busca por alternativas que diminuam o excesso de informação visual através do desenvolvimento de métodos efetivos para codificação de dados em sons (Janata e Childs, 2004) (Holmes, 2005).

Seres humanos estão acostumados a utilizar estímulos sonoros em suas atividades diárias. Isto é feito, por exemplo: na comunicação presencial entre pessoas ou por meio de dispositivos de comunicação como os celulares; na obtenção de informações sonoras transmitidas por rádios e televisores; na percepção de sinais sonoros provenientes de equipamentos eletrônicos que indicam determinado estado de funcionamento; na orientação e localização espacial por meio de sons do ambiente. Sons são de grande utilidade para minimizar a sobrecarga visual (Salvador, 2003), principalmente em alguns ambientes como, por exemplo, em cabines de comando de aviões e em centros de controles de estações de energia, por serem esses ambientes onde a sobrecarga visual já é muito grande e não são admitidas falhas no entendimento das informações. Outro exemplo de aplicação vital de som é o pulsômetro, equipamento utilizado por médicos em procedimentos cirúrgicos para monitorar as condições cardíacas dos pacientes (Hermann, 2002).

Experimentos com usuários têm demonstrado melhoria no desempenho da exploração dos dados em tarefas de análise de conjuntos de dados usando visualização conjuntamente com som (Pauletto e Hunt, 2004) (Salvador et al., 2005). Estes experimentos provam o conceito de que representação sonora de dados pode ser também utilizada como complemento da visualização, pois aumenta a quantidade de informação a ser comunicada ao usuário e reduz a quantidade de informação que o usuário tem de distinguir através do canal visual.

Muitos trabalhos ainda devem ser realizados para estabelecer a relevância da representação sonora como ferramenta para análise e exploração de dados. Existem relativamente poucas pesquisas formais que medem a efetividade das interfaces sonoras em aplicações do mundo real ou até mesmo que estudam formas para melhorar seu entendimento. O conhecimento atual da eficácia do uso de som para comunicar interativamente informação é ainda escasso se comparado com o desenvolvimento de interfaces visuais. 
O grupo de Visualização do SCC-ICMC-USP tem trabalhado há vários anos nos aspectos de interação e sonificação associados a apresentações gráficas, com destaque para o desenvolvimento do DSVol (Distributed Sound for Volumes) (Salvador e Minghim, 2003). O DSVol é um sistema de visualização com uso de sonificação que foi expandido do SVol (Sound for Volumes) (Salvador et al., 1998) (ver Capítulo 3). No ano de 2005 foi publicada uma avaliação com usuários utilizando o modo de interação 2D Spider Cursor (Salvador et al., 2005) desta ferramenta.

Em continuidade as contribuições do grupo na área de pesquisa, este trabalho propõe:

- Reproduzir e melhorar os mapeamentos sonoros do DSVol numa ferramenta nova de interação para visualizações baseadas em superfícies, o Super Spider (Watanabe, 2007). A principal sonificação implementada neste novo sistema foi o mapeamento sonoro dos valores escalares dos pontos de uma visualização. A sonificação é gerada através da interação ponto-a-ponto com a representação gráfica que é realizada com o auxílio do $2 D$ Spider Cursor, um dispositivo de exploração pontual com o ponteiro do mouse. Os parâmetros sonoros utilizados no mapeamento dos pontos são: intensidade, entoação e inflexão da entoação.

- Apresentar uma nova metodologia e um sistema de sonificação de dados, o Sonar 2D, que permite ao usuário ouvir determinado conjunto de dados sem a necessidade de interagir ponto-a-ponto com a representação gráfica. A idéia principal do sistema é criar um "mundo virtual sonoro" onde cada registro ou conjunto de registros é transformado em uma nota de instrumento musical e sua execução é realizada à medida que os pontos são atingidos por uma "onda mecânica" representada por uma esfera ou um círculo (no caso da representação gráfica 3D ou 2D, respectivamente) que se expande a partir de um foco. O sistema apresenta diversos parâmetros sonoros (timbre, entoação, intensidade e duração) que são utilizados para mapear conjuntos de registros de dados com características específicas. O Sonar 2D está integrado ao Super Spider.

- Expandir a análise do impacto do uso de sonificação para a exploração de dados apoiada por visualização através de novos experimentos com usuários.

Este trabalho foi desenvolvido dentro do projeto InfoVis2 do grupo de Computação Gráfica e Processamento de Imagens do ICMC-USP. O InfoVis2 tem como objetivo, entre outras coisas, disponibilizar um repositório de técnicas de visualização, mineração visual e sonificação que possam ser acessadas remotamente, atuem de forma integrada e sejam adaptáveis às necessidades do usuário. Os arquivos correspondentes aos códigos fontes das ferramentas desenvolvidas e outros detalhes do projeto estão disponíveis no endereço eletrônico http://infoserver.lcad. icmc.usp.br/infovis2.

\subsection{Organização do trabalho}

Esta dissertação apresenta a seguinte organização: 
- O Capítulo 2 apresenta uma definição de som e de algumas propriedades sonoras, os fenômenos que afetam a propagação do som no ambiente e a função do som em nosso dia-a-dia, destacando os benefícios e limitações do uso de estímulos sonoros em aplicações computacionais. Uma seção do capítulo detalha a forma como o som é captado pelo ouvido humano e suas formas de percepção. A última seção do capítulo apresenta um estudo sobre sonificação, abordando suas áreas de pesquisa, campos de aplicação e as técnicas de sonificação mais conhecidas, difundidas e aplicadas em sistemas computacionais.

- O Capítulo 3 traz uma revisão bibliográfica de trabalhos que utilizaram som em ambientes computacionais, além de uma revisão de experimentos com usuários em sistemas de computação onde foram avaliados os aspectos perceptuais dos estímulos sonoros criados.

- O Capítulo 4 apresenta a ferramenta para exploração de dados Spider Cursor que serviu de base para a realização do presente trabalho, bem como a sua derivada, o Super Spider, abordando principalmente o novo módulo de sonificação. A nova ferramenta para exploração sonora de dados, o Sonar 2D, também é apresentada.

- O Capítulo 5 descreve experimentos com usuários sobre ambas as ferramentas e seus resultados. Tais resultados confirmam a hipótese que sonificação pode ser empregada para complementar a apresentação visual.

- O Capítulo 6 traz conclusões e discussões sobre o trabalho, além de apresentar algumas propostas para trabalhos futuros. 


를

\section{Percepção Sonora e Sonificação}

\subsection{Considerações Iniciais}

Sons são fenômenos acústicos produzidos pelo movimento de vibração de um corpo sonoro em meios que tenham massa e elasticidade como o sólido, líquido ou gasoso (Wikipedia, 2007). A função do meio transmissor é fundamental já que o som não se propaga no vácuo. Para que exista som são necessários uma fonte de vibração mecânica e um meio elástico através do qual a perturbação se propaga. O meio mais comum de transmissão do som é o ar, com velocidade de propagação de 340 metros por segundo. Em geral, a velocidade do som é maior nos sólidos que nos líquidos. Nos líquidos a velocidade de propagação é maior que nos gases. Alguns dos fenômenos físicos que afetam a propagação do som são: reflexão (a onda não é capaz de passar por um obstáculo e é refletida), absorção (toda ou parte da energia da onda sonora é absorvida pelo meio) e refração (desvio na direção de propagação da onda sonora ao alterar o meio de transmissão) (Wikipedia, 2007).

Algumas das propriedades físicas do som são (Wikipedia, 2007):

- Duração (duration): É a característica que permite distinguir a permanência temporal de um dado som (sons curtos e sons longos);

- Intensidade (intensity): Força com que um som é emitido (sons fracos e sons fortes). A intensidade do som (volume) é medida em Decibéis (dB);

- Entoação (pitch): Refere-se aos sons médios, graves e agudos. A entoação de um som é defina por sua freqüência em Hertz $(\mathrm{Hz})$. Sons agudos possuem altas freqüências, enquanto que sons graves possuem baixas freqüências. 
- Timbre: É a propriedade que caracteriza a fonte que produz o som (voz humana, instrumento musical, etc). É esta característica que permite distinguir, por exemplo, um violino de um clarinete, ainda que toquem com a mesma intensidade e na mesma entoação;

Este capítulo apresenta na Seção 2.2 o processo de captação de sons pelo ouvido humano. A Seção 2.3 descreve os rudimentos de percepção humana de estímulos sonoros. A Seção 2.4 destaca algumas das funções do som em nosso ambiente. A Seção 2.5 discute os benefícios e as limitações na utilização de som, abordando inclusive sua aplicação em interfaces sonoras. A Seção 2.6 apresenta um estudo sobre sonificação, tema central deste trabalho de mestrado. A Seção 2.7 traz as considerações finais do capítulo.

\subsection{Captação sonora pelo ouvido humano}

O ouvido humano é um órgão sensível que possibilita a percepção e interpretação de ondas sonoras em uma variação de freqüências entre $20 \mathrm{~Hz}$ e $20000 \mathrm{~Hz}$ (Wikipedia, 2007). Desde o momento de captação do som até sua percepção e interpretação, a energia sonora passa por uma série de transformações, passando pela mecânica, hidráulica e finalizando com a energia elétrica dos impulsos nervosos que chegam ao cérebro. A energia sonora é captada pelo pavilhão auditivo (orelha) (ver Figura 2.1) e penetra o conduto auditivo que termina em uma delicada membrana - o tímpano. O tímpano transforma as vibrações sonoras em vibrações mecânicas que são comunicadas aos ossículos (martelo, bigorna e estribo). Os ossículos funcionam como alavancas, aumentando a força das vibrações mecânicas e reduzindo sua amplitude. É através dos ossículos que o ouvido tem a capacidade de "ouvir mais" ou "ouvir menos". Esse controle é feito através de pequenos músculos que posicionam os ossículos em condições de transferirem toda ou apenas parte da energia mecânica recebida do tímpano. Quando ouvimos uma freada violenta de um automóvel, por exemplo, instintivamente esperamos pelo barulho da batida. Neste momento, automaticamente os ossículos são posicionados para que ouçamos tal barulho com menor intensidade. O último ossículo (o estribo) pressiona a janela oval do caracol, local onde as vibrações mecânicas se transformam em ondas de pressão hidráulica que se propagam no fluido que preenche o caracol. Finalmente, as ondas no fluido são detectadas pelas células ciliadas que enviam ao cérebro sinais nervosos (elétricos) que são interpretados como som (corpohumano.hpg.ig.com.br, 2007).

\subsection{Percepção sonora}

De acordo com Williams (Williams, 1994), "sensação" se refere a experiências básicas e imediatas geradas por estímulos simples e isolados, enquanto que "percepção" envolve a interpretação das sensações, dando a elas organização e significado. Williams define duas formas de percepção sonora: percepção sintética (synthetic perception) e percepção analítica (analytic perception). Percepção sintética é quando a informação sonora apresentada é interpretada da forma mais geral 


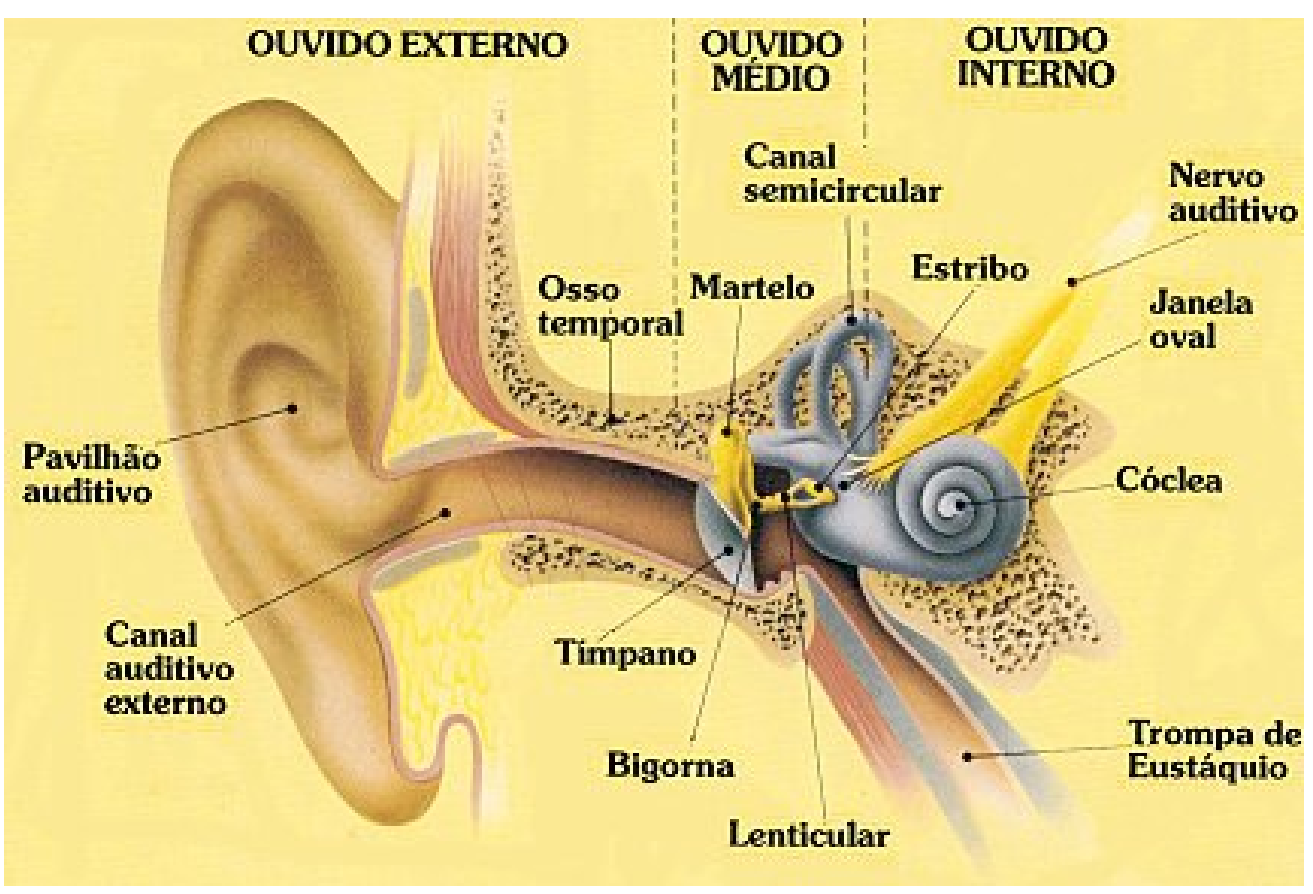

Figura 2.1: Ouvido externo, ouvido médio e ouvido interno (extraído de (corpohumano.hpg.ig.com.br, 2007)).

possível, ou seja, sem nenhum enfoque específico, por exemplo, escutar uma música sem perceber as notas de um específico instrumento. Já a percepção analítica visa usar a informação para identificar os componentes do ambiente de forma mais detalhada, por exemplo, ouvir a voz de uma pessoa em particular em uma sala cheia de pessoas ou identificar nuances de afinação de um instrumento. A interpretação de sons do ambiente geralmente envolve a combinação das duas formas de percepção. Por exemplo, ao ouvir uma mensagem por meio de caixas acústicas, a percepção sintética é utilizada para extrair a informação sendo transmitida pelas caixas, enquanto que a percepção analítica separa a informação dos sons do ambiente.

Agrupamento auditivo (auditory grouping) é o processo perceptual pelo qual os ouvintes separam as informações de um sinal acústico em sons significativos (Williams, 1994). O resultado deste processo são os objetos auditivos também conhecidos como correntes auditivas (auditory streams). Bregman (Bregman, 1994) descreveu o processo de agrupamento de uma ou mais correntes auditivas em som como um processo análogo aos princípios de agrupamento Gestalt na percepção visual. A psicologia Gestalt é o estudo da tendência humana de reconhecer padrões e configurações que aparecem no meio ambiente (Williams, 1994). A Teoria da Gestalt afirma que não se pode ter conhecimento do todo através das partes, e sim das partes através do todo. Só através da percepção da totalidade é que o cérebro pode de fato perceber, decodificar e assimilar um conceito, já que os conjuntos possuem leis próprias e estas regem seus elementos. Princípios da Gestalt têm sido investigados principalmente no estudo da percepção visual. Entretanto, princípios similares existem e estão sendo confirmados para a percepção sonora. Os mais importantes princípios da Gestalt no domínio auditivo são: 
- Semelhança: componentes que compartilham os mesmos atributos são percebidos de forma relacionada. Isto normalmente implica conexão com relação a timbre, entoação e sonoridade.

- Proximidade: componentes são agrupados de acordo com a distância entre eles, por exemplo, proximidade temporal e de freqüência.

- Boa continuidade: a transição suave entre dois componentes permite que eles sejam percebidos de forma relacionada, por exemplo, a transição "contínua" entre duas sequiências sonoras.

- Familiaridade: experiências anteriores com sons podem influenciar na percepção. As estruturas de sons complexos são armazenadas na memória e colaboram em futuras inspeções sonoras. Um exemplo bastante comum é a escala diatônica ${ }^{1}$.

- Estabilidade: quando uma primeira interpretação de um sinal acústico é obtida, esta interpretação permanece constante mesmo com alterações pequenas em suas propriedades. Isto indica que o som é percebido e interpretado no contexto que o precede e não somente na sua forma atual.

Para uma discussão mais profunda sobre este tópico ver (Williams, 1994) e (Bregman, 1994).

\subsection{Funções do som}

Os seres humanos percebem os sons do ambiente durante todo o tempo. Estes sons incluem cantos de pássaros, tráfego de automóveis e pessoas, alguém batendo na porta ou conversando, etc. Outra forma de percepção de sons pode ocorrer quando interagimos com um objeto do ambiente. Dessa forma, sons podem ser agrupados em duas categorias: sons passivos - sons emitidos naturalmente (fenômenos naturais como a chuva e o vento) e sons ativos - sons produzidos pela interação humana com o ambiente.

Sons passivos possuem duas funções principais: a primeira é nos informar das condições do ambiente em que estamos (calmo, agitado, barulhento). A segunda função é alertar e chamar a atenção para eventos de interesse que podem ser potencialmente perigosos, por exemplo, o ataque de um animal ou a aproximação de um carro. O sentido da audição está sempre "acionado" já que não existem "pálpebras sonoras" (como nos olhos) para obstruir a transmissão do canal de sentidos sonoros do ambiente, mesmo em momentos que estamos distraídos ou dormindo.

Sons ativos são os sons que utilizamos durante a exploração do ambiente. Sua função, quando existe, é fornecer informações sobre o material de um objeto que estamos manipulando (áspero,

\footnotetext{
${ }^{1}$ Escala diatônica (diatonic scale) é a escala musical mais utilizada na música ocidental, composta de cinco tons e dois semitons. Compreende as escalas maior e menor.
} 
liso), sobre o progresso de uma ação (som emitido durante o deslocamento de um esfera de metal sobre uma superfície) e sobre objetos que não podem ser vistos (sacudindo uma caixa opaca que possui objetos em seu interior).

Sons também são empregados para auxiliar a comunicação. Um exemplo é o ato de tocar um instrumento musical. Executado-o apropriadamente e de maneira harmônica, a música produzida pode ser entendida como uma fonte de expressão e comunicação de emoção e sentimento.

O processo de aquisição de informações acústicas do ambiente acontece na maioria das vezes de forma subconsciente pelos seres humanos. Por exemplo, muitas pessoas automaticamente posicionam os ouvidos em direção a uma fonte que emitiu um som repentino, como o latido de um cachorro. Este é um caso típico da utilização do som para orientação da visão. Outro exemplo é que à medida que enchemos uma garrafa, o aumento da entoação do som emitido no processo nos indica o grau de enchimento do recipiente, ou seja, o som também nos permite monitorar um processo (Hermann, 2002). Estes são alguns exemplos que mostram como o som é utilizado rotineiramente sem nenhuma pretensão em particular. Outro exemplo é a comunicação entre humanos que é feita principalmente por sons. Na fala humana, diferentes informações estão disponíveis como: o significado das palavras, a identidade da pessoa, a idade aproximada, sexo e outras informações físicas e emocionais da pessoa.

Da mesma forma que sons são empregados intuitivamente, pode existir aprendizado na interpretação de sons. Música é um exemplo típico.

\subsection{Benefícios e dificuldades com o uso do som}

Nesta Seção serão apresentados alguns dos benefícios da utilização do som previamente discutidos na Seção 2.4, além de algumas limitações e dificuldades típicas do uso de som.

O uso independente da visão é um benefício essencial do uso do som, principalmente em situações onde o operador de um sistema tem de manter contato visual com outros elementos do ambiente, ou quando não é possível utilizar a visão por causa de deficiência ou oclusão visual, por exemplo, em ambientes escuros (Kramer, 1994). O papel das interfaces sonoras em alertar o usuário é extensamente usado em diversas aplicações como em relógios, agendas eletrônicas, celulares, equipamentos hospitalares e computadores. Como não é preciso olhar em uma direção particular para ouvir um alarme, estes sinais sonoros são apropriados para alertar os usuários de sistemas para algum evento importante, pois são de rápida detecção e de fácil localização. A audição paralela permite ao usuário de uma aplicação monitorar múltiplos processos. Um analista poderia explorar e comparar múltiplos conjuntos de dados simultaneamente e possivelmente encontrar correlações entre eles (Hermann, 2002). Audição paralela também abre a possibilidade do desenvolvimento de aplicações capazes de representar conjuntos de dados de alta dimensionalidade. A resposta afetiva dos seres humanos ao som, se usada apropriadamente, pode produzir aplicações computacionais mais atraentes e capazes de transmitir diferentes informações. $\mathrm{O}$ uso 
de trilhas sonoras em software de computador oferece os mesmos benefícios que são apresentados em filmes (Kramer, 1994). Medo, suspense, humor e ação são alguns dos aspectos que efeitos sonoros e músicas desempenham nos filmes.

Outros benefícios do som podem ser identificados em combinação com visualização. Sonificação pode ser utilizada para aumentar a dimensionalidade de uma visualização distribuindo algumas dimensões dos dados para atributos sonoros ou até mesmo para promover redundância para auxílio à confirmação visual (Minghim e Forrest, 1995). O comprometimento proveniente de interfaces multisensorias pode diminuir o tempo de aprendizado, reduzindo o cansaço e aumentando o entusiasmo (Hermann, 2002). A adição de música e efeitos sonoros complementam e provêem realismo à aplicação. Por exemplo, para identificar o material que constitui uma esfera pingando (madeira, aço ou borracha) é dificilmente obtido sem efeitos sonoros.

Uma das principais dificuldades e limitações da utilização de som é que a sonificação de dados é relativa, ou seja, é possível detectar a variação de entoação de um som, mas é muito difícil determinar o valor exato que a variação representa. Essa é uma desvantagem também em aplicações visuais que fazem o uso de cor para representar dados (Salvador, 2003). A dificuldade de representação de valores absolutos com som limita suas aplicações. A falta de ortogonalidade é um problema decorrente da dependência perceptual de muitos dos parâmetros sonoros, ou seja, a alteração de um parâmetro sonoro pode interferir na percepção de outros parâmetros do som. Por exemplo, ao elevar a freqüência de um som, a percepção da intensidade do som também aumenta (Neuhoff et al., 2000). Por fim, a divulgação dos resultados em revistas, relatórios, jornais e livros fica comprometida pelo fato das apresentações sonoras não produzirem resultados visíveis (Hermann, 2002).

\subsection{Sonificação}

Sonificação (sonification) pode ser definida como o uso de som para representar informação. Mais especificamente, sonificação é a transformação de dados em sinais acústicos com o propósito de facilitar a comunicação e a interpretação desses dados (Kramer, 1994).

Para que um som seja definido como sonificação, ele deve atender dois itens essenciais:

- o som deve ser sintetizado de acordo com o domínio dos dados em estudo;

- o propósito da geração do som é aprender algo sobre os dados ouvindo suas informações. O som é considerado somente como um meio de comunicação, assim como os gráficos e projeções para a visão. 


\subsection{1 Áreas de pesquisa em sonificação}

Sonificação é uma área de pesquisa interdisciplinar. Diversos campos de pesquisa contribuem para a implementação e o entendimento dos processos envolvidos. A Figura 2.2 mostra o fluxo de dados em um sistema de sonificação.

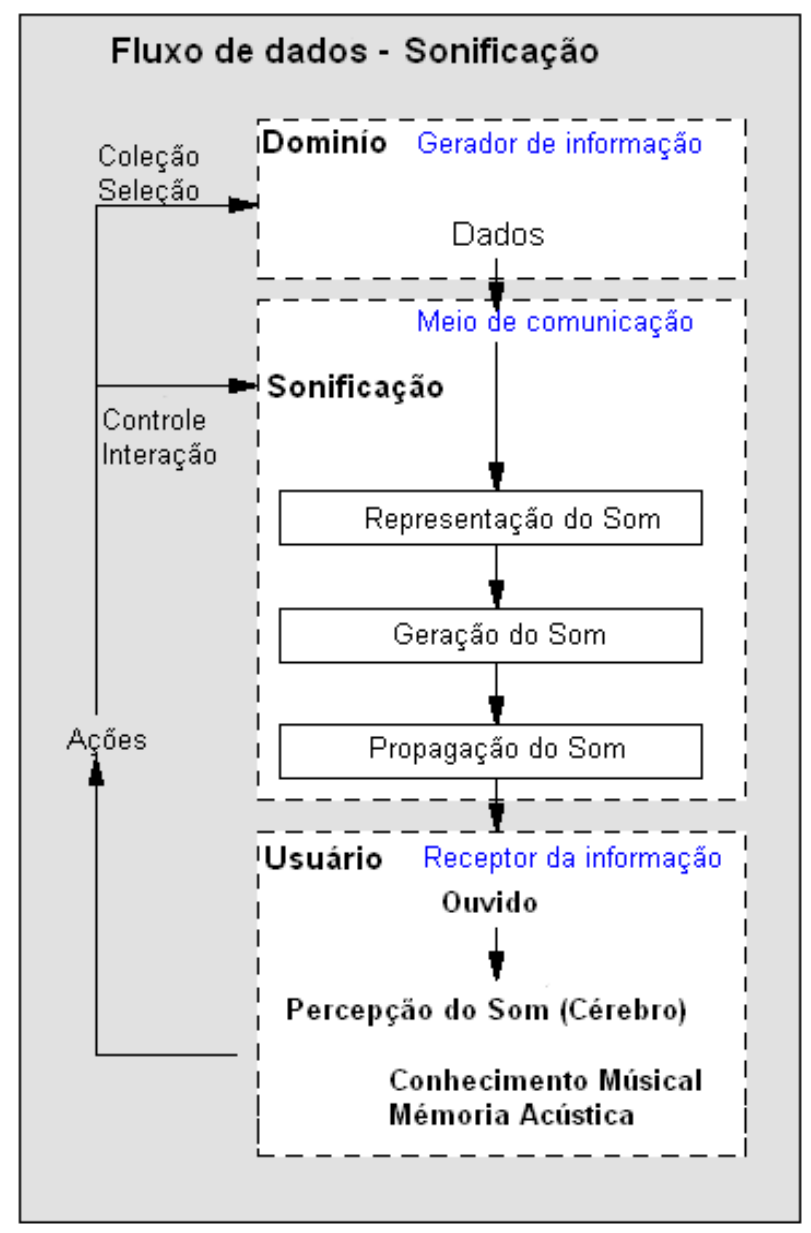

Figura 2.2: Fluxo de dados em sonificação (adaptado de (Hermann, 2002))

Para o desenvolvimento de um sistema de sonificação, primeiramente é necessário saber qual é o tipo dos dados e a forma que eles se encontram. No caso de sonificação de dados multidimensionais, técnicas estatística e de mineração de dados contribuem para o pré-processamento dos dados. Um exemplo é a redução de dimensionalidade (Faloutsos e Lin, 1995). As ciências da computação contribuem na fase de implementação do sistema de sonificação em diferentes aspectos: Engenharia de software é responsável em indicar como desenvolver a interface e implementar a renderização e sonificação dos dados; Processamento de sinais fornece técnicas de manipulação de sinais sonoros; Bancos de dados fornecem técnicas de armazenamento e acesso às informações; a disciplina de interação humano-computador (HCI) contribui com normas e processos para desenvolvimento de ferramentas, projeto de sistemas e usabilidade (Salvador, 2003). Os fundamentos da geração de som estão relacionados à acústica que é parte da física. A engenharia sonora lida com 
os aspectos do som e sua propagação em um ambiente. As disciplinas de psicologia e neurologia estão interessadas em entender como é o processamento do sinal sonoro após ele atingir o ouvido humano. A musicologia contribui para o entendimento de diferentes aspectos do som como ritmo e harmonia.

\subsubsection{Campos de aplicação de sonificação}

Como este trabalho está mais voltado para aplicação de sonificação para análise exploratória de dados, nesta seção apresentaremos uma visão geral de outros campos de aplicação de sonificação além desta.

\section{Interfaces sonoras para deficientes visuais}

O primeiro sistema de áudio para pessoas cegas foi o Optophone, uma máquina de leitura desenvolvida em 1914 por Fornier e D’Albe (Hermann, 2002). A máquina produz um código de seis tons para cada letra de um documento escaneado. Naquela época, sonificação era utilizada para substituir a síntese de fala, recurso este impossibilitado naquele tempo, mas que agora está sendo utilizado em aplicações para deficientes visuais (Nakatani e Miyoshi, 2003). Atualmente, sonificações têm desempenhado um papel importante em trabalhos de inspeção de ambientes visuais (Meijer, 2003) ou para apresentar informações sobre a estrutura de páginas da Internet (Roth et al., 1998) para cegos.

\section{Sistemas de alarme sonoro}

A característica principal de um alarme é atrair a atenção de pessoas para situações de urgência ou eventos importantes. De um modo geral, alarmes sonoros são encontrados em telefones, campainhas, buzinas de veículos, despertadores, detectores de incêndio e etc. Com o desenvolvimento das tecnologias de som, sistemas de alarmes mais elaborados têm sido desenvolvidos de modo a transmitir diferentes situações e eventos por meio de diferentes propriedades sonoras (Hermann, 2002). Um exemplo notório de aplicação de alarmes sonoros é em cabine de comandos de avião, onde mais de dez tipos de alarmes podem ocorrer (Patterson, 1982).

\section{Melhoria das interfaces gráficas}

As pessoas já estão acostumadas com as interfaces gráficas dos computadores e seus componentes de controle e interação como o ponteiro do mouse, botões, ícones e janelas. A integração de sons auxiliares e respostas acústicas aos eventos tem por objetivo melhorar o desempenho do usuário e reduzir a taxa de erros durante a interação do usuário com a interface gráfica de um sistema. Uma das primeiras pessoas a utilizar esta integração sonora foi Gaver (Gaver, 1989) que programou o SonicFinder para Macintosh. 
Os sistemas operacionais atuais (MS Windows, Linux) contam com sinais de áudio que alertam os usuários para alguns eventos do sistema, como erro em um aplicativo ou carga baixa da bateria do computador.

\section{Monitoramento de processos}

Alguns sistemas já foram desenvolvidos com o propósito de monitorar processos através de sons. Fitch e Kramer (Fitch e Kramer, 1994) desenvolveram uma interface sonora para monitorar as condições dos pacientes durante cirurgias que incluíam mais de oitos sons a serem observados. Em experimentos com usuários, onde a tarefa era manter vivo um paciente virtual, os resultados de desempenho e precisão na execução das tarefas foram melhores com interfaces sonoras do que com interfaces visuais. Gaver e outros (Gaver et al., 1991) aplicaram monitoramento de processos utilizando som para simular uma fábrica de refrigerantes (Coca-Cola). Em um experimento com usuários, os participantes tiveram que controlar o processo de fabricação da bebida utilizando o sistema ARKola. Os usuários interagiam com a aplicação à medida que problemas eram encontrados na linha de produção e apresentados por meio de imagens ou sons. O resultado final deste teste mostrou que a utilização de interfaces sonoras reduziu a taxa de erro e acelerou o tempo de reação dos participantes.

\section{Realidade Virtual}

Os ambientes virtuais devem fornecer ambientes sonoros realísticos. Para isso, é importante consideradar aspectos da percepção sonora dos seres humanos como localização sonora tridimensional, que permite a distinção das fontes sonoras do ambiente. Esta área de pesquisa tem conseguido avanços em diversos campos como medicina, engenharia, educação e treinamento (de Haan et al., 2002).

\subsubsection{Técnicas de sonificação}

Nesta seção, diferentes técnicas de renderização auditiva de dados auditivos são apresentadas. A primeira técnica que é apresentada é Audificação (Audification), técnica que traduz diretamente os dados para o domínio auditivo. Earcons e Ícones sonoros (Auditory Icons) são discutidos depois como técnicas para apresentar dados categóricos. Mapeamento de parâmetros (Parameter Mapping) é a técnica mais comum de geração de sonificação e dominante na literatura. Por último, é apresentada a técnica Model-Based Sonification desenvolvida por Hermann (Hermann e Ritter, 1999).

\section{Audificaçao (Audification)}

Audificação é a mais simples e direta técnica de tradução de dados em som. Dado um conjunto de registros, um sinal de áudio é construído através das séries de valores presente em cada um 
dos registros através de mapeamento direto do valor para freqüência sonora (Hermann, 2002). Normalmente são criados sons que atendam a capacidade da audição humana, ou seja, sons com freqüências que variam de $20 \mathrm{~Hz}$ a $20000 \mathrm{~Hz}$ e que estão no limiar da audição quanto a intensidade (ver Figura 2.3).

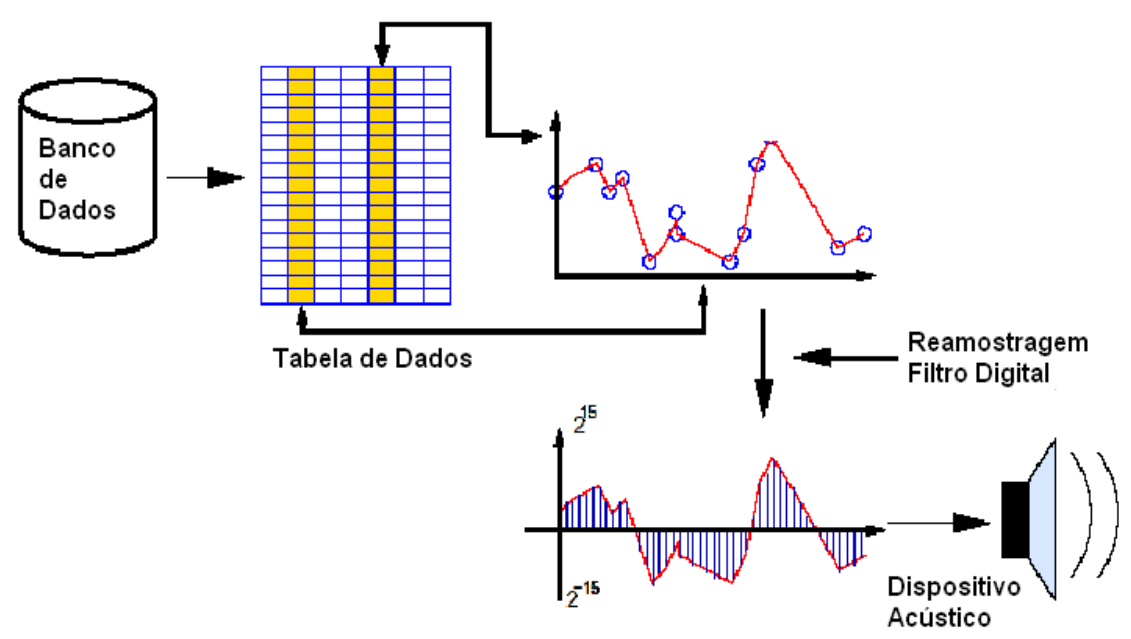

Figura 2.3: Passos da técnica de sonificação por audificação (adaptado de (Hermann, 2002))

Obviamente, é necessário um grande conjunto de valores mesmo para a geração de uma pequena audificação. Além disso, audificação é limitada aos conjuntos de dados que podem ser ordenados de forma razoável, por exemplo, uma série temporal. Dados com esta configuração estão disponíveis em algumas aplicações como em medição sísmica (Hayward, 1994) ou análise de sistemas dinâmicos (McCabe e Rangwalla, 1994).

Muitas vezes, os dados audificados devem passar por ajustes já que suas freqüências estão abaixo do limite da audição. Para isso, técnicas de prolongamento do tempo de execução e escalonamento de entoação podem ser aplicadas antes da execução da audificação. Outras operações no sinal sonoro como escalonamento, normalização e compressão são possíveis alternativas para o pós-processamento da audificação, de modo a aperfeiçoar a percepção de características acústicas (Moore, 1990).

O resultado final de uma audificação são sons que devem ser executados sem nenhuma interrupção, como uma trilha de $\mathrm{CD}^{2}$. Para que uma audificação seja interativa, deve-se permitir ao usuário acesso livre ao arquivo de dados. Com isto, é possível conhecer as características sonoras de determinado ponto do conjunto de dados de forma instantânea. A interação pode ser realçada com a adição de mecanismos de controle das propriedades sonoras, por exemplo, a entoação e a intensidade do arquivo de som criado (Hermann e Hunt, 2005).

${ }^{2}$ Compact Disk 


\section{Earcons}

Earcons são mensagens sonoras não verbais constituídas de pequenas seqüências rítmicas de tons com timbre, entoação e amplitude variáveis. O seu principal uso é comunicar mensagens simbólicas em interfaces computacionais. Por exemplo, pode existir um earcon que representa "Arquivo" e outro que representa "Abrir". Estes earcons podem ser executados em uma sequiência ordenada para informar ao usuário que um arquivo foi aberto (Brewster et al., 1994).

Além de justaposição, existem outros métodos como herança e transposição para combinar earcons. Earcons podem ser aplicados de uma maneira similar às palavras em linguiística. $\mathrm{O}$ primeiro passo é o aprendizado das palavras e depois suas combinações em sentenças (Papp et al., 1994).

Sintetizadores $\mathrm{MIDI}^{3}$ de som oferecem um variado repertório de sons musicais e de percussão que são freqüentemente usados na criação de earcons. O conjunto de valores de uma variável categórica pode ser atribuído à diferentes earcons, por exemplo, a utilização de um earcon para cada tipo de prédio em um mapa virtual sonoro de uma cidade.

Earcons têm sido aplicados para realçar interfaces gráficas e para ajudar na orientação durante a exploração de árvores hierarquicas (Frauenberger e Stockman, 2006). No contexto de sonificação de dados, earcons podem ser usados para informar certos eventos de interesse, por exemplo, Thomas (Thomas, 2001) utilizou earcons em combinação com mapeamento de parâmetros em uma sonificação de mercado de ações como indicadores da "compra" e "venda" de ações.

\section{Ícones sonoros (Auditory Icons)}

A técnica de sonificação por ícones sonoros consiste em comunicar as informações sobre eventos que ocorrem no computador ou em outros dispositivos eletrônicos, por analogia aos sons do dia-a-dia (Gaver, 1994). Em outras palavras, uma caricatura do evento sendo representado é simbolicamente e metaforicamente apresentada em som.

As primeiras aplicações de ícones sonoros foram desenvolvidas com o intuito de produzir efeitos sonoros durante a interação com os ícones do desktop de sistemas operacionais de computadores (Salvador, 2003). Nestas aplicações, ao selecionar um arquivo, por exemplo, um som que reproduz a interação com um objeto é executado. Outro exemplo é a reprodução do som de uma pilha de papéis sendo jogado em uma lixeira para representar a deleção de um arquivo.

Assim como nos ícones visuais, quanto mais direta a analogia dos ícones sonoros com os sons comuns do cotidiano, mais fácil será o seu entendimento. Apropriadamente projetados, ícones sonoros permitem às pessoas fazerem uso de suas habilidades de reconhecimento dos diferentes sons do dia-a-dia em sistemas de sonificação (Hermann, 2002).

A principal diferença entre ícones sonoros e earcons se encontra na forma como os ouvintes podem associar o som ao seu siginificado. Enquanto que os ícones sonoros são facilmente entendi-

\footnotetext{
${ }^{3}$ Musical Instrument Digital Interface (http : / / www . midi.org)
} 
dos por meio de associação metafórica da sonorização do objeto selecionado, o significado sonoro de um earcon deve ser memorizado (Barrass e Kramer, 1999). Outra diferença é que os ícones sonoros são edificados nas habilidades de reconhecimento dos sons do cotidiano. Já os earcons fazem uso de habilidades de audição musical e abstrata. Bussemakers e Haan (Bussemakers e Hann, 2000) fazem uma comparação destas duas técnicas de sonificação integradas à interface gráfica e discutem algumas vantagens e desvantagens de ambas as técnicas através de experimentos com usuários.

Ícones sonoros são freqüentemente aplicados para sinalizar um evento. Entretanto, em combinação com outras técnicas como mapeamento de parâmetros, ícones sonoros podem ser usados para auxiliar na orientação e para o mapeamento de certos tipos de dados, como marcadores de eventos, exceções e ações (Salvador, 2003). Até mesmo a combinação de mais de um ícone sonoro em seqüência pode ser projetado para representar uma seqüência de acontecimentos como fez Hermann (Hermann et al., 2003a) em um projeto piloto de sonificação de previsões diárias das condições meteorológicas de uma cidade européia .

Uma evolução desta técnica é o uso de ícones sonoros parametrizáveis, onde a informação é codificada nos atributos do som, por exemplo, a intensidade do som ao apagar um arquivo é proporcional ao seu tamanho.

\section{Mapeamento de parâmetros (Parameter Mapping)}

Enquanto que os métodos de sonificação anteriores são limitados a grande conjunto de dados (audificação) ou sinais discretos (earcons e ícones sonoros), mapeamento de parâmetros é considerada a técnica mais versátil e difundida. O conceito de mapeamento (mapping) é inspirado na técnica de projeção de dados visuais, onde elementos gráficos (símbolos) são adicionados à tela e seus atributos (coordenadas x e y, cor, tipo e tamanho do símbolo) são as variáveis que representam um registro (Hermann, 2002). Analogamente, a sonificação por mapeamento de parâmetros é constituída pela duração da sonificação e outros elementos sonoros (eventos) que podem ter diferentes atributos acústicos como duração, volume, entoação, variação da entoação, timbre, amplitude e modulação de amplitude (Scaletti, 1994) (Barrass e Kramer, 1999). Eventos mais complexos podem usar aspectos rítmicos e harmônicos como atributos. A Figura 2.4 representa os passos desta técnica.

A principal vantagem desta técnica está na sua baixa complexidade computacional. Sonificações são implementadas por meio de algoritmos simples, renderizadas em tempo real (Barrass e Kramer, 1999) (Salvador, 2003).

O mapeamento de parâmetros apresenta algumas limitações (Hermann e Ritter, 1999):

- Mapeamento não único: Não existe um único mapeamento de dados para atributos acústicos. A necessidade de atribuição de parâmetros leva a uma explosão combinatória de possibilidades. 


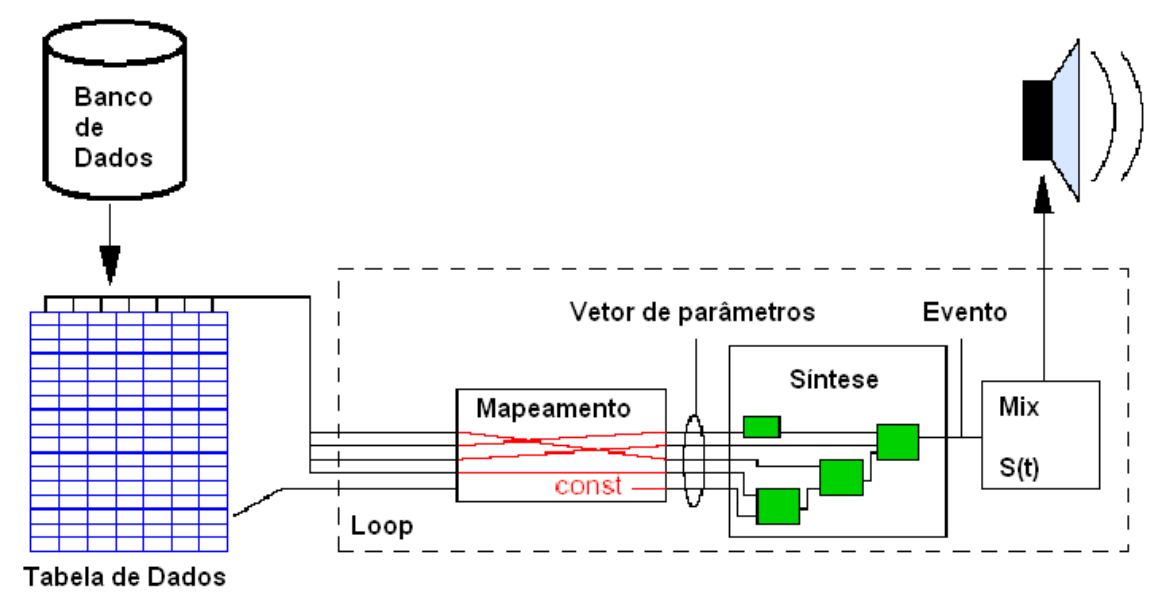

Figura 2.4: Passos da técnica de sonificação por mapeamento de parâmetros (adaptado de (Hermann, 2002))

- Polaridade não única: não está claro ainda a qual polaridade (positiva ou negativa) associar variações de dados em variação perceptível. Por exemplo, o aumento de um escalar como densidade pode ser representado aumentando ou diminuindo a entoação ou a freqüência de um som.

- Aprendizagem / Interpretação: Sonificação depende do mapeamento escolhido. Como o som gerado por cada mapeamento sonoro é diferente, isto torna o aprendizado e a adaptação a estas sonificações um processo difícil. A falta de costume também é fator importante.

- Dimensionalidade limitada: a dimensionalidade é limitada pelo número de atributos acústicos. Assim, a técnica não é capaz de representar dados de dimensão arbitrária, da mesma forma que acontece com atributos visuais.

\section{Model-Based Sonification}

Model-Based Sonification (Hermann e Ritter, 1999) é uma técnica de sonificação baseada na idéia de que objetos passivos são silenciosos, e para descobrir mais sobre suas características por meio de sons é necessário interagir com eles (sacudir uma garrafa ou bater em um pedaço de madeira, por exemplo) através de alguma forma de excitação para descobrir a estrutura deste material.

Esta técnica consiste em transformar um conjunto de dados em uma estrutura material que é definida tanto pelas instâncias dos dados como pela interação entre elas. O modelo de sonificação ou a "física virtual" do conjunto de dados permite simular o processo de vibração e excitação similar à sonorização de materiais reais. Indiretamente, os dados são transformados em um instrumento sonoro que é examinado e tocado pelo ouvinte (ver Figura 2.5).

A principal vantagem desta técnica é que ela pode ser projetada de modo a funcionar com dados de dimensionalidade arbitrária. O conhecimento do modelo utilizado é a informação principal 


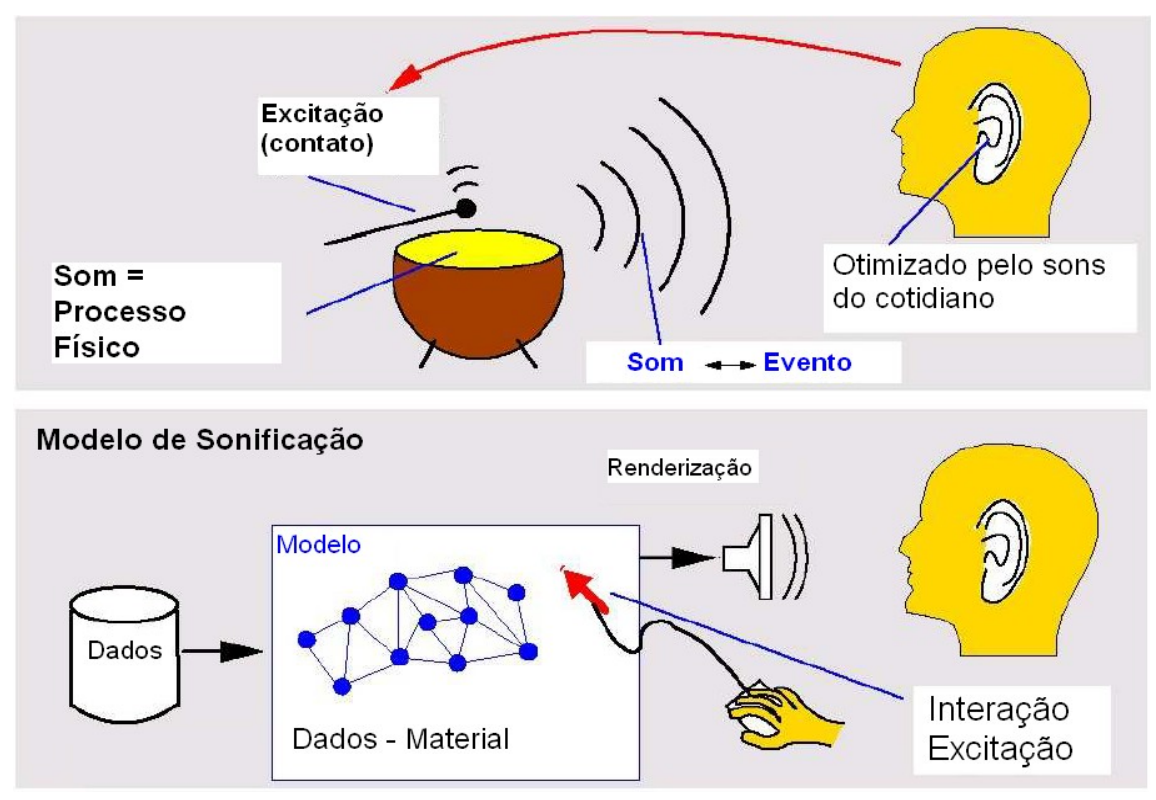

Figura 2.5: Representação da técnica de sonificação Model-Based Sonification (adaptado de (Hermann, 2002))

para o entendimento e interpretação do som de acordo com os dados. Diferentemente do mapeamento de parâmetros, esta técnica possui poucos parâmetros e são relacionados às propriedades físicas atribuídas aos dados. Esta técnica apresenta maior custo computacional se comparada com a técnica de mapeamento de parâmetros (Hermann e Ritter, 1999).

\subsection{Considerações Finais}

Este capítulo apresentou definições e conceitos básicos sobre som, suas principais propriedades e os fenômenos que envolvem sua propagação em um meio elástico, por exemplo, o ar. Foi descrito todo o processo envolvendo a captação do som pelo ouvido humano desde a chegada da energia sonora ao pavilhão auditivo (orelha) até sua conversão em sinais nervosos que é transmitida ao cérebro.

Conhecer formas de percepção sonora pelos seres humanos é um aspecto importante no desenvolvimento de um sistema que faz uso de som no mapeamento de dados. Como já foi observado por alguns pesquisadores, os princípios da psicologia Gestalt, que estuda principalmente a tendência humana em reconhecer padrões e configurações em imagens, também pode ser comprovada para sons, o que favorece a segregação de estímulos sonoros quando são apresentados ao mesmo tempo ou em um pequeno intervalo.

Este capítulo ainda ressaltou o importante papel do som em uma infinidade de situações em nosso cotidiano, como a comunicação, orientação, localização, monitoramento de processo e alerta a eventuais perigos ou eventos. Benefícios e limitações no uso de som, bem como vantagens e desvantagens de sua utilização em sistemas computacionais, foram levantados. 
O som pode melhorar o entendimento dos dados quando usados em representações gráficas de sistemas computacionais. Sonificação é o mapeamento de dados em sons com a intenção de fornecer informações ou de realçar a apresentação gráfica, permitindo a detecção rápida de informações ocultas, orientando o usuário no entendimento de informações ou eventos importantes. Sonificação vem sendo estudada com a finalidade de acentuar a interação e a interpretação de dados pelos usuários de sistemas computacionais dentro ou fora do contexto de visualização.

Pela sua própria natureza, sonificação é um tema interdisciplinar e integra conceitos de percepção humana, acústica, computação e engenharia. O desenvolvimento de representações sonoras efetivas requer colaboração interdisciplinar que abrange conhecimentos na área da psicologia, ciências da computação, engenharia, física, música e estatística.

Sonificação tem sido aplicada em diversas áreas da computação, como no processo de desenvolvimento de interfaces sonoras para deficientes visuais, na implementação de recursos sonoros em sistema críticos para alertar os usuários de possível alteração nas informações, no monitoramento de processos e para prover realismo à realidade virtual.

Neste capítulo foram apresentadas as técnicas de sonificação mais conhecidas e utilizadas em aplicações computacionais: Audificação, Earcons, Ícones sonoros, Mapeamento de parâmetros e Model-Based Sonification. Cada técnica possue suas próprias caracteríticas e são empregadas levando-se em consideração o conjunto de dados e o propósito sonoro a ser alcançado com sua implementação.

O próximo capítulo traz uma revisão bibliográfica de trabalhos e estudos com usuários em sonificação. 



\section{Revisão Bibliográfica}

\subsection{Considerações Iniciais}

Este capítulo apresenta um levantamento sobre o estado de arte em sonificação. Esta etapa forneceu subsídios para as tarefas inseridas neste projeto de mestrado que tem por objetivo adicionar e avaliar estímulos sonoros como recurso de apoio à exploração visual de dados. A Seção 3.2 traz uma revisão de trabalhos de sonificação realizados nos últimos anos, abordando os principais conceitos, suas características e funcionalidades principais. A Seção 3.3 traz informações de estudos com usuários executados com o objetivo de avaliar o potencial de percepção dos estímulos gerados, tanto em sistemas que fizeram uso somente de sonificação ou de sonificação combinada com visualização computacional. Cada experimento apresentado na Seção 3.3 é descrito de forma detalhada, onde são apresentadas informações de sua concepção, execução, número de participantes envolvidos e os principais resultados obtidos.

\subsection{Revisão dos trabalhos de sonificação}

Um dos primeiros trabalhos que fez uso de som como forma de representação de dados foi realizado por Yeung (Yeung, 1980). Ele projetou um sistema sonoro para análise de dados em química analítica. Os dados consistiam de vetores cujos valores representavam o nível de determinado metal em uma amostra de material. Os parâmetros de som utilizados foram: frequiência, intensidade, direção ou localização espacial e duração. 
Wilson e Lodha (Wilson e Lodha, 1996) desenvolveram o LISTEN, uma ferramenta para sonificação de dados composta por quatro módulos que geram sons com diferentes graus de complexidade. Os módulos se diferenciam na forma de execução (linha de comando ou interface visual) e opções de controle de parâmetros sonoros na interface. Os parâmetros sonoros manipulados são entoação, duração, volume e localização espacial. A ferramenta foi incorporada pelos autores em um sistema para visualização geométrica para superfícies interpolantes (multiquádricas, multiquádricas inversas, linear, bilinear) (Lodha et al., 1996) e um sistema para visualização de algoritmos de fluxo de fluidos.

Lodha e outros (Lodha et al., 1997) desenvolveram uma ferramenta de sonificação de dados científicos denominada MUSE (Musical Sonification Environment). Diferentemente do LISTEN (Wilson e Lodha, 1996), o MUSE gera sons musicais por meio da adição de novos parâmetros sonoros como ritmo (notas executadas em intervalos de tempo) e harmonia (combinação de dois ou mais sons musicais). Também foram usados outros parâmetros sonoros como timbre, volume, entoação e tempo.

Hansen e outros (Hansen et al., 1999) apresentaram um sistema de sonificação musical para o cálculo do alinhamento da estrutura de proteínas. Eles empregaram componentes melódicos em um sistema que é utilizado para visualizar a sobreposição de estruturas de proteínas em 3D, denominado RasMol. O mapeamento sonoro dos parâmetros foi baseado na idéia de um típico quarteto de jazz, consistindo de: um instrumento solo que toca uma linha melódica, uma bateria, um baixo e uma parte harmônica, isto é, um acompanhamento rítmico consistindo de acordes. Cada característica das proteínas foi mapeada para uma das partes do quarteto de jazz: qualidade da forma (pobre, média ou boa) através da linha melódica, exposição (oculta, parcialmente oculta ou exposta) através da bateria, estruturas secundárias (hélice, loop ou camada beta) através do baixo e polaridade (baixa, média ou alta) através da parte harmônica.

Joseph e Lodha (Joseph e Lodha, 2002) apresentaram o MUSART (MUSical Audio transfer function Realtime Toolkit) (ver Figura 3.1), ferramenta de sonificação que produz sons musicais para dados multidimensionais tocados em tempo real. O MUSART sonifica as informações à medida que vai lendo o conjunto de dados, em um processo que combina conceitos musicais com funções de transferência de áudio (Audio Transfer Functions - funções de mapeamento de dados em sons). Os parâmetros musicais disponibilizados para seleção do usuário são: register (faixa de entoações), entoação, timbre, densidade, duração, silêncio (tempo que nenhum som é ouvido), intensidade, balance (localização do som entre o ouvido esquerdo e direito), batida (repetição musical de um tom) e consonância (combinação de tons de forma harmônica). Os autores utilizaram o MUSART para sonificar conjunto de dados sísmicos tridimensionais. 


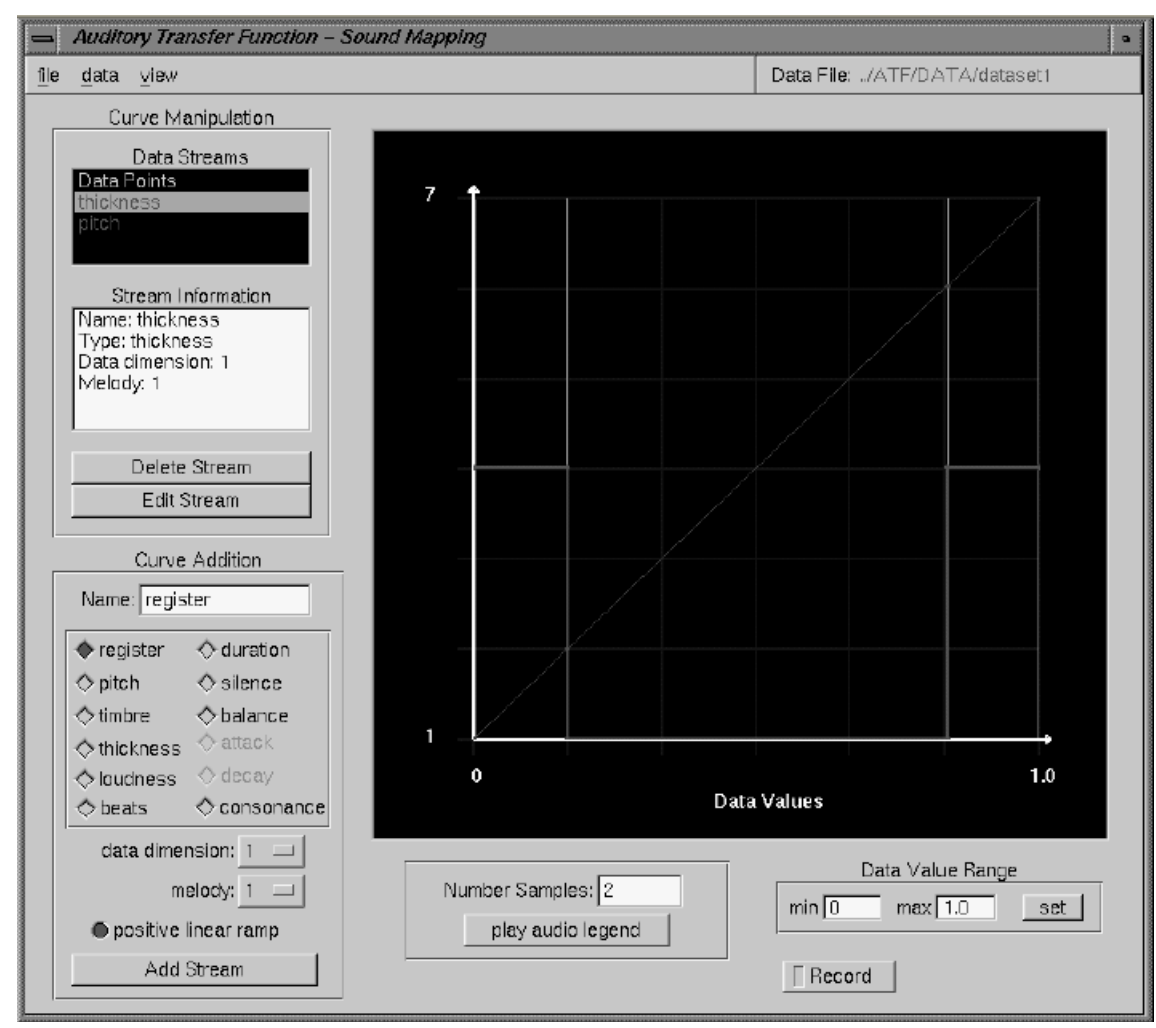

Figura 3.1: Interface visual do sistema MUSART (adaptado de (Joseph e Lodha, 2002))

Minghim e Forrest (Minghim e Forrest, 1995) desenvolveram um sistema de som para dados de superfície, chamado SSound. O SSound implementa um número de funções sonoras para apoiar apresentação e análise de dados escalares para visualização baseada em superfícies. São eles: Grid Sonification, Volume Scan e Coordinate Mapping. Os sons foram apresentados na interface usando um paradigma metafórico: freqüências altas foram utilizadas para representar valores escalares altos e altas densidades e baixas frequiências o oposto. Timbre foi utilizado para representar aspectos qualitativos dos dados e balanço estéreo para oferecer informação de direção.

Veridiana e Minghim desenvolveram o SVol (Salvador et al., 1998) baseado no SSound (Minghim e Forrest, 1995), que por sua vez serviu como guia para o desenvolvimento do protótipo DSVol (Salvador, 2003). O DSVol contém sete formas de interação sonora e cada uma delas possui um processo gráfico associado. São elas ${ }^{1}$ : Dimensão animada (Progressive Display), Sondagem pontual (Grid Display) (ver Figura 3.2(a)), Sondagem do plano (2D Scan), Sondagem de superfície (Plane Scan) (ver Figura 3.3), Vizinhança 2D (2D Spider Cursor), Sondagem de volume (Sound Probe) (ver Figura 3.2(b)) e Lente tridimensional (Magic Box). Essas sonificações mapeiam valores ou características dos dados para frequiência. Outro mapeamento que pode ser utilizado é referente à polaridade do mapeamento (positiva ou negativa).

\footnotetext{
${ }^{1}$ Processo gráfico da interação informado entre parênteses.
} 


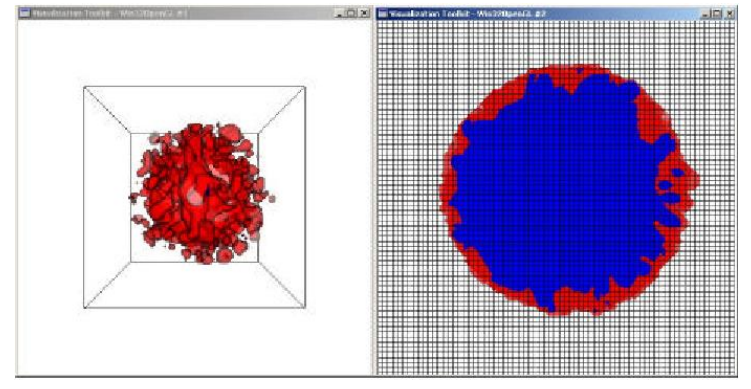

(a) Sondagem pontual (Grid Display)

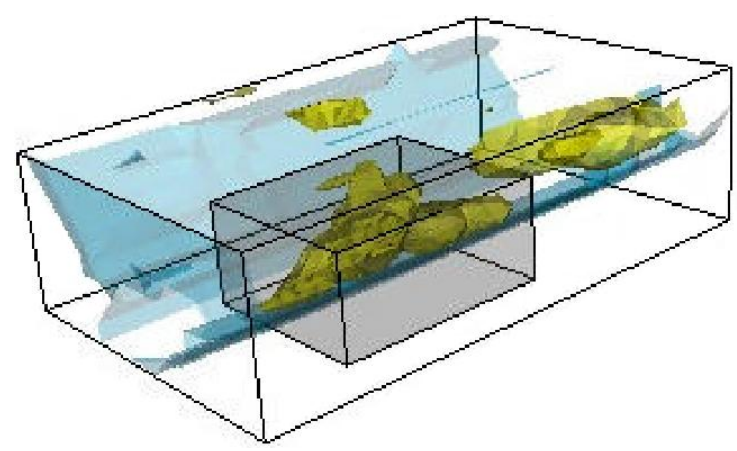

(b) Sondagem de volume (Sound Probe)

Figura 3.2: Duas formas de interação presente no DSVol (adaptado de (Salvador, 2003)).
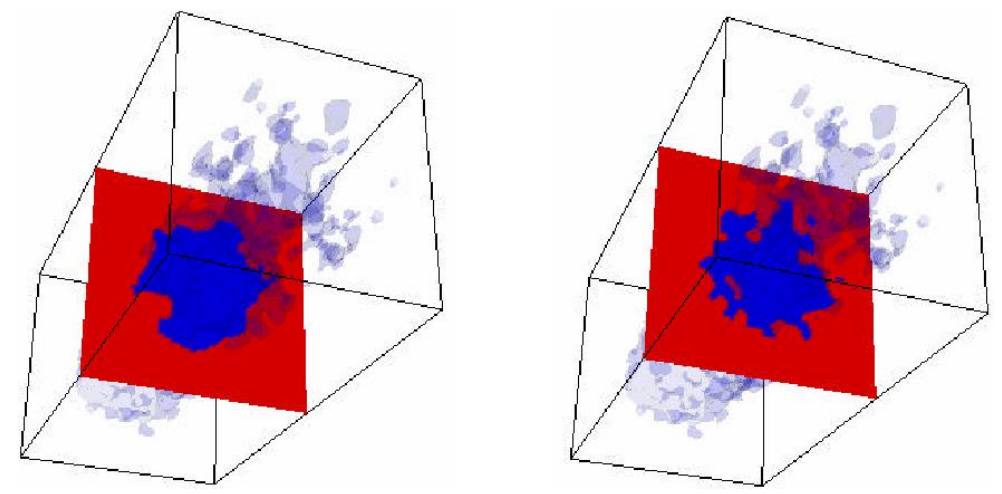

Figura 3.3: Sondagem de superfície (Plane Scan) em dois gráficos (adaptado de (Salvador, 2003))

Hermann, Meinicke e Ritter (Hermann et al., 2000) apresentaram uma nova abordagem para sonificação de dados multidimensionais que permite a percepção da estrutura da distribuição dos dados. Isto foi obtido "sonificando" a curva principal (Principal Curve (Hastie e Stuetzle, 1989)) de um conjunto de dados. A trajetória da curva principal (que passa entre um conjunto de pontos) permite definir uma ordem de tempo para cada ponto (ver Figura 3.4). Denominada Principal Curve Sonification (PCS), esta abordagem cria a apresentação sonora através da movimentação pela curva principal, utilizando as técnicas de sonificação mapeamento de parâmetros e ModelBased Sonification (ver Seção 2.6.3) para apresentar as diferentes informações dos pontos.

Saue (Saue, 2000) apresentou um modelo geral para sonificação de grandes conjuntos de dados espaciais (dados sísmicos e dados médicos) baseado em sons do cotidiano ou ícones sonoros. O usuário interage com a representação se movimentando através das regiões do conjunto de dados, ouvindo sons locais e globais e tomando novas decisões no decorrer do caminho. Os sons que constituem o modelo construído são:

- MoveSounds: sons locais conectados com o fato do usuário se mover (som de passos); 


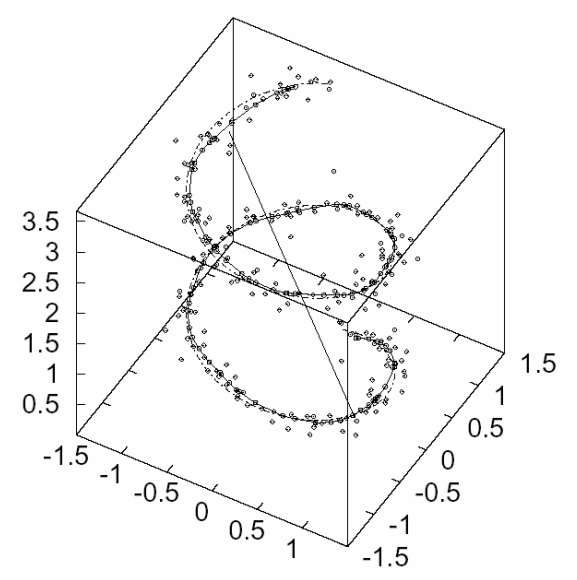

Figura 3.4: Gráfico de dispersão (scatter plot) dos dados e a curva principal (adaptado de (Hermann et al., 2000))

- ObjectSounds: sons decorrentes de eventos e sons de objetos próximos (canto de pássaro, escoamento de um riacho);

- AmbientSounds: sons globais caracterizando uma área (chuva e vento);

- ExamineSounds: sons locais causados por interação com objetos.

Para cada classe de sons são utilizados diferentes parâmetros sonoros, ou combinação deles, com diferente duração.

Dieberger (Dieberger, 2000) apresentou uma ferramenta de sonificação para $C o W e b^{2}$. Neste trabalho foi apresentado a sonificação do histórico dos links acessados. Para isso, cinco notas sonoras com entoações diferentes foram usadas para representar cinco taxas de acesso. Três sonificações foram criadas para representar os links de cada página, múltiplos links simultâneos e a quantidade de acesso de cada link.

Hermann e Ritter (Hermann e Ritter, 2002) apresentaram um modelo de sonificação para análise exploratória de conjuntos de dados multidimensionais, o Crystallization Sonification (ver interface do sistema na Figura 3.5). O modelo sonifica o processo de união de pontos de um espaço de dados multidimensional em uma estrutura que se assemelha a um cristal. O usuário inicia a sonificação escolhendo um ponto inicial (núcleo do cristal) em um gráfico de dispersão 2D (2D scatter plot). Em seguida, os demais pontos do conjunto de dados vão sendo incluídos automaticamente no cristal ordenados por suas distâncias em relação ao núcleo. As sucessivas inclusões alteram a estrutura (forma) e a propriedade acústica (esta mapeada por timbre e intensidade) do

\footnotetext{
${ }^{2}$ Collaborative Web space são páginas da internet similares às páginas comuns, com a diferença de que todos os usuários podem alterar o seu conteúdo.
} 
cristal. A sonificação só termina quando todos os pontos estiverem na estrutura do cristal. Segundo os autores, essa sonificação permite perceber agrupamento de pontos com informações similares (clusters) no conjunto de dados.

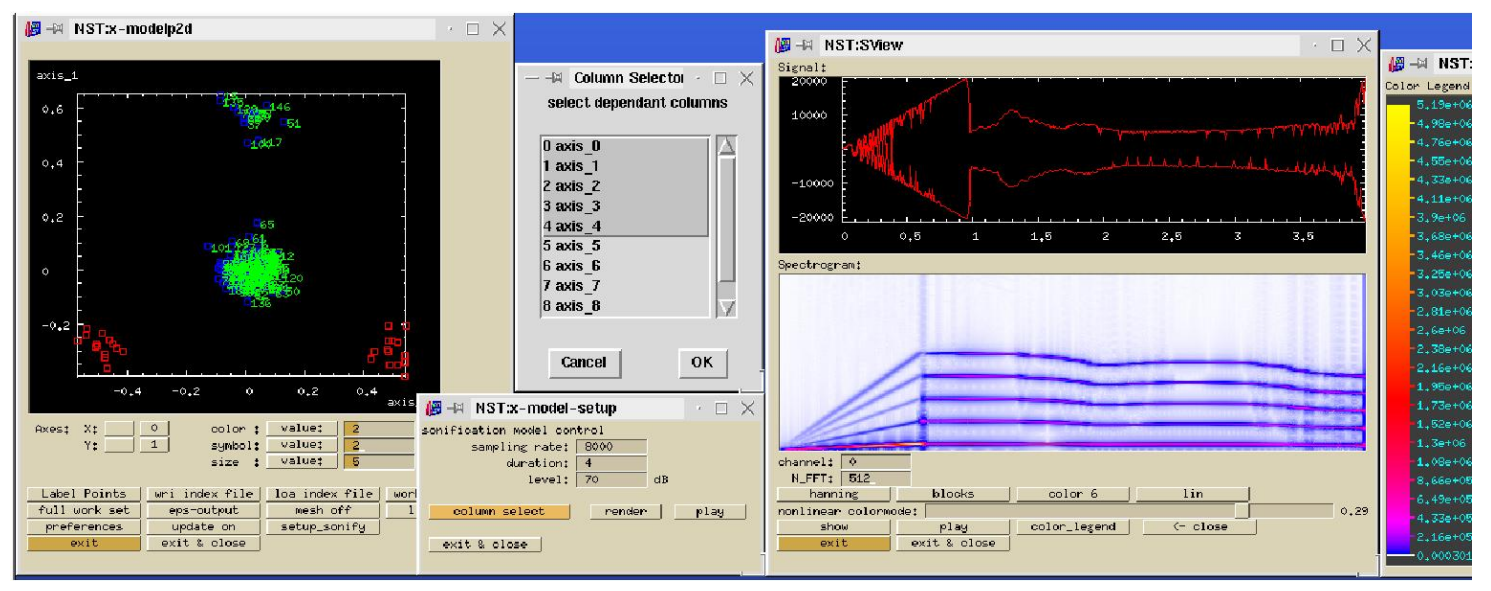

Figura 3.5: Interface do usuário para controle do modelo sonificação de dados por cristalização (adaptado de (Hermann et al., 2000))

Nesbitt e Barrass (Nesbitt e Barrass, 2002) avaliaram a utilização de sonificação, visualização e os dois modos em conjunto, para auxiliar na análise de conjunto de dados de mercado de ações, este composto por valores de ofertas de ações (compra e venda) e o volume (quantidade) destas ações. Para cada par (oferta de compra e oferta de venda) de ações foram atribuídos níveis de importância (baixo, médio e alto) utilizando o seguinte mapeamento: quanto menor a diferença entre eles maior é a importância. O mesmo aconteceu para o volume das movimentações das ações, com o mapeamento: quanto maior o volume, maior a importância. A sonificação foi desenvolvida utilizando uma amostra de uma voz feminina falando Sell (vende, para venda de ações) e de uma voz masculina falando Buy (compra, para compra de ações). Propriedades sonoras como entoação, intensidade e localização espacial, foram atribuídas a estas vozes de acordo com os parâmetros de importância definidos anteriormente. Outra informação extraída desta sonificação foi o grau de atividade no mercado de ações, identificado pelo número de eventos sonoros em determinado intervalo de tempo. Em avaliações com 15 participantes (sem nenhum conhecimento de mercado de ações) que tinham que identificar as oscilações de valores, as taxas de acerto foram: $61.3 \%$ com interfaces visuais, $70 \%$ com interfaces sonoras e $70 \%$ com interfaces multimodais.

Hermann, Niehus e Ritter (Hermann et al., 2003b) apresentaram o AVDisplay, um sistema que combina visualização (ver Figura 3.6) e sonificação para monitoramento, consulta e acesso a informações sobre módulos ou processos em sistemas complexos (neste trabalho foi utilizado um sistema de robótica para interação homem-computador). Três estratégias de sonificação foram utilizadas: 
- Sonificação simples: a utilização de tons com diferentes entoações para identificar módulos diferentes.

- Sonificação musical: esta sonificação teve como objetivo integrar todas as informações disponíveis no módulo (como o tipo de mensagem, resultados, tempo de execução, densidade, estado) em som, sendo que cada módulo é representado por um instrumento musical diferente.

- Model-Based Sonification: esta técnica de sonificação (descrita na Seção 2.6.3 desta dissertação) consiste em criar uma estrutura material (com propriedades sonoras) para o conjunto de dados. Neste trabalho, mensagens foram utilizadas para excitar objetos que respondiam aos estímulos produzindo sons.

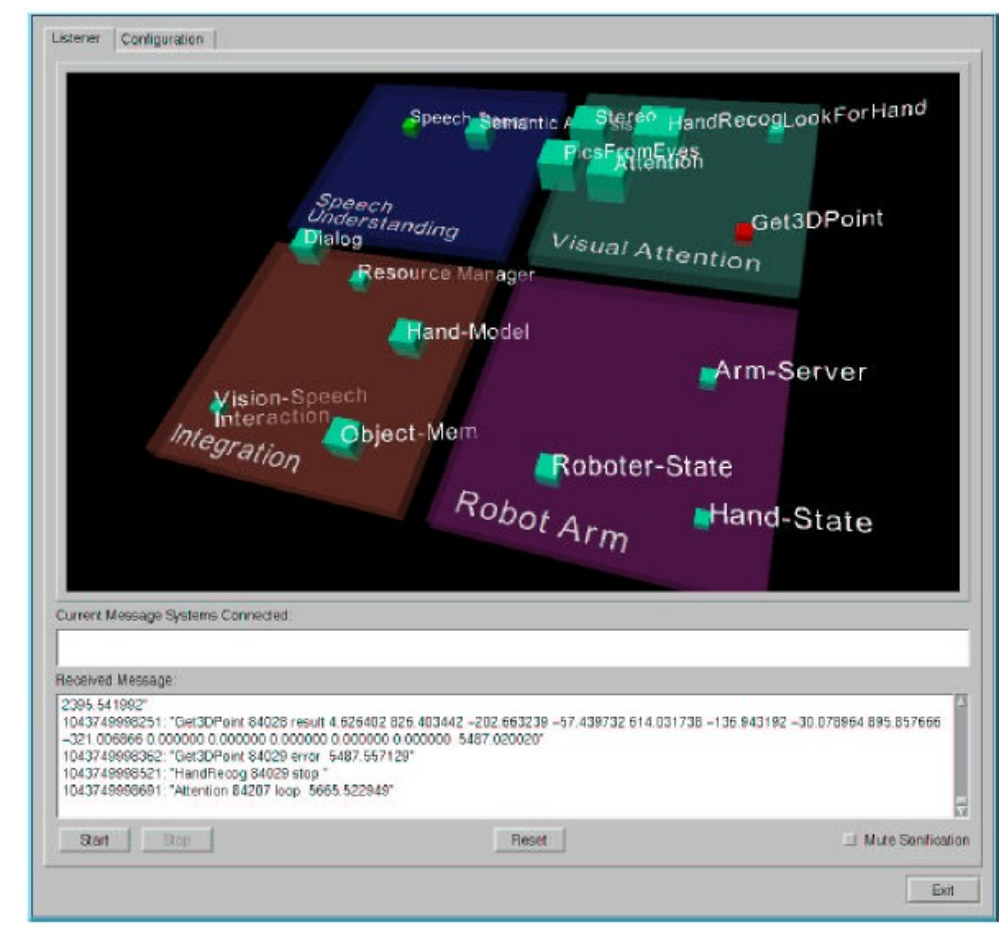

Figura 3.6: Tela do modelo de visualização do AVDisplay Visualization (adaptado de (Hermann et al., 2003b))

Thought-Translation-Device (TTD) é uma interface cérebro-computador desenvolvida para auxiliar na comunicação de pacientes completamente paralisados por meio de sinais emitidos pelo cérebro e que são capturados por eletroencefolograma (EEG). Hinterberger e Baier (Hinterberger e Baier, 2005) apresentaram o POSER (Parametric Orchestral Sonification of EEG in Real-time) um dispositivo de sonificação de informações geradas pelo EEG. Cada parâmetro extraído do EEG é atribuído a um canal MIDI (máximo de 16 canais). Cada canal é definido por três características sonoras: instrumento, volume e equilíbrio. As amplitudes de sinal presentes em cada parâmetro do EEG são mapeadas para entoação. 
Walker e Cothran (Walker e Cothran, 2003) motivados pela necessidade de uma ferramenta multi-plataforma e de propósito geral para sonificação de dados, apresentaram o toolkit Sonification Sandbox (ver Figura 3.7). O sistema permite ao usuário o mapeamento independente de dados numéricos (contidos em uma tabela Excel$^{3}$ ) para timbre, entoação, volume e localização espacial, disponibilizando controles para configurar os valores máximos, mínimos e a polaridade destas propriedades sonoras. A aplicação também possibilita a adição de contexto a sonificação, por exemplo, a repetição constante de um tom de percussão indicando tempo ou tons notificando ao usuário que valores máximos e mínimos do conjunto de dados foram alcançados. Sonification Sandbox foi desenvolvido em Java usando a $\mathrm{API}^{4}$ Java Sound.

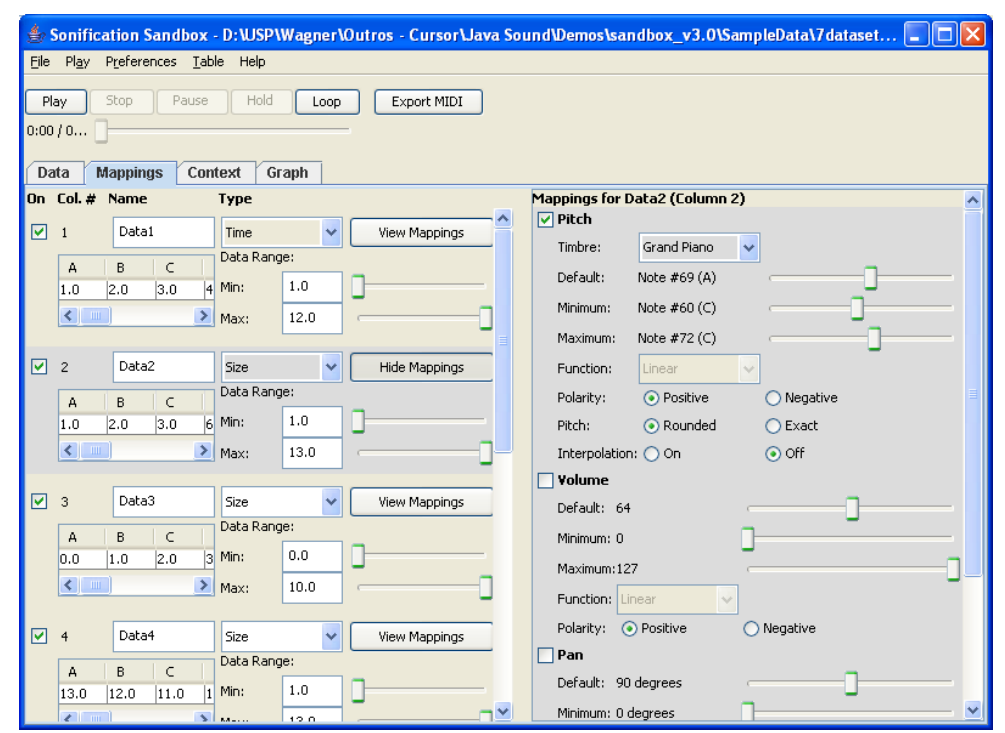

Figura 3.7: Tela de mapeamento sonoro do sistema Sonification Sandbox

Ramaswamy, Hutchinson e Kuester (Ramaswamy et al., 2004) apresentaram uma estrutura de visualização e sonificação para análise de terremotos. Duas abordagens acústicas simples foram usadas para analisar os sinais emitidos pelas ondas sísmicas: frequency-based (baseado na freqüência) e time-based (basedo no tempo).

- frequency-based: as freqüências contidas no sinal são mapeadas para valores que se enquadram na faíxal audível $(20 \mathrm{~Hz}-20000 \mathrm{~Hz})$.

- time-based: as amplitudes das ondas sísmicas são convertidas em variações acústicas por simples transformação linear no domínio tempo, processo conhecido como Modulação de Amplitude. Como as amplitudes podem ser positivas e negativas, esta abordagem contém também uma etapa de normalização.

\footnotetext{
${ }^{3}$ Microsoft Excel

${ }^{4}$ Application Programming Interface
} 
Walker e outros (Walker et al., 2004) apresentaram o Audio Abacus (ver Figura 3.8), uma aplicação projetada para transformar números em sons, seguindo a analogia de um ábaco ${ }^{5}$ (abacus). A idéia básica é executar seguidos tons sonoros para representar um número. Por exemplo, para o número 582, três sons sucessivos são tocados para cada dígito. As propriedades contidas nos tons que podem ser definidas pelo usuário são:

- entoação: os dígitos são mapeados diretamente a partir de um parâmetro com valores máximo e mínimo de entoações;

- localização espacial: a ordem da apresentação dos dígitos no número pode ser feita mapeando os tons para serem tocados com intensidades diferentes nos dois dispositivos de saída de áudio (fones de ouvido, caixas acústicas);

- passagem para decimal: um tom de um instrumento de percussão (que não possui variação de entoação) é executado quando um ponto decimal é encontrado;

- razão: identifica o tempo de execução do tom para cada unidade do número (unidade, dezena, centena e etc).

- escala de tempo: define o tempo de execução do som. Usado principalmente para acelerar ou não a execução de várias sequiências de números.

- instrumento: define o timbre do instrumento musical responsável pela reprodução sonora.

Yeo e outros (Yeo et al., 2004) apresentaram o SonART, um ambiente multimídia que oferece uma estrutura para sonificação e visualização de dados. Originalmente criada para exploração sonora de dados, atualmente a ferramenta conta com funcionalidades para criação, manipulação e exploração de som e imagem (ver exemplo na Figura 3.9). Com relação a sonificação de dados, o software apresenta três características principais:

- A ferramenta utiliza mapeamento de parâmetros como técnica de processamento sonoro nas interfaces audíveis;

- Sonificações podem ser feitas diretamente de imagens. Um exemplo apresentado é a utilização dos valores $\mathrm{RGB}^{6}$ da imagem como parâmetros da sonificação;

\footnotetext{
${ }^{5} \mathrm{O}$ ábaco é um antigo instrumento de cálculo formado por uma moldura com bastões ou arames paralelos, dispostos no sentido vertical. Cada bastão contém dez bolas móveis que podem ser movidas para cima e para baixo. Assim, o valor representado é determinado de acordo com o número de bolas na posição inferior. Ele é utilizado ainda hoje para ensinar às crianças as operações de somar e subtrair.

${ }^{6}$ RGB é a abreviatura do sistema de cores aditivas formado por Vermelho (Red), Verde (Green) e Azul (Blue).
} 


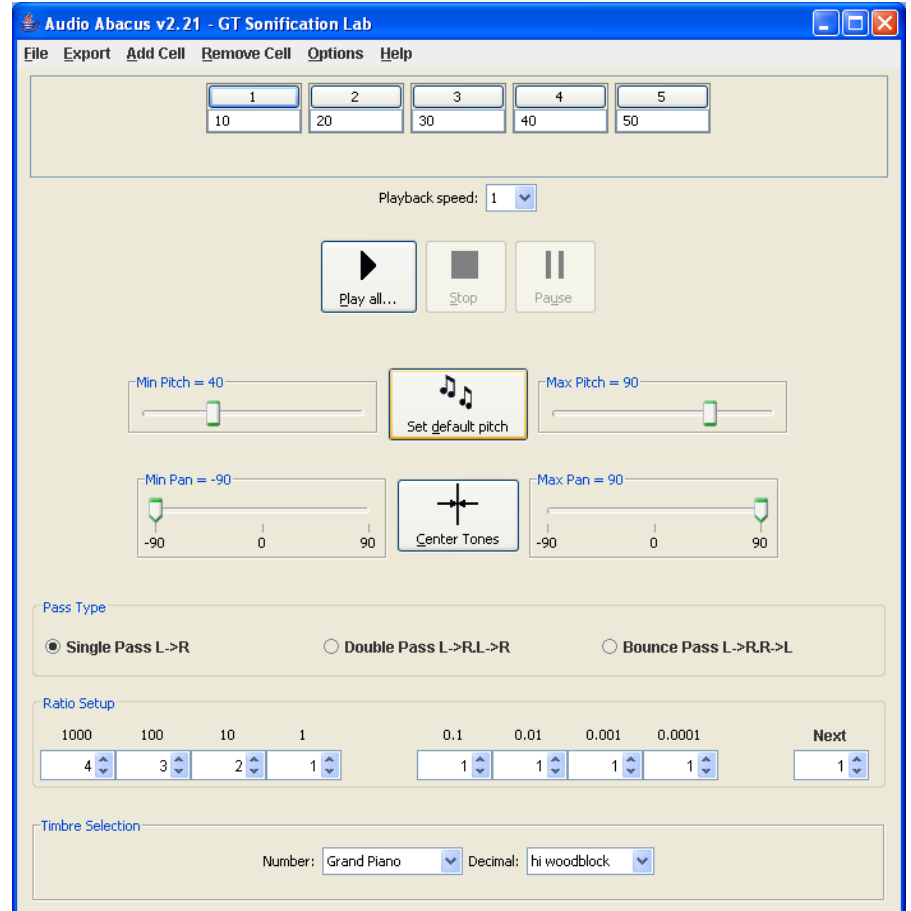

Figura 3.8: Tela principal do sistema Audio Abacus

- Associa timbres e outras propriedades sonoras como localização, entoação e harmonia, às ferramentas visuais como pinceis, filtros de cor e modos de pintura, com o propósito de oferecer resposta sonora em tempo real das operações realizadas na interface visual.

Potenciais aplicações do SonART com sonificação citadas no trabalho incluem: imagens para diagnósticos médicos, análise financeira e segurança residencial.

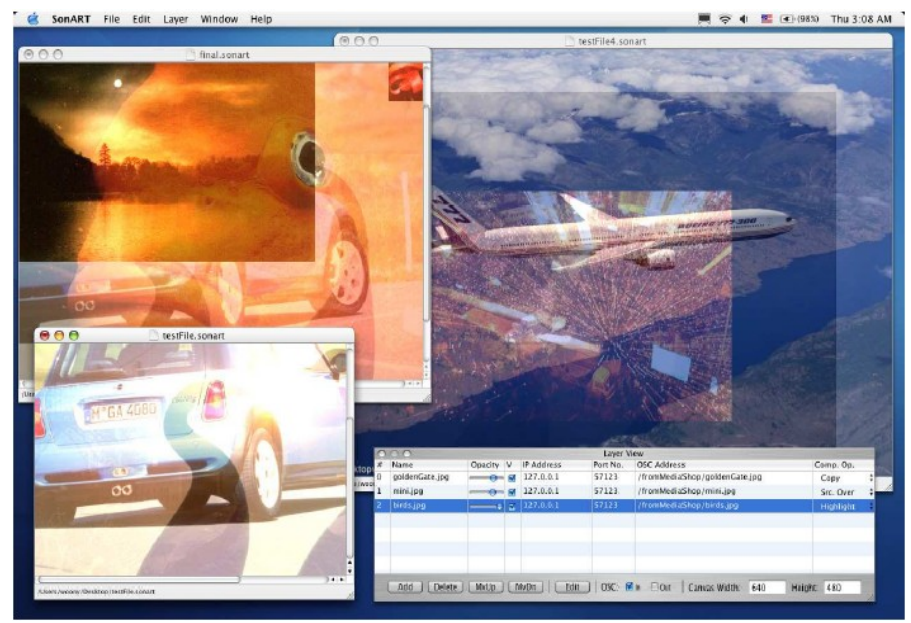

Figura 3.9: Diferentes figuras com suas opacidades controladas por parâmetros sonoros na interface gráfica do SonART (adaptado de (Yeo et al., 2004)) 
A necessidade de ferramentas para monitoramento de grande quantidade de dados em tempo real, levaram Janata e Childs (Janata e Childs, 2004) a desenvolver um protótipo para sonificação de dados financeiros. Após pesquisas com agentes financeiros, quatro padrões genéricos de comportamento dos dados foram observados e sonificados:

- Movimento relativo: a sonificação é feita executando duas notas com entoações diferentes que indicam se determinado índice é maior ou menor comparado ao dia anterior. Se existe aumento, a segunda nota tem entoação maior do que a primeira;

- Movimento absoluto: três notas são tocadas em intervalos diferentes. Nesta sonificação, os intervalos de tempo entre as execuções da primeira, segunda e terceira notas indicam a diferença de preço (valores absolutos) entre um ponto atual e um ponto de referência.

- Aproximação do índice alvo: o objetivo é conhecer a aproximação de um valor a um índice de preço diário, por exemplo. Esta sonificação utiliza as três notas do movimento absoluto e adiciona uma quarta nota. O intervalo de tempo entre a quarta e primeira notas indica a diferença de valor entre o ponto alvo e o ponto referencial.

- Bid-Ask Stack: esta sonificação representa ofertas de compra e venda de ações. A informação é apresentada por dois tons em sequiência (com duas notas distintas) seguidos por um tom mais longo. No caso de uma oferta de compra, a sonificação começa tocando a nota mais baixa dos dois primeiros tons e termina, no tom mais longo, tocando a mesma nota.

Pauletto e Hunt (Pauletto e Hunt, 2004) apresentaram um protótipo de uma ferramenta de sonificação interativa que tem como objetivo auxiliar na análise de conjuntos de dados genéricos. A ferramenta permite ao usuário processar e escalar os dados de interesse e, em seguida, sonificálos. Para isso, ela foi desenvolvida em dois módulos: data scaling e interactive sonification. A ferramenta conta com onze métodos de sonificação interativa para o mapeamento das informações. Dentre os mais conhecidos estão audificação, oscilador de freqüências, mapeamento de dados para entoação e duração do som. Aplicações do sistema estão relacionadas à análise de dados seqüenciais, informações estas coletadas principalmente por meio de múltiplos sensores instalados, por exemplo, no motor de um helicóptero para análise mecânicas durante o vôo ou nos músculos da perna de uma pessoa para examinar os movimentos em sessões de fisioterapia.

Watson (Watson, 2006) apresentou um trabalho sobre earcons-escaláveis (uma extensão do conceito de earcons). O projeto teve o objetivo de adicionar uma nova funcionalidade aos earcons, ou seja, além de serem utilizados para representar sons intermitentes ou eventos discretos, earcons também poderiam ser utilizados para representar sons gerados a partir de dados contínuos. Dessa forma, Watson desenvolveu um sistema sonoro de monitoramento da pressão sanguínea de pacientes. A sonificação final produzida pelo sistema era earcons sendo executados em certo intervalo de 
tempo (de acordo com os intervalos das medições de pressão), sendo que cada earcon tocado tinha suas propriedades sonoras (duração e freqüência) mapeadas conforme as informações da pressão sanguínea do paciente.

Walker e outros (Walker et al., 2006) compararam o tempo de busca e a precisão na navegação em menu de uma interface visual, utilizando quatro tipos de representação sonora: fala humana, earcons, ícones sonoros e spearcons. Spearcons (Speech-based earcons) funcionam da mesma forma que earcons e ícones sonoros. Eles são criados convertendo o texto de um menu, por exemplo, Export File, via texto-para-fala (text-to-speech - TTS). O som da mensagem gerada é então acelerado até que a mesma não seja mais reconhecida pelo ouvinte. Testes realizados com usuários indicaram que spearcons foi a melhor das quatro alternativas utilizadas principalmente com relação ao tempo de execução. Entretanto, um aspecto negativo apresentado foi que spearcons são dependentes de um idioma, ou seja, spearcons em inglês e espanhol são diferentes, problema este que não ocorre com earcons, por exemplo.

Campo e outros (de Campo et al., 2006) aproveitaram que sonificação é uma área de pesquisa interdisciplinar para apresentar um software (ainda em fase de construção) que tem o objetivo de criar um ambiente geral de sonificação incluindo diversas áreas de pesquisa como: neurologia, física, sociologia e processamento de sinais. Segundo os autores, o principal objetivo do SonEnvir é desenvolver um framework de sonificação que permitirá a criação de sonificação de forma eficiente e fácil. Atualmente, eles estão desenvolvendo e validando as sonificações para cada uma das áreas de pesquisas abordadas.

Com o objetivo de compreender mais facilmente e de forma mais rápida códigos fontes de sistemas de computação em sistemas de desenvolvimento interativo ( $\operatorname{IDE}^{7}$ ), Berman e Gallagher (Berman e Gallagher, 2006) desenvolveram três diferentes formas de sonificações interativas para este propósito. Primeiro o usuário seleciona as variáveis que comporão o seu critério de busca. Depois, ao selecionar ou passar o ponteiro do mouse sobre um método, objeto ou linha de código, sons são emitidos e suas propriedades acústicas indicam a relação com as variáveis selecionadas (notas com entoações altas representam relação, com entoações baixas representam falta de relação). As formas de sonificação desenvolvidas se diferenciam principalmente na maneira como o código fonte é analisado, oferecendo níveis de observação diferentes para análise de instruções, métodos e objetos.

\footnotetext{
${ }^{7}$ Integrated Development Environment.
} 


\subsection{Revisão dos trabalhos com experimentos em sonifi- cação}

Bonebright e outros (Bonebright et al., 2001) realizaram um projeto cujo objetivo era avaliar a eficiência de sonificação de gráficos gerados a partir de conjunto de dados. No projeto foram realizados três experimentos que contaram com a participação de 51 estudantes. $O$ primeiro experimento avaliou a capacidade dos participantes em associar a representação sonora de um gráfico com a sua representação visual (ver Figura 3.10). Também foi avaliada a utilização de sons monofônicos (mono) e estereofônicos (estéreo) nos diferentes gráficos. No segundo experimento eles avaliaram a compreensão dos participantes ao analisarem os gráficos visuais com e sem a presença de sonificação. As sonificações no segundo experimento apresentaram sons ritmados (com presença de ritmo ou cadência) e não-ritmados. O propósito do terceiro experimento foi avaliar se a prática ou o treino pode levar a uma melhora no entendimento dos gráficos visuais e sonoros. Nas sonificações eles utilizaram timbres de flauta e fagote ${ }^{8}$. As entoações foram mapeadas de acordo com as coordenadas $\mathrm{X}$ e $\mathrm{Y}$ dos gráficos. O instrumento de percussão utilizado para marcação de ritmo foi um tambor de corda (snare drum). O principal resultado apresentado neste trabalho foi obtido no primeiro experimento onde os participantes tiveram uma boa taxa de acerto já que foram 42.3 associações corretas em média (em um máximo de 51), nos 20 gráficos testados.

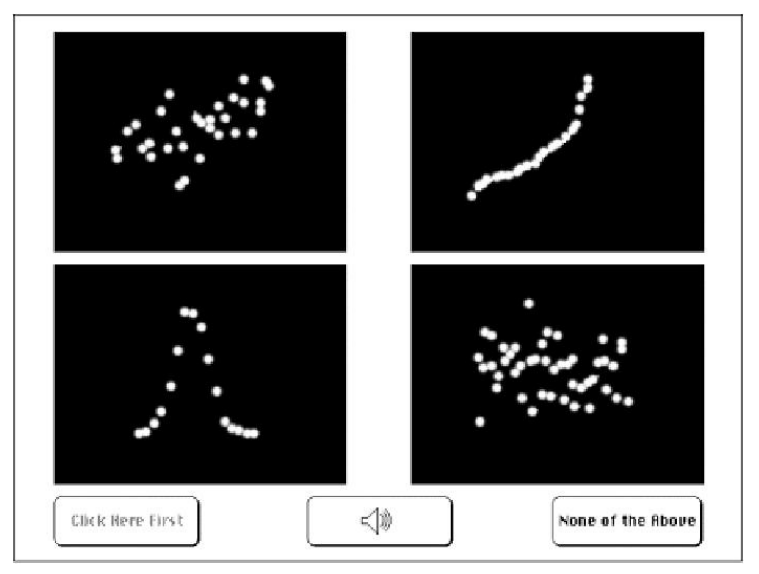

Figura 3.10: Tela do teste de associação do som ao gráfico (adaptado de (Bonebright et al., 2001))

Smith e Walker (Smith e Walker, 2002) estudaram o uso de contextos ou marcadores sonoros (repetição de determinado tom em um intervalo de tempo ou para determinados valores) em interfaces sonoras. O conjunto de dados utilizado foi a variação de preços (10 horas de transação) de um tipo de ação não identificado (mercado de ações). Os preços foram audificados em frequiência utilizando mapeamento direto. O experimento, que contou com 58 estudantes, foi separado em

\footnotetext{
${ }^{8}$ Fagote (bassoon), instrumento de sopro utilizado em orquestras e bandas militares.
} 
duas seções. Na primeira seção todos os participantes tiveram que identificar as variações dos preços da ação nos gráficos sonoros sem a utilização de contextos. Na segunda seção os participantes foram divididos em 6 grupos e cada grupo analisou novamente os gráficos sonoros com a adição de diferentes contextos, com exceção do grupo 1 que realizou novamente a primeira seção do experimento. Alguns dos contextos incluíam a marcação da passagem das horas do dia de transação em tiques sonoros e a utilização de tons com diferentes entoações para indicar o preço de abertura da ação. Os autores afirmaram que a aplicação de alguns contextos auxiliou a reduzir erros na análise dos gráficos sonoros.

Peres e Lane (Peres e Lane, 2003) conduziram dois experimentos de sonificação de diagramas de caixa ${ }^{9}$ utilizando diferentes parâmetros de som. No primeiro experimento, que contou com a participação de 58 estudantes de graduação, comparou-se a eficiência da utilização de entoação, localização espacial e a combinação das duas propriedades para representar as informações estatísticas apresentadas pelo diagrama de caixa. Já no segundo experimento foram testados os parâmetros sonoros entoação e tempo. Comparando os resultados dos dois experimentos apresentados, os autores identificaram uma maior porcentagem de acerto quando foram utilizados tempo e entoação. Outro resultado observado foi que os melhores resultados do primeiro experimento ocorreram ao utilizar os parâmetros entoação e localização espacial separadamente e não combinados.

Salvador e outros (Salvador et al., 2005) avaliaram o uso do sons e imagens em conjunto como uma forma de representação de dados. Os valores dos dados foram mapeados linearmente para freqüência nas apresentações sonoras e para cor nas apresentações visuais. Os participantes do experimento interagiram com projeções de dados genéricos (quantidade de precipitação de 164 pontos em um relevo (ver Figura 3.11) e os indicadores de desenvolvimento humano (IDH ${ }^{10}$ ) de 174 países) utilizando a ferramenta de interação 2D Spider Cursor no sistema DSVol (Salvador et al., 2002). Nos experimentos foram avaliados as polaridades de mapeamento sonoro direta e inversa, uso de som para apoiar tarefas de visualização e os três modos possíveis de apresentação (sonoro, visual e multimodal). Participaram dos experimentos 84 estudantes do primeiro ano de graduação do curso Bacharelado em Ciência da Computação do Instituto de Computação e Matemática Computacional (ICMC) da Universidade de São Paulo. Os resultados obtidos validaram principalmente a utilização de sonificação em conjunto com visualização, já que a apresentação multimodal obteve maior porcentagem de acertos nas tarefas.

\footnotetext{
${ }^{9}$ Diagramas de caixa (box plots) são representações diagramáticas dos cinco números sumários: mínimo, quartil inferior, mediana, quartil superior, máximo.

${ }^{10}$ Índice de Desenvolvimento Humano
} 


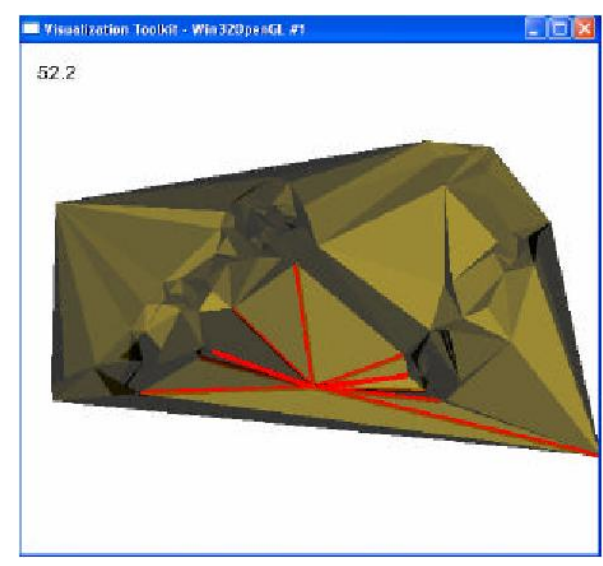

(a) Imagem dos conjuntos de testes sonoro.

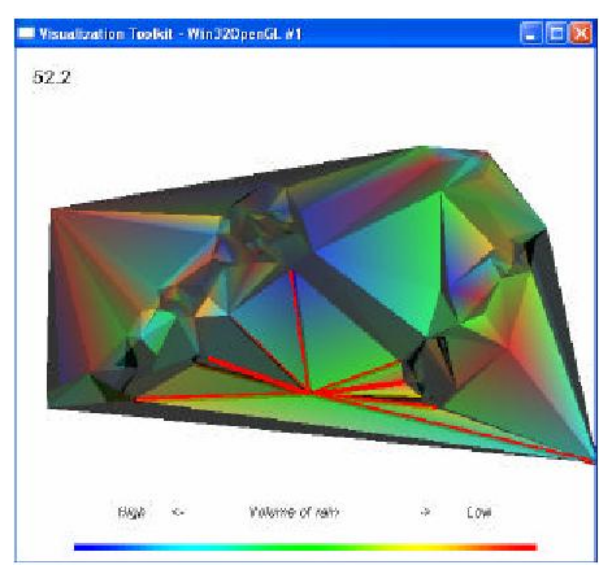

(b) Imagem do conjunto de testes visual.

Figura 3.11: Imagens do conjunto de dados Volume de Chuva (adaptado de (Salvador, 2003)).

O objetivo do experimento de Pauletto e Hunt (Pauletto e Hunt, 2005) era comparar como os usuários classificavam ${ }^{11}$ a presença de cinco atributos de dados (ruído, elementos repetitivos, oscilação em freqüência fixas, descontinuidades e nível de força do sinal) extraídos durante meia hora de vôo de um helicóptero, no domínio auditivo e visual. Na exibição visual foram utilizados espectrogramas e na exibição sonora foram utilizados sons gerados por audificação dos espectogramas (ver Figura 3.12). Participaram do experimento 23 pessoas, todos com conhecimentos de som e espectrograma. Os resultados mostraram que para cada um dos cinco atributos a média de acerto na análise do espectrograma apresentou alta correlação ${ }^{12}$ com a média de acerto para sons.

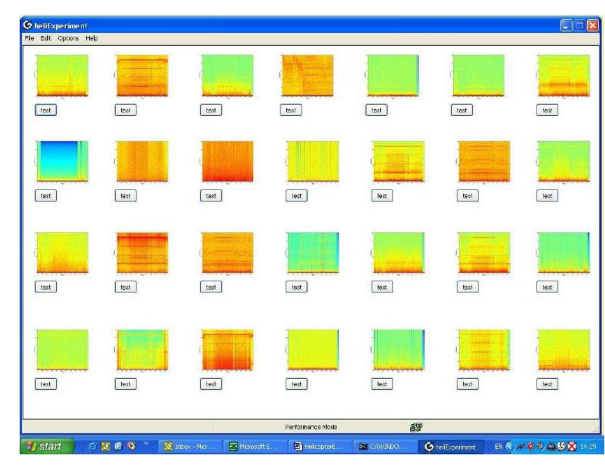

(a) Teste com os espectogramas.

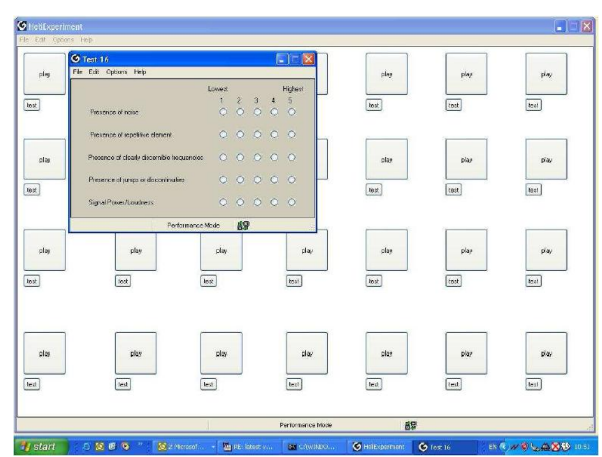

(b) Testes sonoros.

Figura 3.12: Imagens das telas do experimento (adaptado de (Pauletto e Hunt, 2005)).

Stevens e outros (Stevens et al., 2004) investigaram a facilidade dos usuários em reconhecer e interpretar o significado de uma a quatro características presentes em um som: identificação do som, distância do objeto, direção do movimento e tamanho do objeto. No experimento foram utilizados ícones sonoros manipulados em quatro parâmetros: a identificação do som (campainha de bicicleta, latido de cachorro, buzina de carro e passos de pessoas), a distância do objeto (perto

\footnotetext{
${ }^{11}$ A classificação de presença de cada atributo variava de "Muito baixo" (1) a "Muito Alto" (5).

${ }^{12}$ Relacionamento linear entre os acertos na análise por espectograma e som.
} 
ou longe), a direção de movimento do objeto (aproximando ou distanciando) e o tamanho do objeto (pequeno ou grande). O principal resultado deste experimento, que contou com a participação de 60 estudantes, foi a observação de que quanto maior o número de parâmetros contidos no som, menor sua precisão de reconhecimento.

O experimento de Holmes (Holmes, 2005) foi conduzido para determinar a precisão dos participantes em localizar o ponto de maior nível de concentração de ozônio usando somente apresentação sonora em quatro mapas diferentes (ver Figura 3.13). A interface visual era uma tela totalmente branca e à medida que o usuário movia o ponteiro do mouse pela tela, os sons gerados eram alterados baseando-se na informação de determinado ponto. Os quatros atributos do som testados foram frequiência-seno, frequiência-sawtooth ${ }^{13}$, volume e duração. Dos 24 participantes que completaram 96 testes (4 testes para cada participante), somente uma pessoa em um teste foi capaz de selecionar precisamente o ponto de maior concentração. O desempenho geral foi considerado bom pelos autores, já que 54\% dos testes ficaram dentro de 50 pixels do ponto de maior valor. Como nenhum participante havia anteriormente realizado aquele tipo de tarefa, os autores tentaram identificar de forma subjetiva alguns padrões e técnicas de busca utilizados por eles. Dois padrões citados foram "busca por setor" e "busca em paralelo".

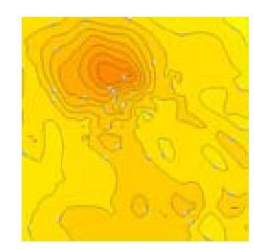

Mapa A

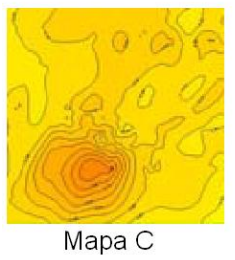

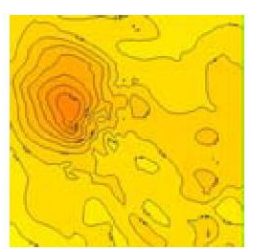

Mapa B

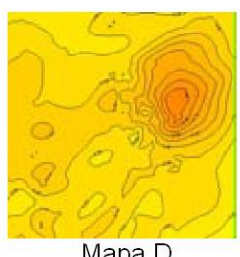

Mapa D

Figura 3.13: Mapas com diferentes níveis de concentração de ozônio utilizados no experimento (adaptado de (Holmes, 2005)).

Inspirados pelo importante papel dos sons reais no cotidiano das pessoas, Brazil e Fernström (Brazil e Fernström, 2006) investigaram em dois experimentos diferentes a capacidade de 11 participantes na identificação de ícones sonoros apresentados simultaneamente. No primeiro experimento não foi utilizada nenhuma categorização ou classificação na seleção dos ícones sonoros, ou seja, os sons (que variavam de três a seis ícones sonoros simultâneos) podiam conter ícones sonoros de um mesmo tipo, por exemplo, sons de objetos feitos de vidro ou motores de veículos.

\footnotetext{
${ }^{13}$ Assim como a freqüência-seno, a freqüência-sawtooth é uma representação de forma de onda.
} 
No segundo experimento, os sons foram compostos por ícones sonoros previamente categorizados conforme a sonorização do objeto, não existindo portanto ícones sonoros similares em um mesmo som. Durante a execução dos testes, cada participante deveria primeiro ouvir o som e, em seguida, digitar uma descrição do que ouviu em um espaço determinado na interface (ver Figura 3.14). Um dos resultados observados no final do estudo pelo autores foi a facilidade que os participantes tiveram em identificar os ícones sonoros no primeiro experimento (média de acerto de 73.04\%) e no segundo (média de acerto de $89.92 \%$ ). A porcentagem de acerto foi menor quando utilizado o máximo possível de ícones sonoros no primeiro experimento. No segundo experimento não houve uma grande variação desta porcentagem nas diferentes variações de execução.

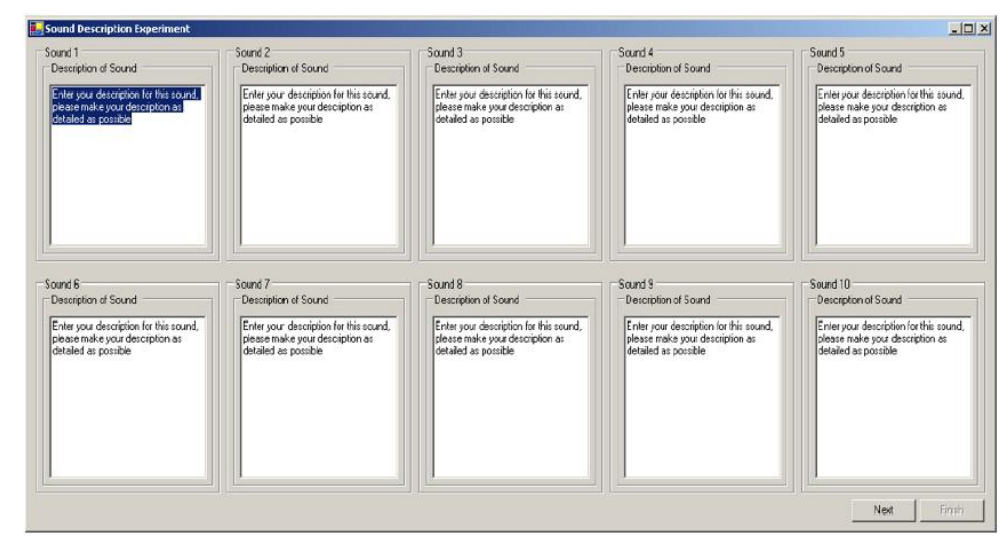

Figura 3.14: Interface utilizada pelos participantes para descrever os sons (adaptado de (Brazil e Fernström, 2006)).

\subsection{Considerações Finais}

Este capítulo fez um levantamento dos trabalhos em sonificação abordando principalmente as técnicas de sonificação utilizadas e o propósito de cada trabalho. Este estudo permitiu a observação das diferentes técnicas de sonificação sendo aplicadas na prática em sistemas de computação destinados às distintas áreas do conhecimento humano: finanças, estatística, geologia, bioquímica e internet.

O mapeamento de parâmetros tem sido a abordagem mais utilizada nos trabalhos de sonificação. Este técnica consiste basicamente em mapear as dimensões dos dados em diferentes propriedades sonoras como duração, entoação e frequiência. Suas principais vantagens são a facilidade de produção e a representação multivariável. Já as técnicas earcons e ícones sonoros têm sido geralmente utilizadas para representar elementos de interfaces e marcadores de eventos e ações. Alguns dos trabalhos mais recentes têm apresentado formas de extensão das técnicas de earcons e ícones sonoros com o objetivo de aproveitar suas vantagens em diferentes tipos de dados, por exemplo, em série temporais. Audificação é a técnica predominante no mapeamento de dados contínuos, por exemplo, dados de medição de movimentos sísmicos. 
Este capítulo trouxe ainda um estudo detalhado de alguns experimentos com usuários que tiveram por finalidade avaliar e validar os aspectos positivos e negativos da aplicação de estímulos sonoros como alternativa para mapeamento e análise de informações em sistemas computacionais. Este estudo foi importante para levantar conceitos, idéias, formas de desenvolvimento e aplicação de experimentos, etapa esta fundamental na conclusão de um projeto de sonificação computacional.

O próximo capítulo descreve as ferramentas envolvidas neste trabalho de mestrado. 


\section{Sistema de sonificação de dados}

\subsection{Considerações Iniciais}

Muitas técnicas de interação têm sido desenvolvidas com o propósito de auxiliar a exploração e manipulação de dados complexos e estruturas 3D. Entretanto, existem poucas ferramentas capazes de fornecer flexibilidade para a exploração de informação em representações gráficas como superfícies, recurso este muito útil ao entendimento de informação e representação de dados (Minghim et al., 2005).

Este capítulo apresenta na Seção 4.2 o Spider Cursor, ferramenta de fácil interação que implementa muitas das funcionalidades que uma ferramenta de exploração de dados deve possuir. $\mathrm{O}$ Spider Cursor é a ferramenta antecessora dos sistemas inseridos neste projeto de mestrado.

Uma evolução do Spider Cursor, o Super Spider, é apresentado na Seção 4.3, onde são descritas suas principais funcionalidades, além de apresentar detalhes de implementação e funcionamento do novo módulo de sonificação do sistema, recurso que foi desenvolvido durante este trabalho de mestrado. A Seção 4.4 descreve o Sonar 2D, novo sistema interativo de sonificação para exploração dados que foi desenvolvido de maneira integrada ao Super Spider.

\subsection{Spider Cursor}

O Spider Cursor (Minghim et al., 2005) é um sistema que auxilia em importantes tarefas de visualização como: identificação de pontos, corte de polígonos, análises de grupos de elementos e seus relacionamentos. Pode ser usado na manipulação e exploração de dados de natureza geo- 
métrica intrínseca, como também para dados genéricos que são mapeados em superfícies. A sua característica de exploração de vizinhança permite a análise de projeções genéricas (exploração de dados), para modelagem e para interação em superfícies 3D (Minghim et al., 2005).

No processo gráfico, o cursor (representação gráfica criada para auxiliar na interação com a visualização) é apresentado a cada movimento do ponteiro do mouse sobre a representação visual dos dados. O centro do cursor é definido pelo vértice ou ponto da superfície de que o ponteiro do mouse está mais próximo e os vértices vizinhos, que são destacados realçando-se as arestas que interligam os pontos vizinhos ao ponto central. O resultado final é semelhante a uma aranha e isso resultou no nome Spider Cursor (ver Figura 4.1).

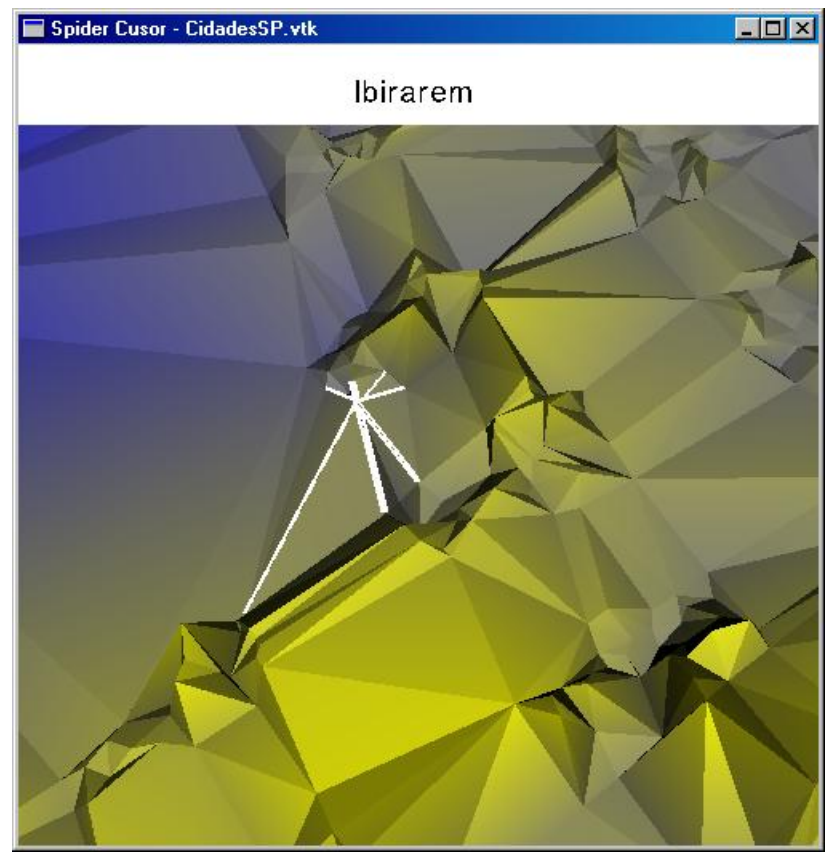

Figura 4.1: Exploração do conjunto de dados com o cursor.

No início da interação, o cursor pode se movimentar livremente pela superfície do polígono representado visualmente. Se determinado ponto for selecionado pelo ponteiro do mouse, o movimento do cursor se limitará aos seus pontos vizinhos. O usuário pode investigar características dos dados relacionados com o ponto corrente e seus vizinhos enquanto caminha com o cursor. Funções sonoras também podem ser utilizadas para auxiliar na percepção dos movimentos realizados, na determinação do caminho a ser percorrido e no entendimento das informações (Salvador, 2003).

Uma opção do sistema é permitir a apresentação textual de informações contidas em cada ponto do conjunto de dados. Após a identificação do ponto indicado pelo ponteiro do mouse, a informação é obtida por consulta de arquivo texto e apresentada na parte superior da janela de interação. Este recurso auxilia o usuário na navegação pela representação visual e na identificação dos pontos (ver Figura 4.1).

O Spider Cursor foi desenvolvido no Microsoft Visual C++ 6.0. O sistema utiliza a biblioteca VTK (The Visualization Toolkit) (Schroeder et al., 2003) para a realização das tarefas de visualiza- 
ção e de interação. A biblioteca STK (The Synthesis Toolkit) (Cook e Scavone, 1999) é empregada para realização da síntese e apresentação sonora.

\subsubsection{Principais funcionalidades}

Algumas das principais funcionalidades do Spider Cursor são:

- Navegação sobre a superfície de objetos: uma vez que o cursor está localizado na superfície de uma representação gráfica, os movimentos do ponteiro do mouse controlam a posição do cursor sobre a superfície.

- Corte (closed path): é possível extrair uma determinada porção da representação gráfica original para análises mais detalhadas. $\mathrm{O}$ caminho do corte pode ser feito de duas maneiras: ponto-a-ponto, no qual o usuário seleciona com o botão direito do mouse cada vértice do caminho, e automático, no qual o usuário seleciona o primeiro vértice com o botão esquerdo do mouse e move o ponteiro do mouse sobre os vértices que comporão o caminho de corte, sem precisar de novos cliques do mouse. A Figura 4.2 mostra a seqüência de operações para a realização de um corte em um polígono.

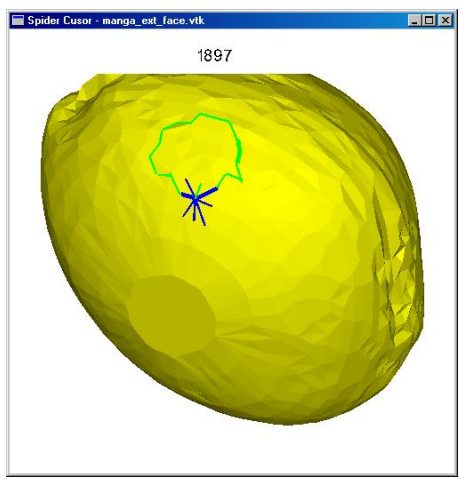

(a) Demarcação do caminho do corte pelo cursor.

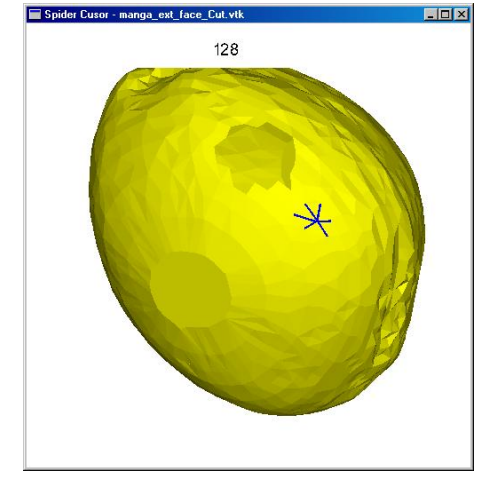

(b) Representação do objeto após o corte.

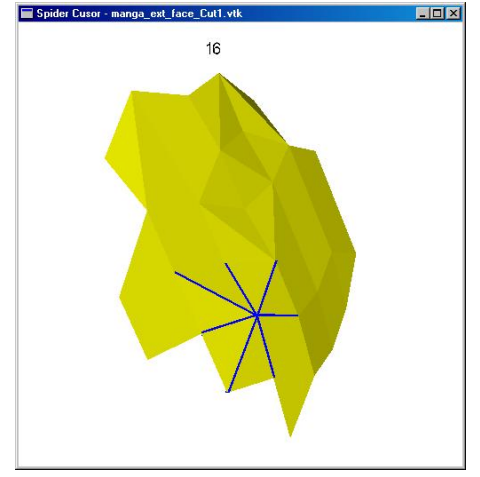

(c) Exploração do polígono recortado com cursor.

Figura 4.2: Sequiência de operações do corte.

- Mapeamento de escalares: Dados numéricos armazenados nos vértices dos polígonos podem ser exibidos por mapeamento sonoro (frequiência sonora de um instrumento musical) ou por valores alfanuméricos que são apresentados na parte superior da janela de interação.

- Sonificação: Quatro sonificações são implementadas para auxiliar o processo gráfico (Salvador, 2003):

- Inclinação do segmento de reta: essa sonificação auxilia o usuário a perceber que movimento está sendo realizado durante o traçado, já que muitas vezes a superfície é visualizada de cima. Para o cálculo da inclinação são considerados o ponto que está 
sendo selecionado e o ponto imediatamente anterior a ele. $\mathrm{O}$ ângulo entre o segmento de reta e o eixo X é calculado e o valor resultante é mapeado para freqüência;

- Tamanho do segmento de reta: Essa sonificação auxilia na percepção do tamanho do segmento de reta que está sendo traçado em relação aos segmentos já traçados. O tamanho do segmento de reta é mapeado diretamente para frequiência, sendo que o primeiro segmento de reta traçado é sempre mapeado para a máxima freqüência e, a partir do segundo segmento, os valores vão se ajustando;

- Número de caminhos: auxilia o usuário na percepção do número de caminhos (opções) que podem ser percorridos a partir de um ponto apontado pelo ponteiro do mouse, durante o traçado do contorno. O número de caminhos é mapeado diretamente para freqüência;

- Valor do dado: apresenta o valor da entidade na posição indicada pelo ponteiro do mouse através de mapeamento direto para frequiência.

\subsection{Super Spider}

O Super Spider (Watanabe, 2007) é uma ferramenta de interação que permite navegar sobre malhas triangulares ${ }^{1}$, consultar os diversos atributos dos dados e representá-los através de cor, altura (height fields) e som. Para realizar o mapeamento visual dos dados, são disponibilizadas as seguintes técnicas: iso-superfícies com transparência, scatterplot, iso-linhas (coloridas, brancas ou pretas) e wireframe ${ }^{2}$.

Baseado na representação de informações através de superfícies e ícones $\left(g l y p h s^{3}\right)$, a ferramenta conta com um novo recurso: as super-quádricas (ver Figura 4.3). Trata-se de uma família de objetos paramétricos 3D utilizados em modelagem geométrica. Estes objetos são configurados por um conjunto de parâmetros que resultam em uma série de formas diferentes: super-elipsóide, super-hiperbolóide de uma lâmina, super-hiperbolóide de duas lâminas e super-toróide (ver Figura 4.4). As super-quádricas consistem de um cursor auto-representativo, ou seja, capaz de exibir simultaneamente diversas características dos dados. Desta forma, através de atributos como forma, tamanho, cor e rotação, as super-quádricas conseguem representar até 9 atributos ou dimensões de dados.

Por ser uma extensão do Spider Cursor, o Super Spider apresenta a maioria das funcionalidades de sua antecessora, por exemplo: corte de polígonos, mapeamento de pontos e sondagem superficial. O Super Spider é desenvolvido na linguagem Java e emprega as bibliotecas Java 3D (no mapeamento visual dos dados) e a biblioteca Java Sound (no mapeamento sonoro da aplicação).

\footnotetext{
${ }^{1}$ Os mapas utilizados são gerados através da triangulação de Delaunay (Nonato et al., 2001).

${ }^{2}$ Contorno dos polígonos.

${ }^{3}$ Graphical User Interface.
} 


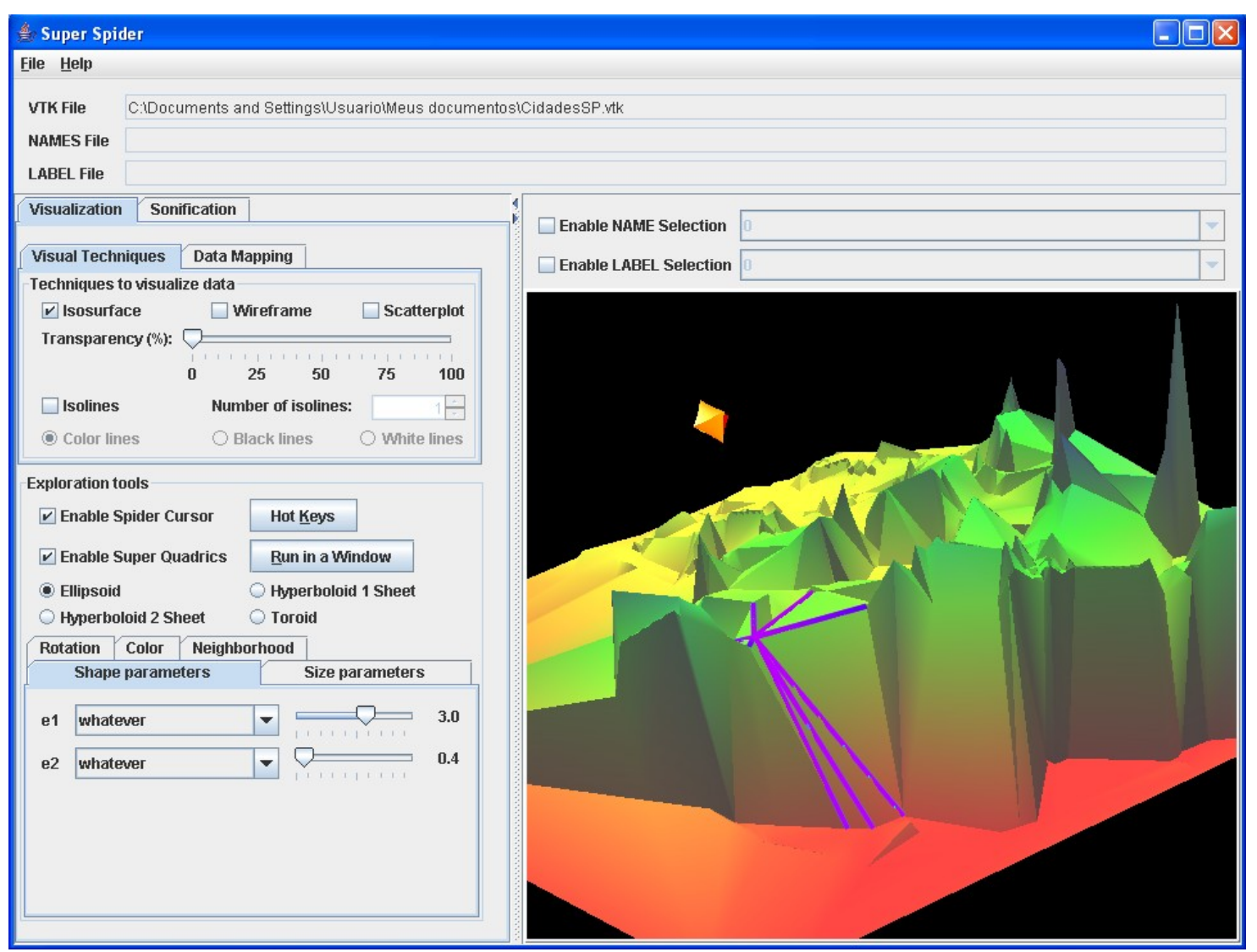

Figura 4.3: Visualização sendo explorada utilizando o 2D Spider Cursor e super-quádricas no sistema Super Spider.

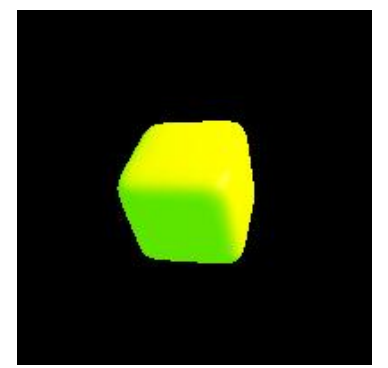

(a) Elipsóide

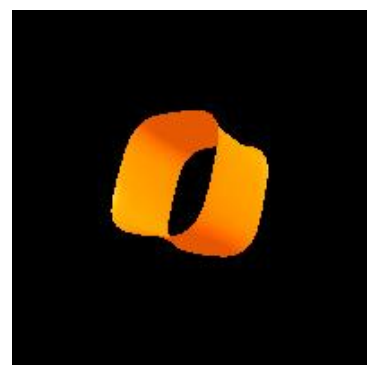

(b) Hiperbolóide 1 lâmina

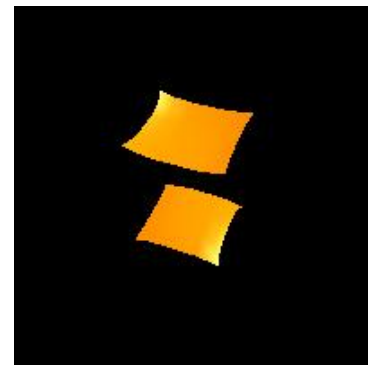

(c) Hiperbolóide 2 lâminas

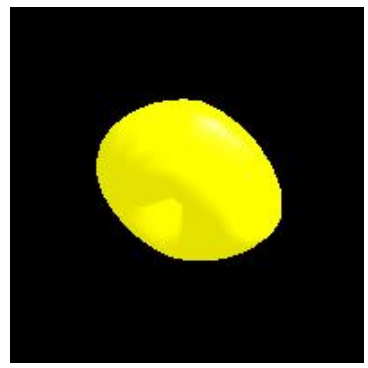

(d) Toróide

Figura 4.4: Super-quádricas disponíveis para a exploração dos dados.

\subsubsection{Módulo de sonificação}

No sistema Spider Cursor, a frequiência do som é a única propriedade sonora utilizada no mapeamento sonoro dos dados, além da possibilidade de escolher um timbre sonoro (de um conjunto de opções) para ser utilizado na exploração ponto-a-ponto. Neste novo módulo de sonificação do Super Spider, desenvolvido neste mestrado utilizando a API Java Sound, é possível utilizar três propriedades sonoras: intensidade (intensity), entoação (pitch) e inflexão da entoação (pitch bend) (ver Figura 4.5). Todas possuem recursos para seleção de limites máximo e mínimo de valores, 
opção de estabelecimento de um valor padrão (default) e a polaridade do mapeamento (positiva ou negativa). As três propriedades são independentes e podem ser utilizadas (ou não) em conjunto para representar as informações.

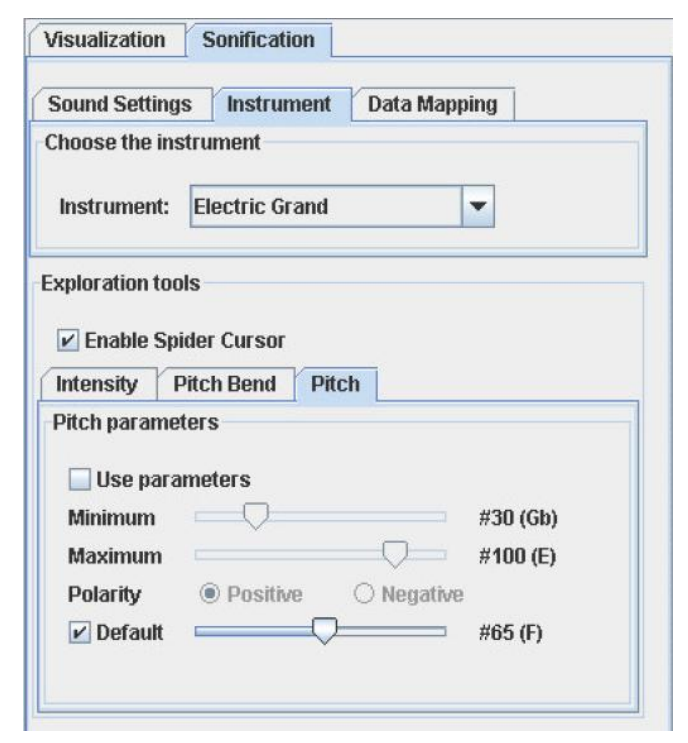

Figura 4.5: Opções de configuração do módulo de sonificação.

A sonificação neste sistema é realizada durante a exploração pontual da visualização, ou seja, os sons são tocados durante o deslocamento do cursor sobre a superfície gráfica. O cálculo dos valores das propriedades sonoras que compõem o som de cada ponto da visualização é feito em tempo real de acordo com os parâmetros definidos no módulo de sonificação. Se uma propriedade estiver configurada com um valor fixo ou padrão, este valor será atribuído diretamente ao som reproduzido. Caso contrário, para o mapeamento com polaridade positiva é utilizada a seguinte fórmula para o cálculo do valor da propriedade:

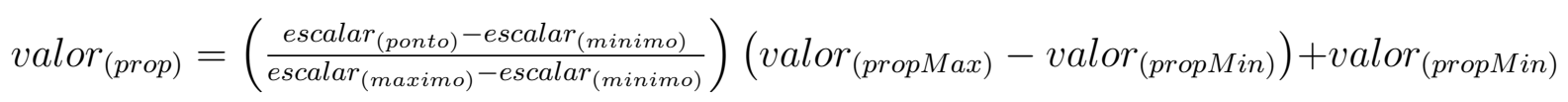

onde,

- $\operatorname{valor}_{(p r o p)}$ é o valor da propriedade (entoação, intensidade ou inflexão da entoação) atribuída ao ponto;

- $\operatorname{escalar}_{(\text {ponto })}$ é o valor escalar de determinado ponto;

- $\operatorname{escalar}_{(\text {minimo }}$ e escalar $($ maximo) são os valores escalares mínimo e máximo presentes em um conjunto de dados;

- valor $_{(\text {propMin) }}$ e valor $($ propMax) são os valores mínimo e máximo definidos nos parâmetros intensidade, entoação e inflexão da entoação configurada no módulo de sonificação. 
Para o mapeamento com polaridade negativa a fórmula utilizada é:

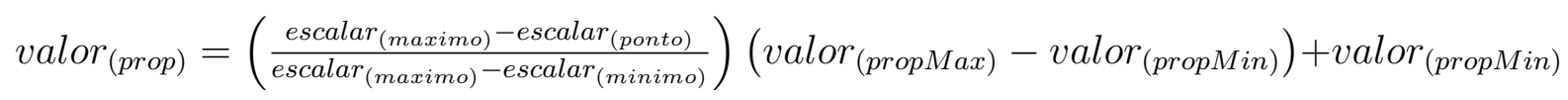

Por exemplo, se os parâmetros do módulo de sonificação tiver a seguinte configuração: intensidade mínima igual a 30 e intensidade máxima igual a 100; entoação mínima igual a 50 e entoação máxima igual a 100; inflexão da entoação mínima igual a 20 e inflexão da entoação máxima igual a 20000. Para um conjunto de dados com valores escalares mínimo e máximo iguais a 0 e 100 , respectivamente, teremos para os pontos com valores escalares 40 e 90, os seguintes valores para as propriedades sonoras: intensidade, entoação ou inflexão da entoação (no mapeamento com polaridade positiva e negativa) (ver Tabela 4.1 e 4.2 ).

Tabela 4.1: Valores das propriedades sonoras do ponto com valor escalar igual a 40 .

\begin{tabular}{|l|c|c|c|}
\hline Mapeamento & Intensidade & Entoação & Inflexão da entoação \\
\hline \hline Polaridade positiva & 58 & 70 & 8012 \\
\hline Polaridade negativa & 72 & 80 & 12008 \\
\hline
\end{tabular}

Tabela 4.2: Valores das propriedades sonoras do ponto com valor escalar igual a 90.

\begin{tabular}{|l|c|c|c|}
\hline Mapeamento & Intensidade & Entoação & Inflexão da entoação \\
\hline \hline Polaridade positiva & 93 & 95 & 18002 \\
\hline Polaridade negativa & 37 & 55 & 2018 \\
\hline
\end{tabular}

O módulo de sonificação do Super Spider conta com um total de 128 timbres de instrumentos sonoros e possibilita o incremento tanto em qualidade sonora quanto em quantidade de timbres, porque eles são definidos por um banco de sons (soundbank) do Java Sound que pode ser alterado ou substituído por outro. No módulo de sonificação é possível também definir a duração de cada som executado na exploração pontual.

Foi desenvolvida também a sonificação do caminho do corte realizado pelo cursor. Nesta funcionalidade, após a definição do caminho (que pode ser um circuito completo ou não), o usuário pode ouvir o som de cada ponto na seqüência em que o corte foi feito ou na ordem inversa. Os sons são tocados conforme as configurações definidas no módulo e executados automaticamente à medida que o cursor se desloca de um ponto a outro. Alterações nas propriedades sonoras durante a execução da sonificação são mapeadas em tempo real. Para acentuar a separação entre os sons de cada ponto do caminho de corte, intervalos (breaks) podem ser incluídos na sonificação. Botões de um tocador (play, pause e stop) são utilizados para iniciar, pausar e parar a sonificação do caminho de corte (ver Figura 4.6). 


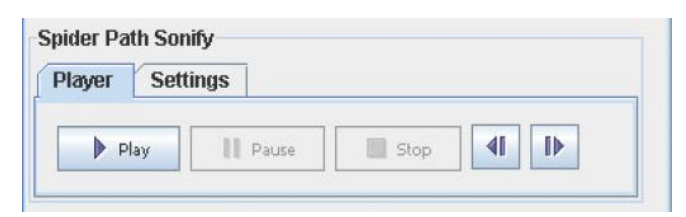

Figura 4.6: Opções de controle da sonificação do caminho de corte.

\subsection{Sonar 2D}

Sonar 2D é uma ferramenta interativa de sonificação para exploração de dados desenvolvida neste trabalho de maneira integrada ao Super Spider utilizando a linguagem de programação Java e as API's Java 3D e Java Sound. A ferramenta, que utiliza mapeamento de parâmetros como técnica de sonificação, permite que o usuário ouça um conjunto de dados com apenas um clique do mouse, sem precisar interagir ponto-a-ponto com a representação gráfica. Em outras palavras, um "cenário virtual sonoro" é criado através da transformação de cada entidade do conjunto de dados em um instrumento acústico, incluindo todas as suas características sonoras parametrizáveis e autônomas. Para produzir a sonificação, é preciso definir um ponto que será o centro do Sonar e depois definir os itens sonoros dos pontos que serão sonificados.

A sonificação é gerada através da expansão de um círculo (em 2D) ou uma esfera (em 3D) a partir do ponto central do Sonar, que é um ponto qualquer do conjunto de dados que pode também ser definido pelo usuário. À medida que as extremidades deste polígono se expandem e atingem outros pontos do conjunto de dados, sons são executados conforme os itens sonoros configurados na fase anterior à execução da sonificação. A Seção 4.4.3 apresenta uma descrição mais detalhada deste processo de mapeamento e execução da sonificação.

Para se ter um melhor entendimento de todo o processo de sonificação, desde a inicialização do sistema até a execução do som criado, as seções seguintes descrevem as etapas da interação, ou seja, começando pela apresentação das interfaces visuais que constituem o sistema, seguida das formas de inicialização do sistema, da definição do ponto central do Sonar, da adição de itens sonoros, do mapeamento sonoro, da execução da sonificação e por fim, de alguns recursos adicionais.

\subsubsection{Interfaces visuais e inicialização do sistema}

O sistema possui uma tela principal e uma secundária. Na tela principal encontram-se os recursos gerais para manipulação dos itens sonoros (criar, alterar, abrir e salvar), exportação de arquivos MIDI gerados, acesso ao Sonar2D Player e as configurações gerais do sistema (ver Figura 4.7). A tela secundária, denominada Sonar2D Display, é utilizada para a visualização dos pontos do conjunto de dados que são apresentados conforme a configuração dos itens sonoros, obedecendo principalmente a cor do item.

Existem duas formas de executar o sistema através do Super Spider: 


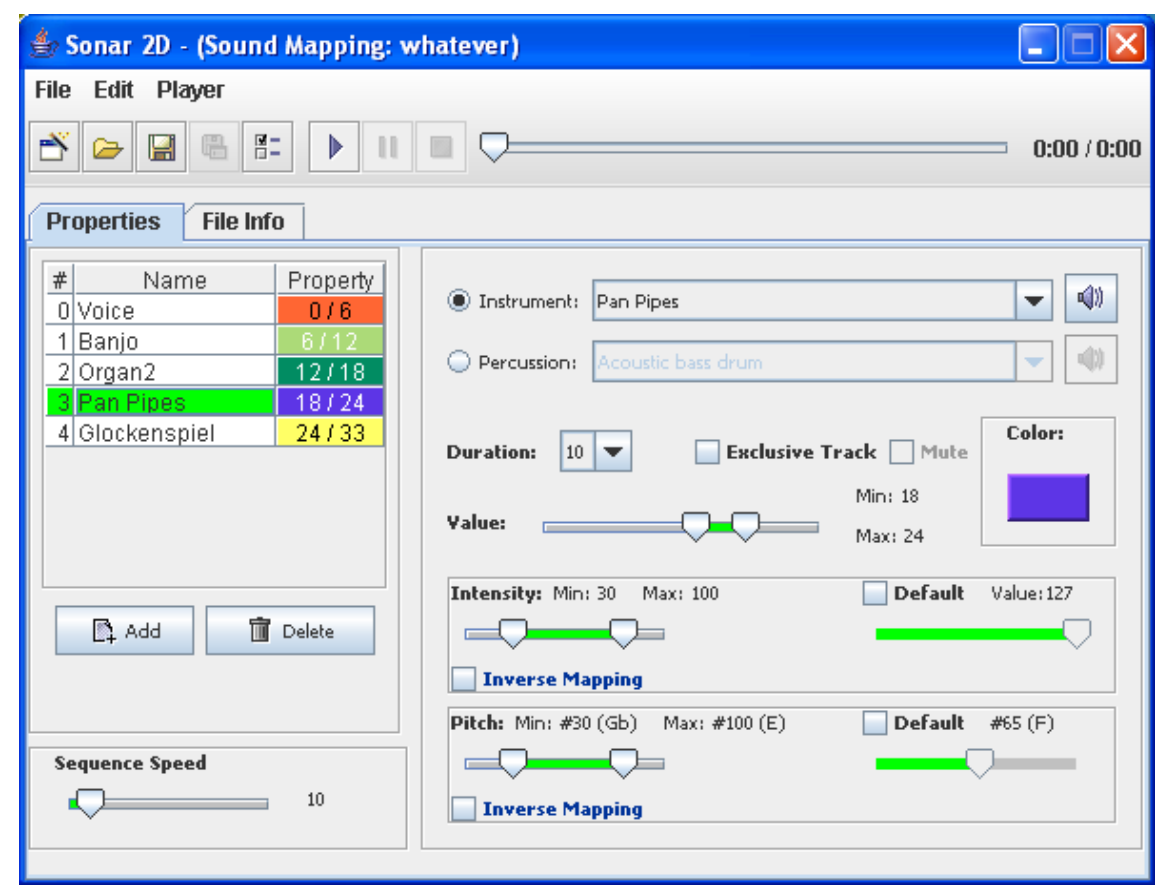

Figura 4.7: Tela principal do Sonar 2D

- Definição do ponto central com o 2D Spider Cursor: A seleção do ponto é feita durante a exploração da representação gráfica pelo $2 D$ Spider Cursor pressionando a tecla "S". A confirmação que o ponto foi selecionado é feita exibindo uma imagem com letra "S" acima do $2 D$ Spider Cursor (que agora fica travado indicando o ponto central do Sonar) juntamente com a emissão de um som (ver Figura 4.8).

- Seleção aleatória de um ponto do conjunto de dados: Nesta alternativa, não é necessária a seleção de nenhum ponto na representação gráfica do Super Spider. O sistema selecionará aleatoriamente um ponto do conjunto de dados como sendo o ponto central do Sonar quando o botão "Sonar 2D" for acionado.

Antes de iniciar o sistema é possível também definir o conjunto de escalares ou data mappings do arquivo VTK ${ }^{4}$ carregado pelo Super Spider com o qual se deseja trabalhar. Um conjunto de escalares pode ser definido no item "Data Mappings" da seção de Sonificação do Super Spider.

Muitas vezes, existe mais de um conjunto de escalares em um arquivo VTK. Para agilizar o trabalho de sonificação dos conjuntos de escalares e facilitar suas comparações, o sistema permite a abertura de uma janela do sistema Sonar 2D para cada um dos campos escalares. Dessa forma, é possível trabalhar com a sonificação de dois ou mais conjunto de escalares independentemente e simultaneamente (ver Figura 4.9).

Na tela principal do sistema, na seção "File Info", existe uma lista contendo informações relevantes sobre cada ponto que pertence ao conjunto dados carregado no arquivo VTK. São elas:

\footnotetext{
${ }^{4}$ Formato de arquivo definido pelo pacote de visualização The Visualization Toolkit (Schroeder et al., 2003).
} 


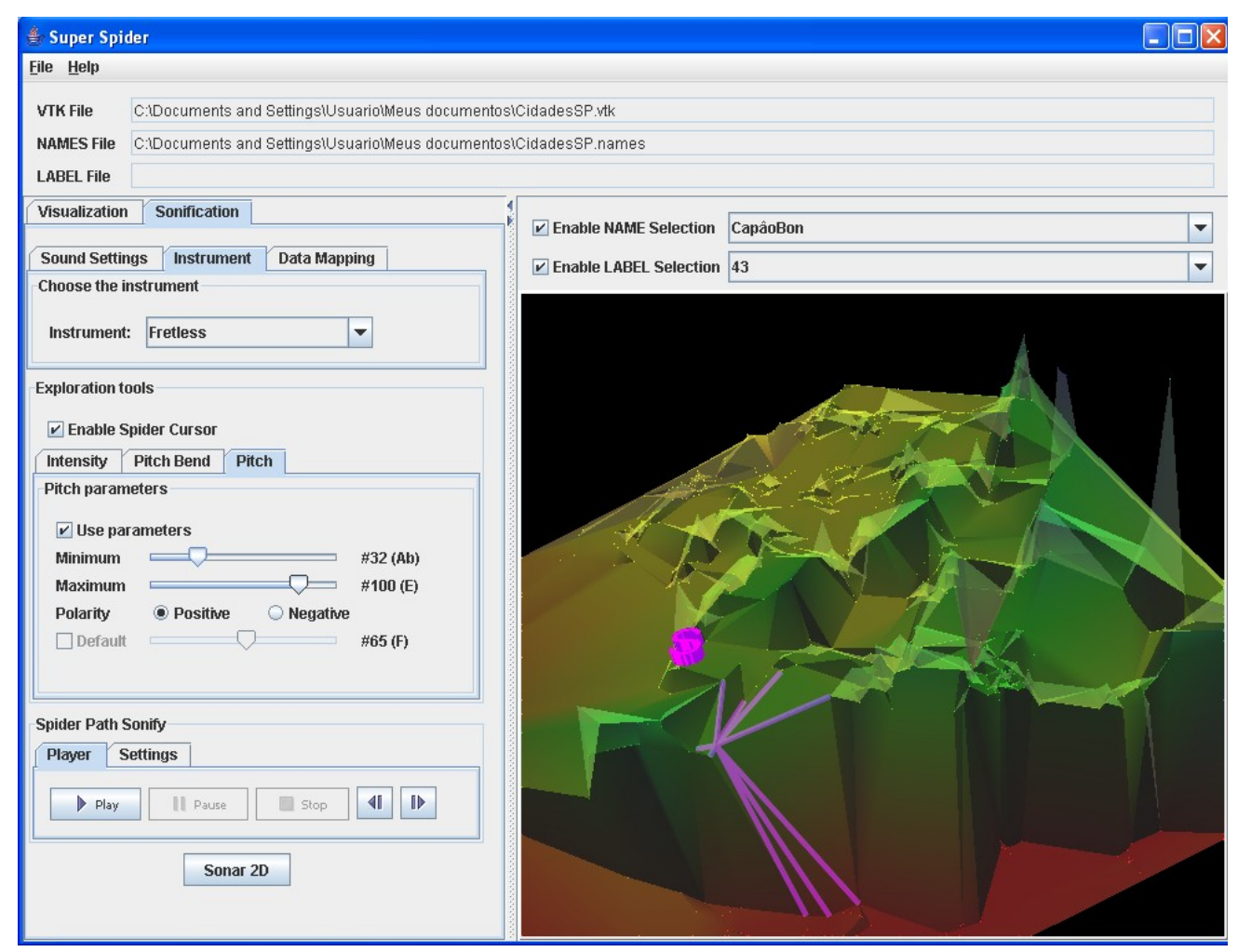

Figura 4.8: Definindo o ponto central do Sonar com o 2D Spider Cursor

"ID" - identificador do ponto; "Name" - nome do ponto que é informado pelo arquivo NAMES; "Value" - valor de seu escalar conforme o conjunto de escalares selecionado; "Dist" - distância do ponto ao centro do Sonar; "Sound Property" - a cor do fundo da célula e a descrição representa a cor e o nome do item sonoro, respectivamente (ver Figura 4.10). Um recurso de busca presente na própria interface facilita a localização de um ponto específico.

Nesta interface é possível também alterar o centro do Sonar. Ao selecionar um item na lista que não está sendo referenciado como o ponto central (representado atráves de uma esfera amarela no Sonar2D Display), uma nova esfera é apresentada no Sonar2D Display na cor laranja indicando a posição do ponto selecionado (ver Figura 4.11). Para alterar o centro, basta clicar em "Change Centre" após a seleção do novo centro.

\subsubsection{Configuração dos itens sonoros}

No sistema, um item sonoro é definido por um intervalo de valores escalares, um instrumento sonoro e uma cor que é usada na representação dos pontos no Sonar2D Display. Existem duas alternativas quanto à definição do instrumento: instrumentos sonoros (Piano, Órgão, Harpa, Violino, etc) com 128 opções ou instrumentos de percussão (Bumbo acústico, Maracas, Pandeiro, etc) com somente uma entoação (ver Figura 4.12). O slider de valores (Values) delimita os valores escalares mínimo e máximo presentes no conjunto de escalares selecionado. Cada item sonoro pode compreender um intervalo do slider, por exemplo, o som de piano pode ser usado para representar os 


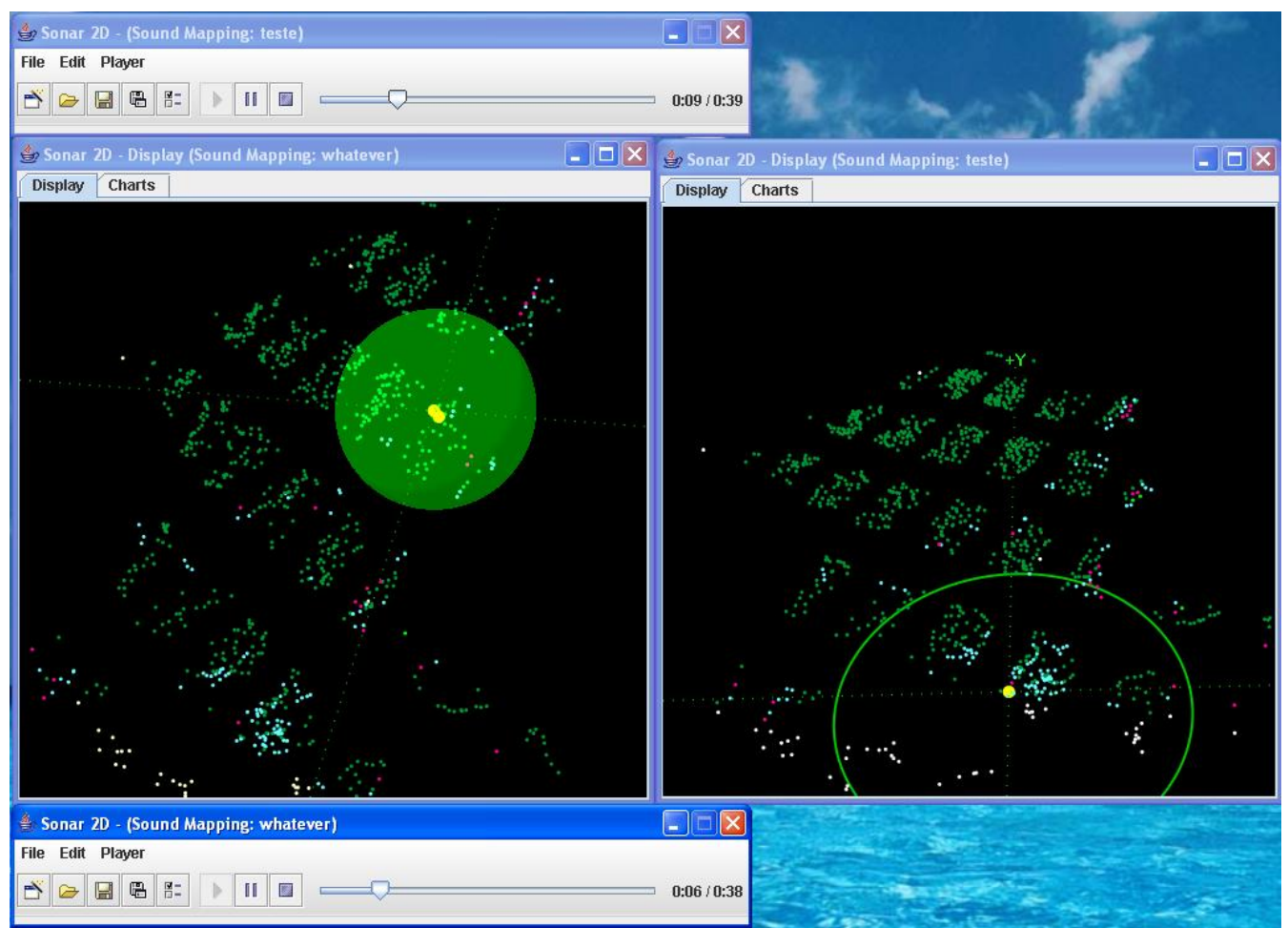

Figura 4.9: Execução de mais de uma janela do Sonar 2D para conjunto de escalares distintos.

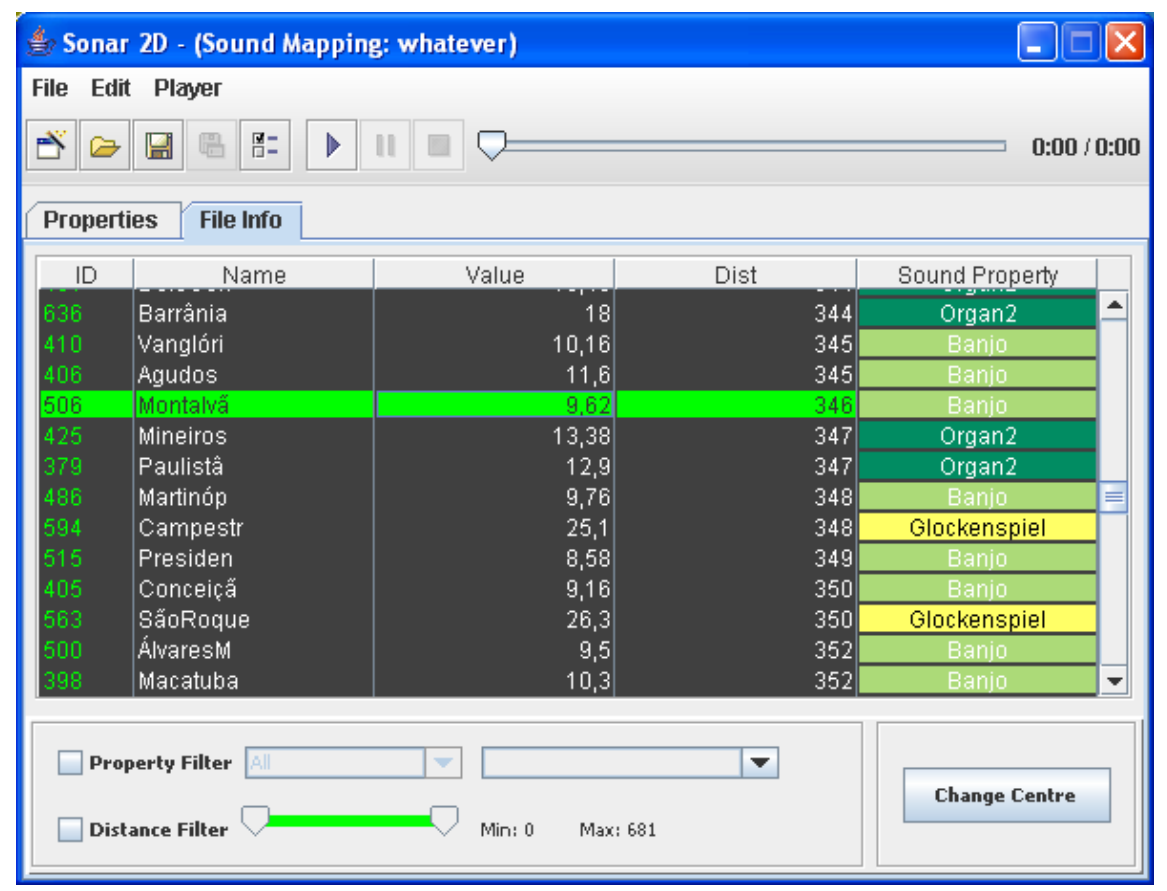

Figura 4.10: Tela principal com a opção File Info selecionada

pontos com valores escalares de 0 a 10 e o som de harpa para representar os pontos com valores de 15 a 20.

Para cada um dos itens sonoros, é possível configurar seus parâmetros de intensidade e entoação por meio de intervalo de valores mínimos e máximos (ver Figura 4.13). Há como definir 


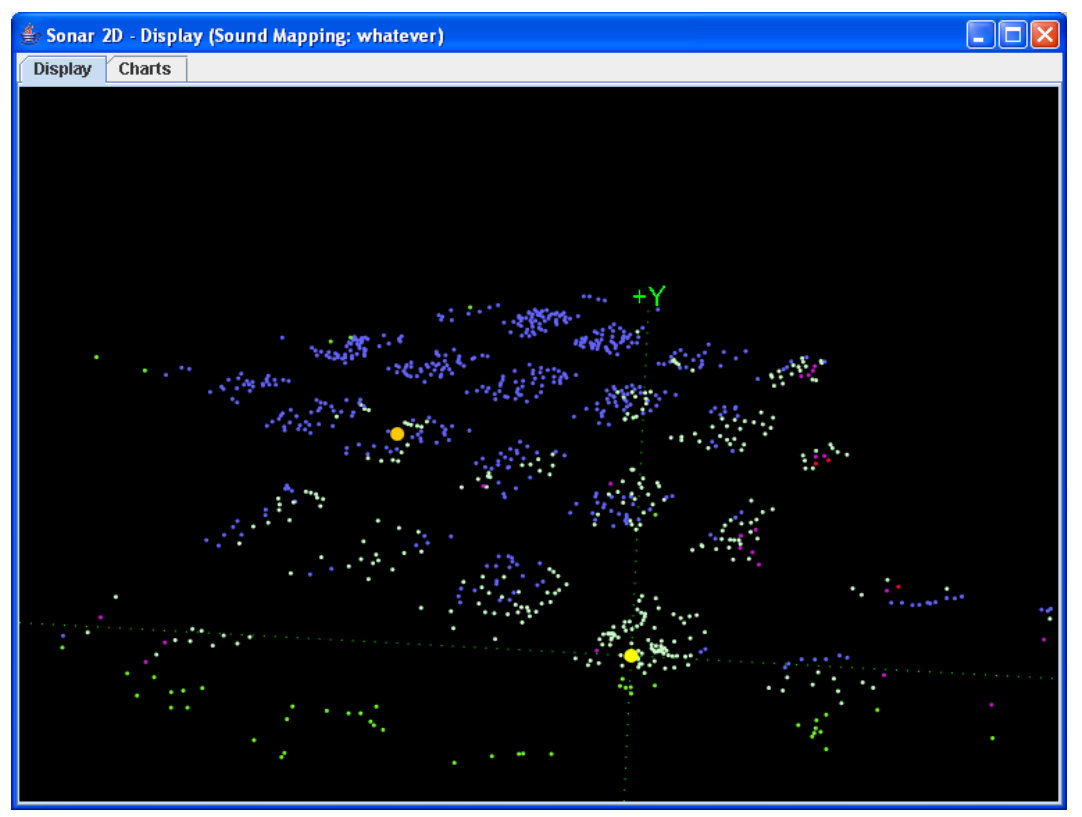

Figura 4.11: Sonar2D Display com a representação de novo ponto selecionado

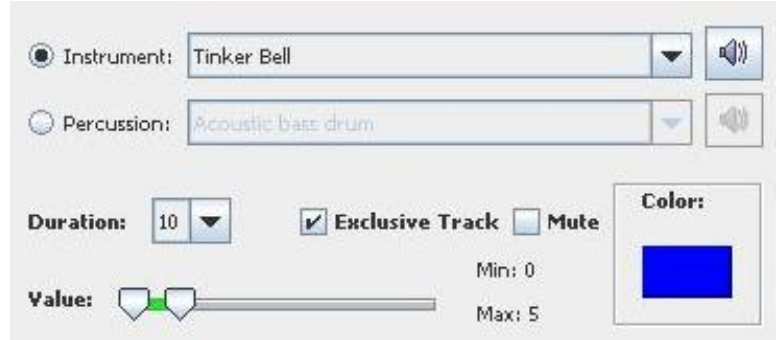

Figura 4.12: Parâmetros: instrumento, valores dos escalares e cor do item sonoro

parâmetros sonoros com um valor padrão (default), e se possuem mapeamento direto ou inverso (Inverse Mapping), isto é, se a propriedade varia direta ou inversamente proporcional ao valor.

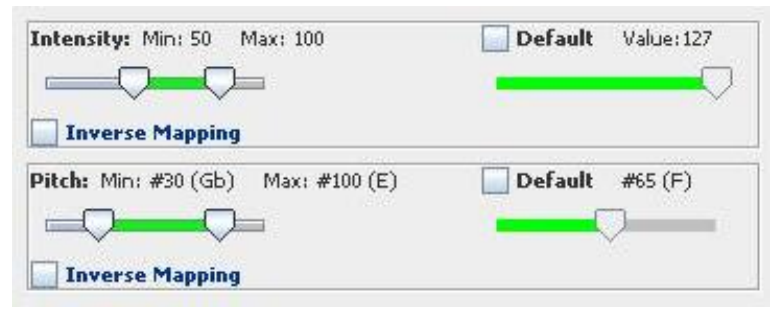

Figura 4.13: Parâmetros: intensidade, entoação e mapeamento inverso

Para o mapeamento direto de entoação e intensidade é utilizada a seguinte fórmula para cada ponto, onde $\operatorname{valor}_{(\text {prop })}$ é o valor da propriedade (entoação ou intensidade) atribuída ao ponto, $\operatorname{escalar}_{(\text {ponto) }}$ é o valor escalar de determinado ponto, escalar $_{(\text {minimo })}$ e escalar $_{(\text {maximo })}$ são os valores escalares mínimo e máximo que configuram o intervalo de valores do item sonoro, valor (propMin) $_{\text {(in }}$ e valor $_{(\text {propMax) }}$ são os valores mínimo e máximo definidos nos parâmetros intensidade e entoação do item sonoro: 


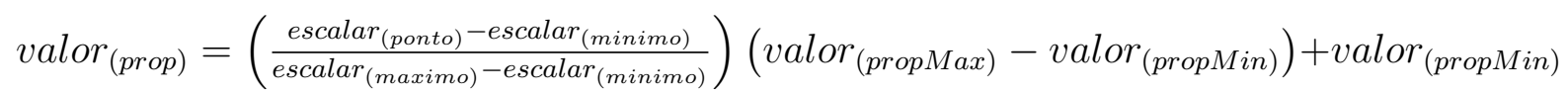

Para o mapeamento inverso a fórmula utilizada é:

$$
\operatorname{valor}_{(\text {prop })}=\left(\frac{\text { escalar }_{(\text {maximo })}-\text { escalar }_{(\text {ponto })}}{\text { escalar }_{(\text {maximo })}-\text { escalar }_{(\text {minimo })}}\right)\left(\operatorname{valor}_{(\text {propMax })}-\operatorname{valor}_{(\text {propMin }))}\right)+\operatorname{valor}_{(\text {propMin })}
$$

Por exemplo, para um dado item sonoro que representa valores escalares de 0 a 20 e está configurado com: intensidade mínima igual a 30 e máxima igual a 100, entoação mínima igual a 50 e máxima igual a 110; um ponto que tem valor escalar igual a 15 se for mapeado diretamente terá valores: 82.5 para intensidade e 95 para entoação. Os valores para o mapeamento inverso são: 47.5 para intensidade e 65 para entoação.

A adição e a remoção dos itens sonoros são feitas por meio dos botões "Add" e "Delete" que se encontram abaixo da tabela de listagem dos itens. Cada item sonoro é apresentado nesta tabela da seguinte forma: \# - ID do item; "Name": nome do item que também indica o nome do instrumento selecionado; "Property": a cor do fundo da linha representa a cor do item e os números separados com "/" apresentados na linha indicam os valores escalares mínimo e máximo definidos no item (ver Figura 4.14).

\begin{tabular}{|c|l|c|}
\hline$\#$ & \multicolumn{1}{|c|}{ Name } & Property \\
\hline 0 & Fret Noise & $0 / 6$ \\
\hline 1 & Contrabass & $6 / 12$ \\
\hline 2 & Voice & $12 / 18$ \\
\hline 3 & Clean Gtr & $18 / 24$ \\
\hline 4 & Brightness & $24 / 33$ \\
\hline & \\
\hline C A Add & 面 Delete \\
\hline
\end{tabular}

Figura 4.14: Tabela de itens sonoros e os botões para adicionar e remover itens.

\subsubsection{Mapeamento sonoro e execução}

O conjunto de itens sonoros, que o usuário deve informar no sistema (ver Seção 4.4.2), funciona como acervo de informações e parâmetros que auxilia o mapeamento sonoro na geração da sonificação que é iniciada a partir do ponto central do Sonar. A sonificação é realizada com o lançamento de um círculo (2D) ou uma esfera (3D), e à medida que o circulo ou a esfera vai se 
expandido e atinge outros pontos ao seu redor, sons que foram previamente mapeados são emitidos em tempo real para aqueles pontos que possuem algum item sonoro definido. A animação do processo pode ser acompanhada através do Sonar2D Display (ver Figura 4.15(a) e 4.15(b)).

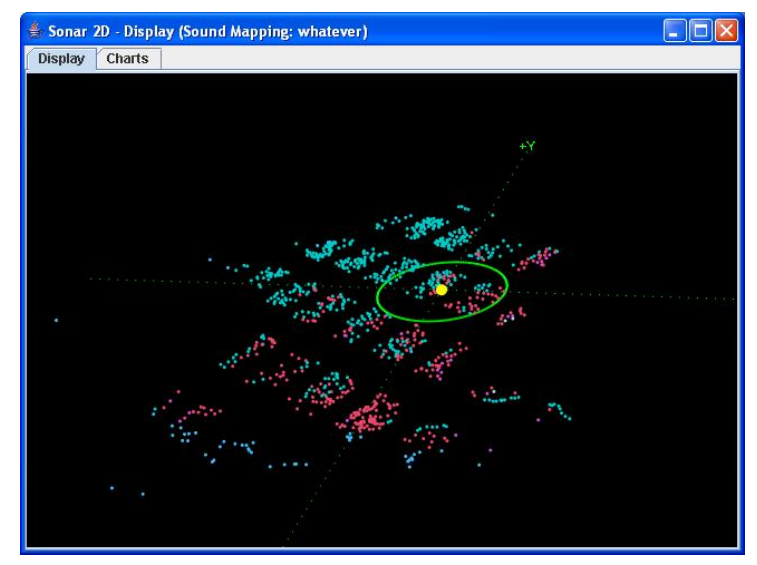

(a) Ambiente 2D

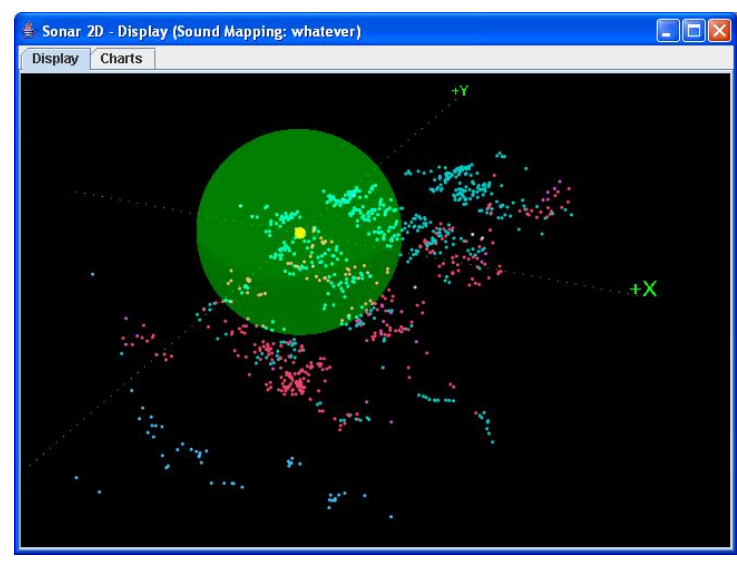

(b) Ambiente 3D

Figura 4.15: Execução do Sonar2D nos dois modos de execução.

Descrevendo o processo mais detalhadamente, ao pressionar o botão Play, o sistema calcula as distâncias do ponto central em relação aos outros pontos do conjunto de dados e, em seguida, cria uma lista de pontos ordenados em ordem crescente pelas distâncias obtidas. A criação do som é controlada por um contador que é iniciado com o valor 0 (zero), e vai sendo incrementado de 1. Se determinado ponto está na distância indicada pelo contador, então é feito o mapeamento sonoro (localização espacial, intensidade, entoação e timbre) do ponto de acordo com a configuração de seu item sonoro e seu valor escalar. No caso de um ponto não possuir um item sonoro especificado, o sistema de criação do som desconsidera o ponto e vai para o próximo. O contador é incrementado até atingir o ponto de maior distância em relação ao centro do Sonar. Após o término deste processo, já se tem um arquivo MIDI criado e ele é executado automaticamente pelo sistema utilizando um sequenciador (sequencer) MIDI, juntamente com a animação gráfica no Sonar $2 D$ Display.

Referindo-se ainda à execução do sonar, na tela de configurações do sistema "Settings", além de definir se a sonificação será realizada em ambiente 2D ou 3D, pode-se também: definir a cor do fundo da tela do Sonar2D Display; ativar ou não a configuração sonora referente à diminuição da intensidade do som à medida que a "onda" do sonar se afasta do centro; e a utilização ou não de panning (mapeamento de intensidade sonora nos dispositivos acústicos esquerdo e direito dependendo da posição do ponto) no eixo de coordenadas X (ver Figura 4.16).

Na janela principal do Sonar 2D existem três botões: "Play", "Pause" e "Stop" que são os responsáveis por iniciar, pausar e parar a execução do som, respectivamente. Um slider e um indicador de tempo apresentam progressão da execução do som (ver Figura 4.7). Para aumentar ou diminuir a velocidade de execução existe um slider com o indicador "Sequence" que configura a tempo de execução. 


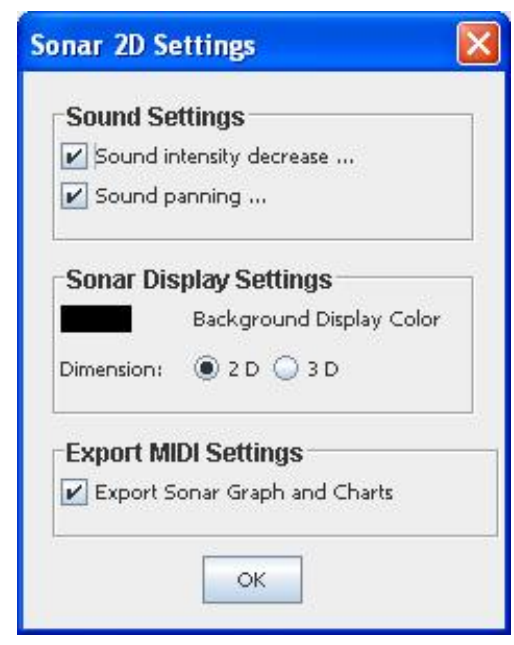

Figura 4.16: Tela de configurações do sistema.

Durante o mapeamento sonoro, algumas dados são coletados com o intuito de apresentar novos meios de analisar a sonificação criada com o uso de gráficos estatísticos. Os dados são transferidos para uma série de quatro gráficos que podem ser acessados na opção Charts do Sonar2D Display. Dois deles, o gráfico de itens (que representa a distribuição dos números de pontos por itens sonoros) e o gráficos de entoação/tempo (número da nota tocada em relação ao tempo de execução) podem ser vistos nas Figuras 4.17(a) e 4.17(b), respectivamente.

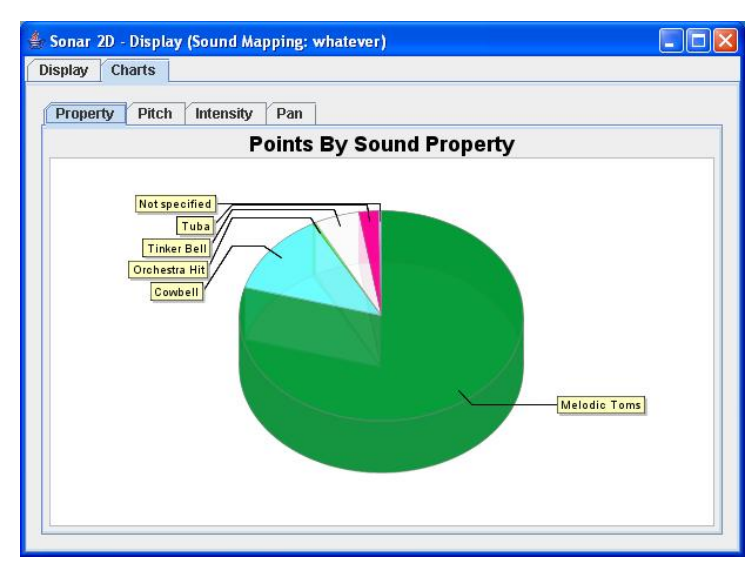

(a) Pie Chart - número de pontos por item sonoro.

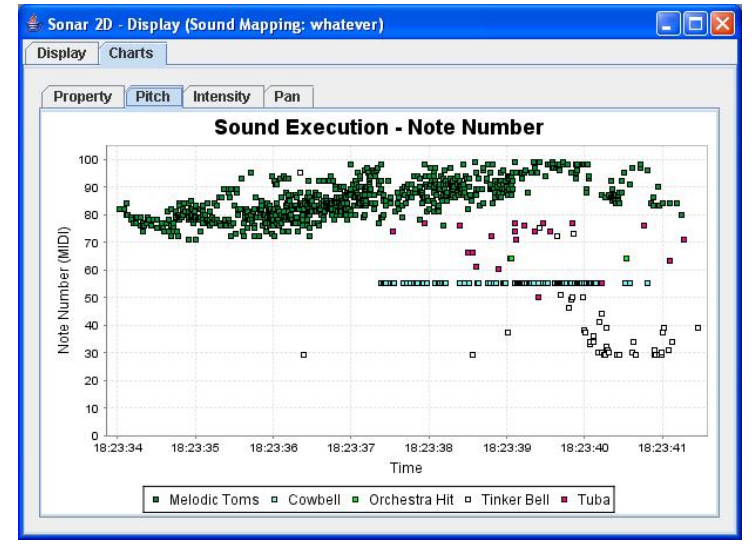

(b) Scatter Plot - Entoação (Notas MIDI) por Tempo de execução.

Figura 4.17: Gráficos gerados durante o mapeamento sonoro.

\subsubsection{Analisando o conjunto de dados sonificado}

Diversas características do conjunto de dados e informações dos registros que o compõe podem ser conhecidos ouvindo a sonificação criada pelo sistema:

- visão geral de dados: se os itens sonoros estiverem devidamente configuradas para representar os diferentes valores escalares dos dados, é possível ter uma idéia de como os registros 
estão distribuídos em relação ao centro do Sonar, a quantidade aproximada de elementos e os valores predominantes;

- existência de pontos específicos: é possível identificar a presença de pontos com um determinado valor escalar (ou uma variação de valores) configurando itens sonoros individualizados para esses pontos. Isto pode ser feito utilizando timbres de mais fácil percepção ou até mesmo mapeando estes pontos para sons agudos e com alta intensidade, funcionando como um sinal de aviso;

- relação dos pontos com o ponto central: dependendo do conjunto de dados, a sonificação gerada permite analisar os pontos que apresentam maior relação com o ponto central, isto por apresentarem menor distância em relação a este (os pontos mais distantes apresentam menor relação). Dessa forma, a sequiência cronológica da exibição dos sons dos pontos pode identificar esta propriedade.

- percepção da presença de clusters: o agrupamento de pontos que apresentam as mesmas características (cluster) pode ser identificado quando em um curto intervalo de tempo, sons com mesmos itens sonoros são executados em maior número.

Com o objetivo de coletar dados sobre a eficácia dos recursos desenvolvidos, testes com usuários foram realizados para algumas funcionalidades visuais e sonoras do Super Spider e Sonar 2D. Esses testes são descritos no próximo capítulo.

\subsection{Considerações Finais}

Este capítulo apresentou três sistemas que fazem uso integrado de sonificação e visualização, todos desenvolvidos pelo grupo de Visualização do SCC-ICMC-USP: o Spider Cursor, o Super Spider e o Sonar 2D. O Spider Cursor é o sistema inicial, onde conceitos como interação pontual com o ponteiro do mouse, representações gráficas de duas e três dimensões e mapeamento sonoro para freqüência foram inicialmente implementados. O Super Spider é considerado uma evolução do Spider Cursor por ter grande parte de suas funcionalidades reprogramadas utilizando uma tecnologia de programação mais atual (Java e Java3D), além de apresentar novos recursos de interação e exploração visual por meio de super-quádricas. Neste sistema, o módulo de sonificação foi desenvolvido neste trabalho (utilizando a API Java Sound) e conta com três de propriedades do som para mapeamento de dados: intensidade, entoação e inflexão da entoação. O Sonar 2D é um sistema de sonificação que foi implementado de forma integrada ao Super Spider. O sistema apresenta uma nova abordagem de sonificação de pontos de um conjunto de dados, o que permite ouvi-los sem que seja necessário interagir com a representação gráfica criada. O usuário somente define os itens sonoros para cada intervalo de valores escalares dos pontos e o ponto central do Sonar. A sonificação é manipulada através de controladores de um reprodutor musical comum. 
Os sistemas funcionam como applets na Web e podem ser acessados através do endereço eletrônico: http: // infoserver. lcad.icmc.usp.br/infovis2. O site também disponibiliza mais informações sobre o projeto, bem como conjunto de dados de exemplicação e documentações dos sistemas (manuais de instrução, vídeos demonstrativos, etc).

O próximo capítulo apresenta um estudo com usuários realizado para testar os componentes visuais e sonoros implementados nos sistemas Super Spider e Sonar 2D. 



\section{Experimento com usuários}

\subsection{Considerações Iniciais}

A avaliação e validação de estímulos auditivos em uma aplicação são componentes importantes para a complementação de um projeto de sonificação, já que os efeitos positivos ou negativos do som sobre os usuários são desconhecidos a princípio (Bonebright et al., 1998). Após estudos, discussões e testes pilotos com colegas do departamento, um conjunto de quatro testes foi realizado. Uma aplicação simples foi desenvolvida utilizando as mesmas API's Java e técnicas de desenvolvimento implementadas no sistema Super Spider.

Para melhor entender todas as etapas envolvidas na avaliação com usuários, este capítulo foi dividido da seguinte forma: a Seção 5.2 apresenta informações sobre a estruturação do experimento (conjunto de dados, mapeamento sonoro e visual, participantes envolvidos e tarefas); a Seção 5.3 apresenta a análise dos resultados obtidos nos testes; a Seção 5.4 apresenta as considerações finais do capítulo.

\subsection{Definição e aplicação dos testes}

Os testes realizados tiveram o objetivo de estudar o impacto do uso de estímulos sonoros e visuais, gerados pelos sistemas Super Spider e seu módulo Sonar 2D, na representação de informações. Foi utilizada entoação como propriedade sonora para os testes com o Super Spider e timbre para os testes com o Sonar 2D. Nas apresentações visuais foram utilizadas representações gráficas de duas dimensões com mapeamento de atributo para cor. 
A aplicação dos testes teve como propósitos: 1) validar a utilização de som como instrumento para ordenação de diferentes regiões de uma representação gráfica; 2) avaliar a utilidade de som para apoiar a identificação de dependência (alta ou baixa) de dois atributos de dados apresentados; 3) avaliar a utilidade de som para analisar a densidade de pontos em um conjunto de dados com o auxílio da sonificação criada pelo Sonar 2D.

\subsubsection{Definição dos conjuntos de dados e mapeamento visual e so- noro}

Para a implementação dos testes foram utilizados dois conjuntos de $\operatorname{dados}^{1}$ que informam os índices de qualidade de vida em cidades do estado de São Paulo e do Rio de Janeiro (HDI - Human Development Index).

Estes conjuntos de dados fornecem mais especificamente os Indicadores de Desenvolvimento Humano (IDH) de 645 cidades do estado de São Paulo e de 91 cidades do estado do Rio de Janeiro, registrados no ano de 2000 e divulgados pelo programa das Nações Unidas para o Desenvolvimento (United Nations Development Program - UNDP). O IDH tenta quantificar o grau de bem-estar social da população de um país, estado, município ou cidade através de três parâmetros: renda, longevidade e educação. A renda de uma cidade significa o rendimento per capita da sua população. A longevidade é a expectativa de vida da população. A educação é calculada em função da taxa de alfabetização dos adultos e da frequiência escolar (PNUD, 2007).

As visualizações desses conjuntos de dados foram definidas partindo dos valores quantitativos representando educação, renda e longevidade, da tabela de cidades de cada estado separadamente. As cidades foram projetadas em pontos no plano utilizando a técnica de projeção IDMAP (Interactive Document Map) (Minghim et al., 2006) usando a métrica euclidiana. Em seguida, os pontos foram conectados formando uma malha utilizando triangulação de Delaunay. Este processo foi feito utilizando o sistema Projection Explorer (PEx) (Paulovich et al., 2007).

As visualizações permitem identificar as cidades e descrever as características do seu IDH. A vizinhança dos pontos não indica proximidade geográfica, mas provável proximidade relativa entre cidades que possuam semelhanças nos parâmetros do IDH. Em algumas visualizações utilizadas no experimento, os mapeamentos para cor e som foram feitos utilizando somente um atributo que compõem o cálculo do IDH, por exemplo, a renda per capita.

\subsubsection{Definição dos participantes}

O experimento foi realizado em duas etapas. Participaram da primeira etapa 32 pessoas, todos estudantes do Instituto de Computação e Matemática Computacional (ICMC) da Universidade de São Paulo, sendo que 28 eram alunos de graduação e 4 alunos de pós-graduação (mestrado e

\footnotetext{
${ }^{1}$ Os dados foram obtidos em: www. frigoletto.com.br
} 
doutorado) em computação. Esta etapa foi aplicada em Maio de 2007 e os participantes realizaram todas as quatro tarefas propostas no experimento.

A segunda etapa foi realizada no mês de Junho de 2007 e teve a participação de 35 pessoas, sendo que 7 eram alunos de graduação e 28 alunos de pós-graduação em computação do ICMCUSP. Na segunda etapa, os participantes realizaram duas tarefas, ambas referentes à analise de dependência de dois atributos em representações visuais e em combinação com representação sonora (ver Tabela 5.1).

Tabela 5.1: Informações sobre as duas etapas do experimento

\begin{tabular}{|l|c|c|}
\hline Informação & Etapa 1 & Etapa 2 \\
\hline \hline Tarefa de ordenação & $\sqrt{ }$ & $\emptyset$ \\
\hline Tarefa de dependência (Som + Cor) & $\sqrt{ }$ & $\sqrt{ }$ \\
\hline Tarefa de dependência (Cor + Cor) & $\sqrt{ }$ & $\sqrt{ }$ \\
\hline Tarefa de análise de densidades & $\sqrt{ }$ & $\emptyset$ \\
\hline Estudantes de graduação & 28 & 7 \\
\hline Estudantes de pós-graduação & 4 & 28 \\
\hline
\end{tabular}

Os distintos números de participantes que cursam graduação e pós-graduação em ambas as etapas do experimento (quase o inverso da primeira etapa para a segunda) não foi proposital, ou seja, o experimento foi realizado com alunos de computação que estavam dispostos e diponíveis a participar dos testes nos períodos de Maio e Junho de forma voluntária. É importante ressaltar que os participantes da primeira etapa não participaram da segunda etapa.

\subsubsection{Aplicação dos testes}

As duas etapas do experimento foram realizadas em laboratórios do ICMC-USP e supervisionadas pelo autor desta dissertação. Instruções de conduta durante o experimento e os requisitos necessários para a realização das tarefas foram informados por meio de um documento impresso que todos leram e assinaram. Instruções necessárias para a realização das tarefas foram apresentadas nas telas do sistema desenvolvido para o experimento de forma clara e direta, sendo que não foi necessária nenhuma explicação oral antes do início dos testes. Isto só foi preciso em casos isolados quando o participante tinha alguma dúvida. Não foi permitida a comunicação entre os participantes e durante todo o experimento os participantes usaram fones de ouvido já que a maioria das tarefas utilizava estímulos sonoros.

Na primeira tela do sistema do experimento, os participantes tiveram um período de adaptação aos intervalos de entoações sonoras utilizando um piano virtual (ver Figura 5.1). Os participantes tiveram a possibilidade de escolher diferentes instrumentos sonoros dispostos em uma tabela e testar distintos timbres. A instrução descrita na tela inicial enfatizou a necessidade de diferenciação entre entoações sonoras (som graves e agudos) já que é esta a propriedade sonora utilizada nas tarefas. Após terminada esta fase, as tarefas foram executadas. 


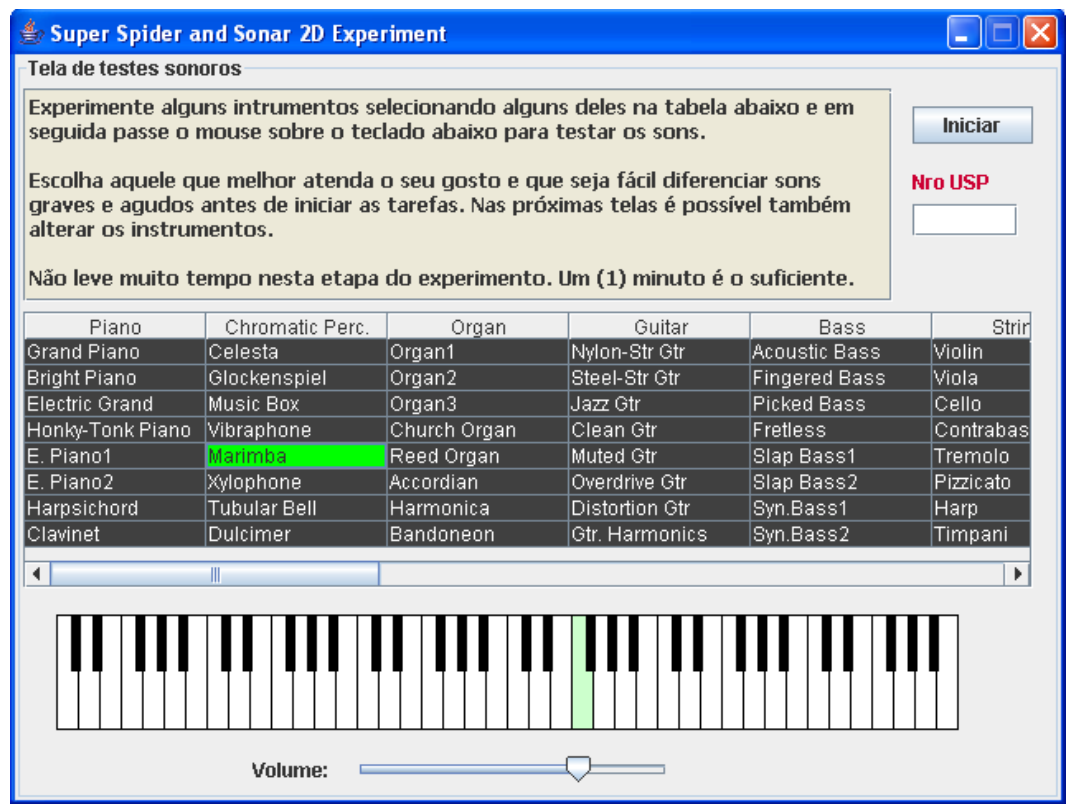

Figura 5.1: Tela inicial do experimento.

\subsubsection{Definição das tarefas}

\section{Tarefa de ordenação sonora por regiões}

Nesta tarefa os participantes tinham que analisar, com o auxílio da ferramenta de interação visual 2D Spider Cursor, as quatro diferentes regiões do mapa, identificadas por quatro cores e entoações sonoras diferentes e, em seguida, ordenar em ordem crescente estas regiões em função da entoação do som executado em cada uma. Como descrito nas instruções apresentadas na tela desta tarefa, a ordenação deveria começar pela região que apresentava o som mais grave e terminar com a região que apresentava o som mais agudo. O participante informava a ordenação em quatro combos (numerados de 1 a 4) identificados pela coloração da região e dispostos no canto direito da interface (ver Figura 5.2). Na mesma tela o participante poderia também escolher diferentes instrumentos sonoros e a intensidade do som para realizar a tarefa. Como foi descrito na Seção 5.2.2, esta tarefa só foi aplicada na primeira etapa do experimento.

O conjunto de dados utilizado nesta visualização foi o índice de qualidade de vida das 645 cidades do estado de São Paulo. A separação de quatro regiões distintas foi feita através da criação de quatro grupo de cidades, cada um composto de aproximadamente 160 cidades. Nesta divisão foi levado em consideração a ordem de classificação de cada cidade na tabela de IDH do estado, ou seja, o primeiro grupo continha as 160 cidades mais bem classificadas e assim por diante.

\section{Tarefa de análise de dependência (Som + Cor)}

Nesta tarefa os participantes tinham que analisar o grau de dependência (correlação) de dois atributos de dados diferentes mapeados para cor e entoação sonora em uma mesma visualização. 


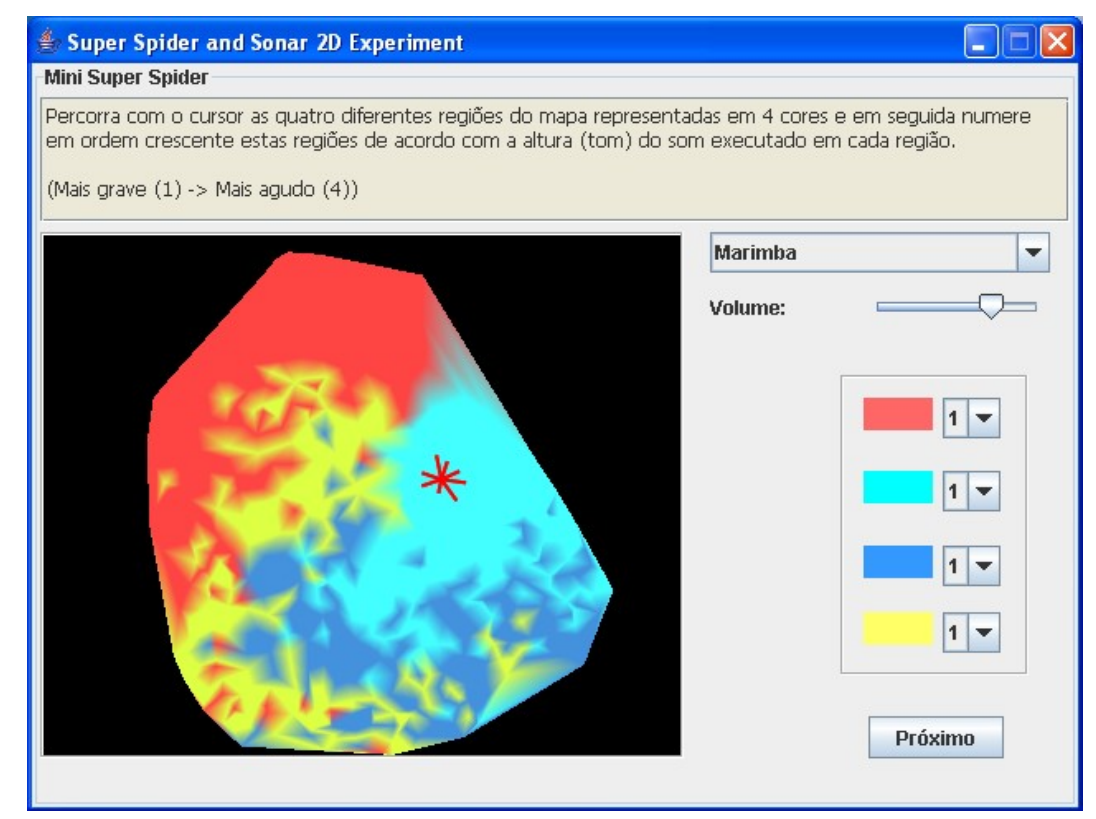

Figura 5.2: Tela do teste de ordenação por regiões utilizando som.

Para realizar a tarefa os participantes deveriam interagir com a representação utilizando o $2 D$ Spider Cursor e analisar se os atributos mapeados para aspectos sensorias distintos (visão e audição) possuíam "Alta dependência" ou "Baixa dependência". As duas opções de resposta foram apresentadas na tela da tarefa e cada participante deveria selecionar uma delas (ver Figura 5.3). Nesta tela os participantes tiveram a opção de escolher diferentes instrumentos sonoros e a intensidade do som para realizar a tarefa.

O conjunto de dados utilizado nesta tarefa foi o índice de qualidade de vida nas 91 cidades do estado do Rio de Janeiro. O mapeamento visual para cor na visualização foi feito utilizando o atributo "Renda per capita". No mapeamento sonoro foi utilizado o atributo "IDH" das cidades. Esta tarefa esteve presente nas duas etapas do experimento e a única diferença foi que na segunda etapa, a visualização apresentou maior contraste de cores no espectro de coloração de amarelo para marrom (ver Figura 5.4).

\section{Tarefa de análise de dependência (Cor + Cor)}

Nesta tarefa os participantes tinham que analisar o grau de dependência (correlação) de dois atributos de dados diferentes mapeados para cor em duas visualizações de um mesmo conjunto de dados. Elas foram dispostas lado-a-lado e os participantes deveriam analisar se os atributos mapeados para cor, nas distintas imagens, possuíam "Alta dependência" ou "Baixa dependência". As duas opções de resposta foram apresentadas na tela do teste e cada participante tinha que selecionar uma delas.

O conjunto de dados utilizado nas visualizações foi o índice de qualidade de vida das cidades do estado de São Paulo. Na primeira etapa do experimento, as visualizações da esquerda e 


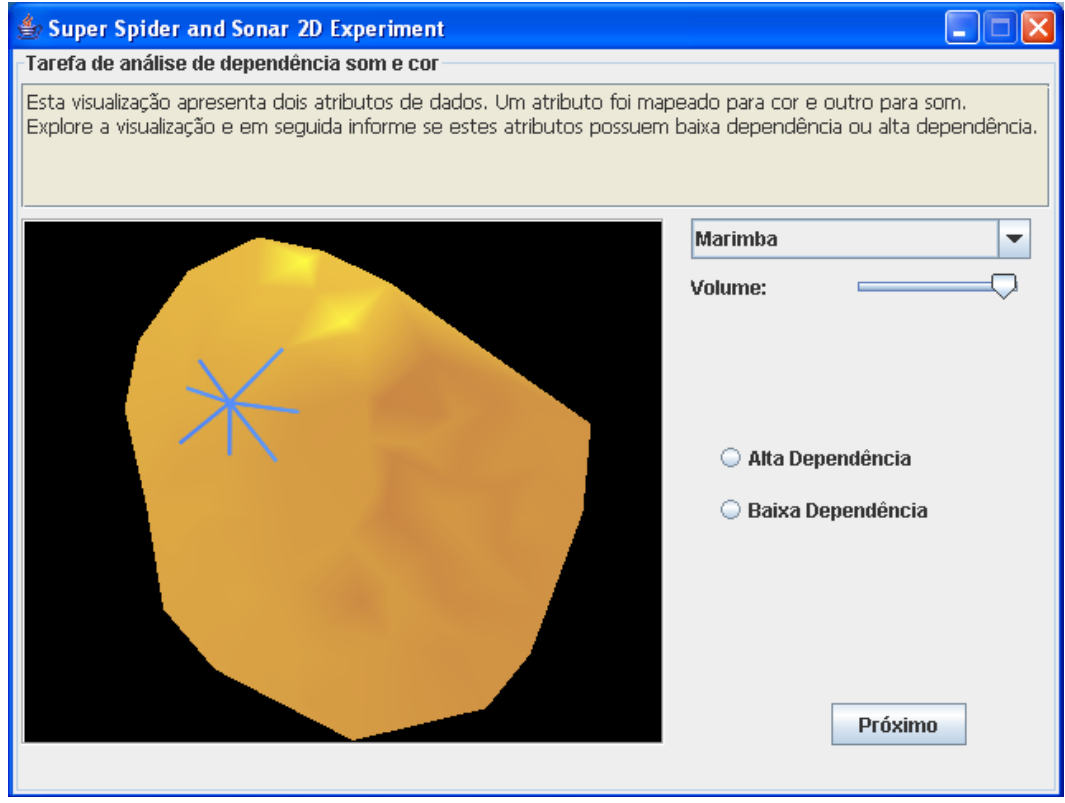

Figura 5.3: Tela da tarefa de análise de dependência (Som + Cor) na etapa 1 .

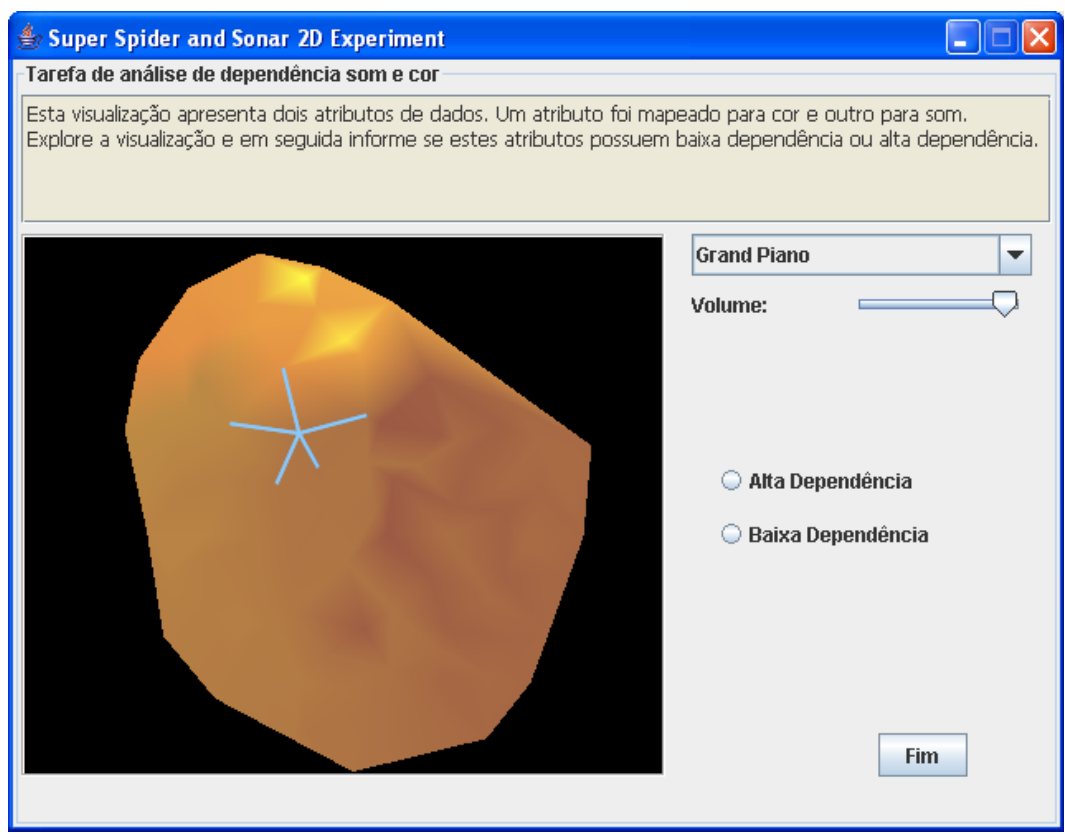

Figura 5.4: Tela da tarefa de análise de dependência (Som + Cor) na etapa 2.

da direita foram mapeadas utilizando os atributos "Renda per capita" e o "IDH" das cidades (respectivamente) no mapeamento visual para cor. Nesta etapa, o espectro de cores utilizado foi o arco-íris (ver Figura 5.5). Na segunda etapa do experimento, as visualizações da esquerda e da direita foram mapeadas utilizando os atributos "Renda per capita" e o "IDH-Renda" (IDH calculado somente com relação à Renda per capita), respectivamente. A espectro de cores utilizado nesta etapa foi uma variação de cores entre o amarelo e o marrom (ver Figura 5.6). A utilização 
de diferentes escalas de cores foi feita nesta tarefa com o propósito de avaliar se diferentes escalas produzem diferentes resultados de análise das visualizações.

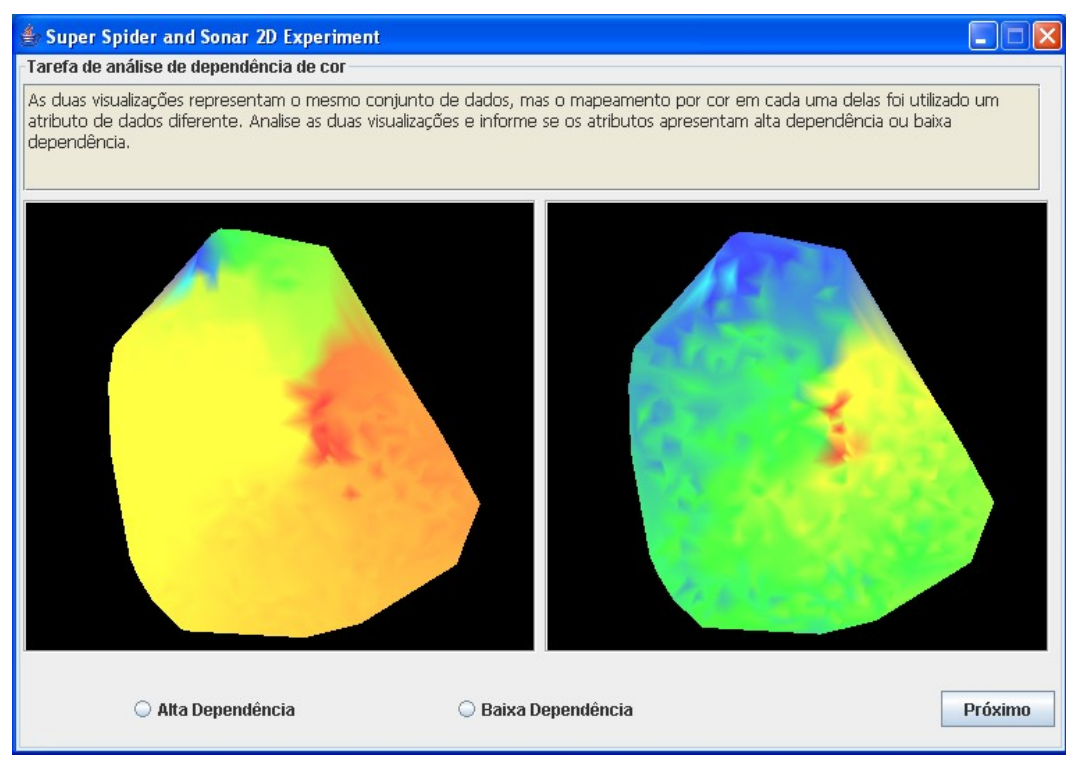

Figura 5.5: Tela da tarefa de análise de dependência (Cor + Cor) na etapa 1 .

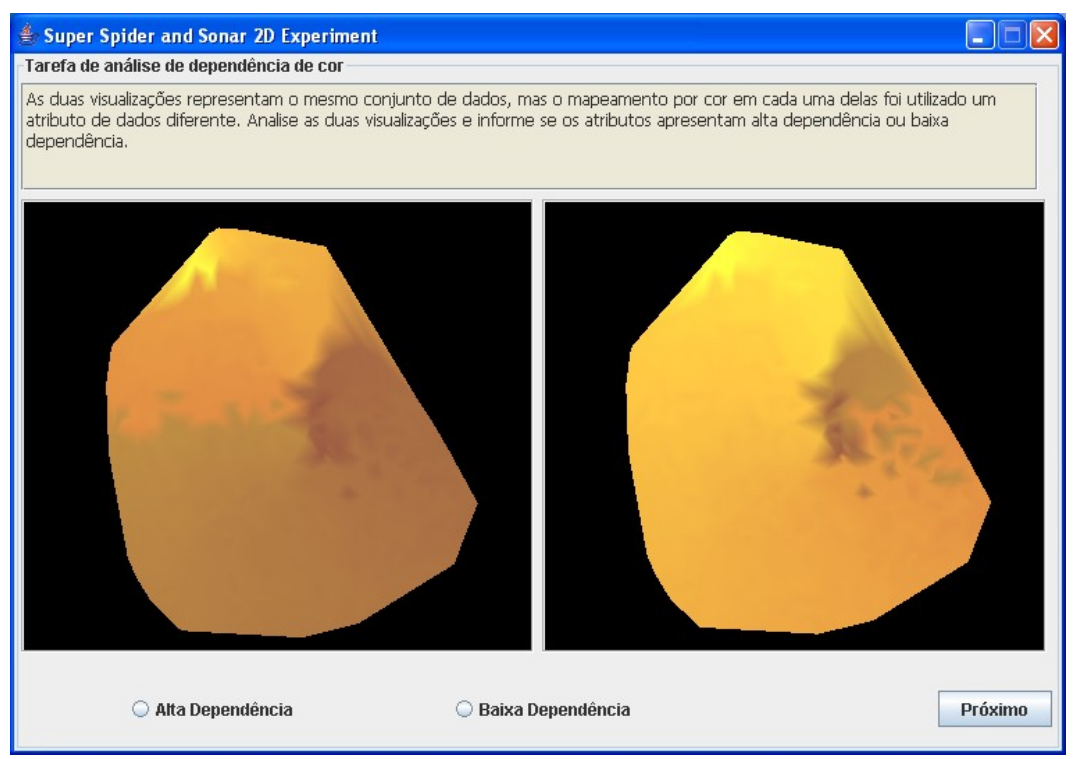

Figura 5.6: Tela da tarefa de análise de dependência (Cor + Cor) na etapa 2.

\section{Tarefa de análise de densidades}

$\mathrm{Na}$ tarefa de análise de densidades de pontos de um conjunto de dados, o participante tinha que primeiramente ler e ouvir as legendas com as informações de mapeamento dos pontos para timbre e posteriormente ouvir a sonificação criada pelo sistema Sonar 2D (a quantidade de vezes que fosse necessária). Para finalizar a tarefa, o participante deveria responder duas perguntas que 
questionavam quais eram os conjuntos de pontos que possuíam a maior e a menor densidade, ou seja, maior e menor quantidade de pontos (ver Figura 5.7). Como foi descrito na Seção 5.2.2, esta tarefa só foi aplicada na primeira etapa do experimento.

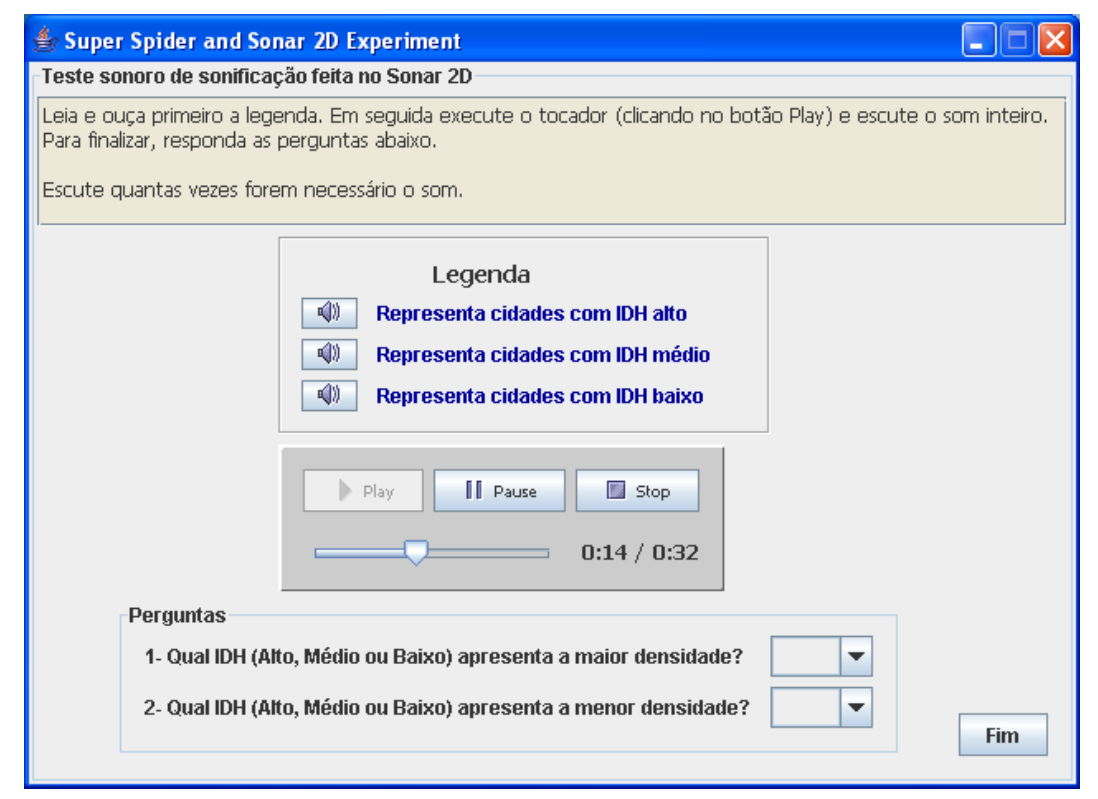

Figura 5.7: Tela do teste de análise de densidades de pontos.

O conjunto de dados utilizado nesta tarefa foi o índice de qualidade de vida nas cidades do estado de São Paulo. O número de cidades do conjunto de dados foi reduzido para que a sonificação não se estendesse por mais de 35 segundos. Cada cidade foi mapeada para um timbre diferente de acordo com a classificação do IDH que foi separado em baixo, médio e alto.

\subsection{Análise dos resultados}

Os arquivos com as informações dos resultados de cada participante foram agrupados e analisados em um sistema desenvolvido com o objetivo de conferir as respostas e informar, por meio de gráficos, o desempenho dos usuários nas tarefas propostas em ambas as etapas e o tempo de execução de cada participante por tarefa. Os resultados crus dos testes se encontram no Apêndice A desta dissertação. As próximas subseções apresentam as conclusões preliminares sobre os resultados obtidos em cada tarefa realizada. Uma análise de significância estatística dos resultados é apresentada utilizando intervalo de confiança, que fornecem intervalos de valores plausíveis para os resultados obtidos nos testes baseados nos dados amostrais, ou seja, se os testes forem repetidos, os resultados dos próximos testes estarão entre os limites inferior e superior dos intervalos de confiança em $95 \%$ dos casos (supondo nível de confiança de 95\%).

Os cálculos dos intervalos de confiança são feitos com a aproximação normal dada por: 


$$
I C_{y}=p \pm z_{y} \sqrt{p(1-p) / n}
$$

onde $p$ representa a proporção estimada, $n$ é o tamanho da amostra e $z_{y}=1.96$ é o percentil $(1-\alpha / 2)$ da distribuição normal padrão $N(0,1)$ correspondente ao nível de significância $\gamma=$ $1-\alpha=95 \%$. Para interpretar este intervalo de confiança, basta observar que a inclusão do zero no intervalo torna a proporção estimada não significativa estatísticamente para o nível de $95 \%$ de confiança. Nos demais resultados que não incluem o zero, a proporção verdadeira (porém desconhecida) pode assumir qualquer valor dentro deste intervalo. A margem de erro para esta suposição é de 5\% (Walpole et al., 2002).

Para comparar as proporções de duas etapas de uma mesma tarefa, o intervalo de confiança da diferença entre as proporções é dado por:

$$
I C_{y}=p_{1}-p_{2} \pm z_{y} \sqrt{\left(p_{1}\left(1-p_{1}\right)+p_{2}\left(1-p_{2}\right)\right) / n}
$$

\subsubsection{Tarefa de ordenação sonora por regiões}

A porcentagem de acertos, os intervalos de confiança (I.C) e o tempo médio para realização dessa tarefa são apresentados na Tabela 5.2.

Tabela 5.2: Tarefa de ordenação sonora por regiões.

\begin{tabular}{|l|c|c|c|}
\hline Classificação & Nro. de pessoas & Porcentagem & I.C \\
\hline \hline Acertou todos os itens da ordenação & 26 & $81,25 \%$ & $67.73-94.77 \%$ \\
\hline Acertou 2 itens da ordenação & 3 & $9,37 \%$ & $0.0-19.47 \%$ \\
\hline Acertou 1 item da ordenação & 1 & $3,12 \%$ & $0.0-9.14 \%$ \\
\hline Não acertou nada & 2 & $6,25 \%$ & $0.0-14.64 \%$ \\
\hline Tempo médio & 51 segundos &
\end{tabular}

A grande porcentagem de acerto nesta tarefa valida a utilização de entoações sonoras em tarefas de ordenação de regiões em visualizações. A maioria dos participantes conseguiu ordenar as regiões utilizando somente as variações das entoações apresentadas em cada região do mapa. A Figura 5.8 apresenta o gráfico dos resultados obtidos para a tarefa de ordenação.

\subsubsection{Tarefa de análise de dependência (Som + Cor)}

As porcentagens de acertos e os tempos médios para realização dessa tarefa em ambas as etapas são apresentados na Tabela 5.3. Os atributos utilizados nesta tarefa apresentavam alta correlação, portanto a resposta correta é "Alta dependência".

A maioria dos participantes acertou a dependência entre os dois atributos (mapeados para cor e entoação sonora) em ambas as etapas. Os resultados obtidos confirmam a utilização de sonificação 


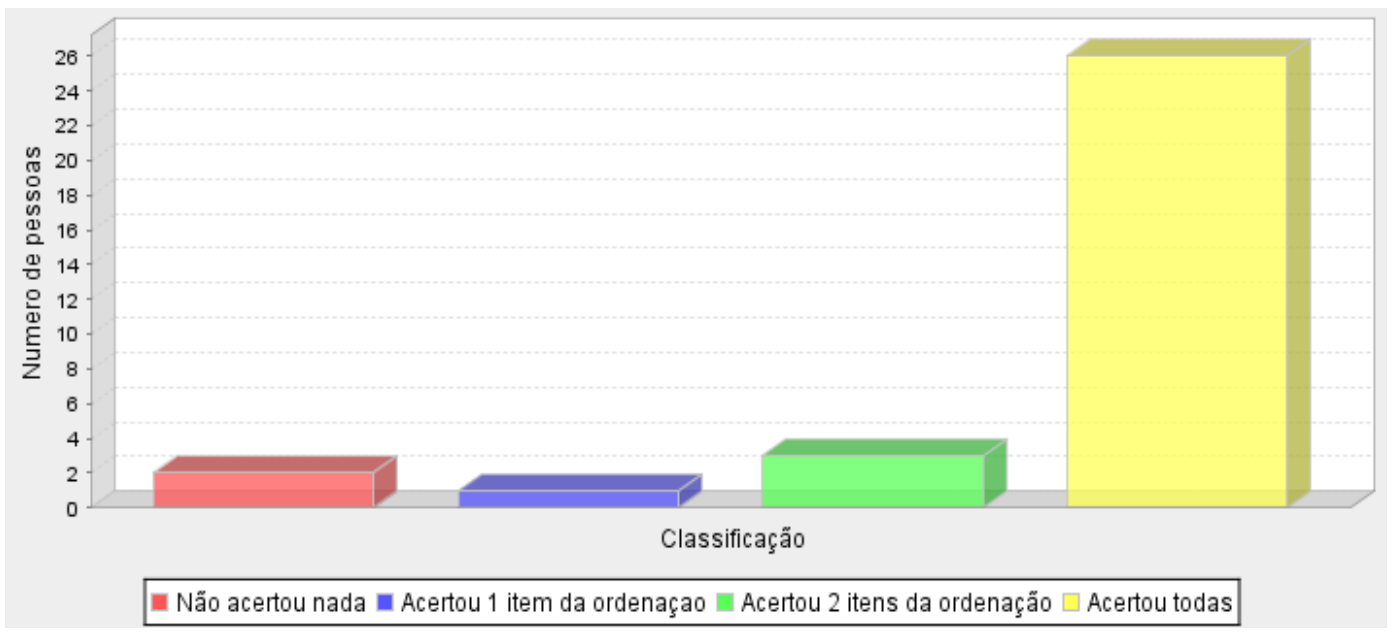

Figura 5.8: Resultados obtidos na tarefa de ordenação (Bar Chart).

Tabela 5.3: Tarefa de análise de dependência som e cor (Etapa 1 e Etapa 2).

\begin{tabular}{|l|c|c|}
\hline Classificação & Etapa 1 & Etapa 2 \\
\hline \hline Acertou a dependência & $23(72 \%)$ & $31(89 \%)$ \\
\hline Errou a dependência & $9(28 \%)$ & $4(11 \%)$ \\
\hline Tempo médio & 46 segundos & 55 segundos \\
\hline
\end{tabular}

como alternativa para auxiliar a representação e a exploração de dados em visualização, principalmente em tarefas de análise de correlação entre atributos de dados. A variação de contraste da coloração da visualização (segunda etapa) facilitou o trabalho de análise dos pontos e, conseqüentemente, aumentou a taxa de acerto na tarefa. A Figura 5.9 apresenta os gráficos dos resultados obtidos para a tarefa de análise de dependência (Som + Cor).

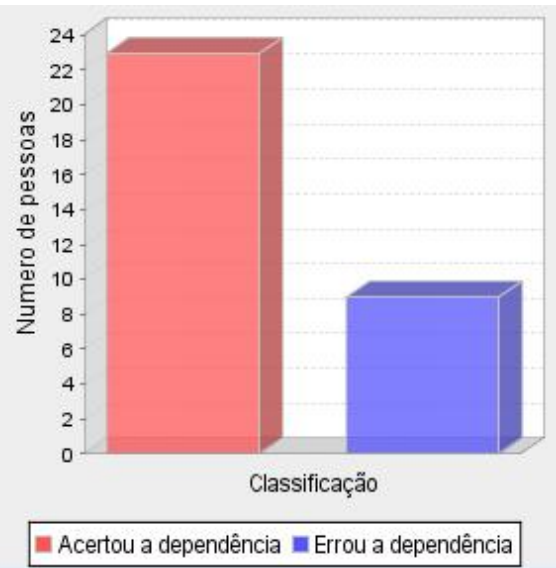

(a) Resultados obtidos na tarefa de análise de dependênica (Som + Cor) da etapa 1.

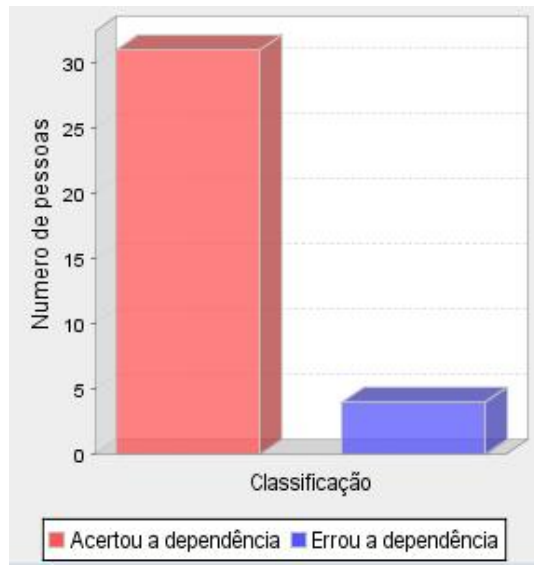

(b) Resultados obtidos na tarefa de análise de dependênica (Som + Cor) da etapa 2.

Figura 5.9: Resultados obtidos na tarefa de análise de dependência som e cor.

A Tabela 5.4 apresenta os intervalos de confiança dos resultados obtidos na tarefa. 
Tabela 5.4: Intervalos com nível de confiança de $95 \%$.

\begin{tabular}{|l|c|c|}
\hline Classificação & Etapa 1 & Etapa 2 \\
\hline \hline Acertar a dependência & $56.44-87.55 \%$ & $78.15-99.84 \%$ \\
\hline Errar a dependência & $12.44-43.55 \%$ & $0.15-21.84 \%$ \\
\hline
\end{tabular}

Os intervalos de confiança da diferença entre as proporções das duas etapas são: "Acertar a dependência": 0 a 1.96\%; "Errar a dependência": 0 a 35.96\%. Notamos que o zero está contido nos dois intervalos, portanto não há diferença significativa entre as proporções das Etapas 1 e 2 ( $72 \%$ e $89 \%)$ e (28\% e $11 \%)$, respectivamente, com nível de $95 \%$ de confiança.

\subsubsection{Tarefa de análise de dependência (Cor + Cor)}

As porcentagens de acertos e os tempos médios para realização dessa tarefa em ambas as etapas são apresentados na Tabela 5.5. Os atributos utilizados nesta tarefa apresentavam alta correlação, portanto a resposta correta é "Alta dependência".

Tabela 5.5: Tarefa de análise de dependência utilizando cor (Etapa 1 e Etapa 2).

\begin{tabular}{|l|c|c|}
\hline Classificação & Etapa 1 & Etapa 2 \\
\hline \hline Acertou a dependência & $9(28 \%)$ & $29(83 \%)$ \\
\hline Errou a dependência & $23(72 \%)$ & $6(17 \%)$ \\
\hline Tempo médio & 50 segundos & 32 segundos \\
\hline
\end{tabular}

Os resultados obtidos indicam que cor pode ser utilizada como um meio de análise de dependência entre atributos desde que seja estabelecido um espectro de cores com variação pequena ou média, por exemplo, de amarelo para marrom. Os resultados não foram satisfatórios quando utilizado todo o espectro de cores (arco-íris) para mapear os escalares das visualizações, como foi testado na primeira etapa do experimento. Essa diferença também colabora na validação de tabelas de cores uniformes para este tipo de tarefa. A Figura 5.10 apresenta os gráficos dos resultados obtidos para a tarefa de análise de dependência (Cor + Cor).

A Tabela 5.6 apresenta os intervalos de confiança dos resultados obtidos na tarefa.

Tabela 5.6: Intervalos com nível de confiança de $95 \%$.

\begin{tabular}{|l|c|c|}
\hline Classificação & Etapa 1 & Etapa 2 \\
\hline \hline Acertar a dependência & $12.4-43.5 \%$ & $70.0-96.0 \%$ \\
\hline Errar a dependência & $56.4-87.6 \%$ & $4.0-30.0 \%$ \\
\hline
\end{tabular}

Os intervalos de confiança da diferença entre as proporções das duas etapas são: "Acertar a dependência": -75.28 a -34.71\%; "Errar a dependência": 34.71 a 75.28\%. O primeiro intervalo corresponde a comparação entre as proporções de acerto $28 \%$ (da Etapa 1) contra $83 \%$ (da Etapa 2). O intervalo negativo indica que $p_{1}-p_{2}<0$, ou seja, $p_{1}=28 \%$ é significativamente inferior a $p_{2}=$ $83 \%$. O segundo intervalo positivo indica que $p_{1}-p_{2}>0$ ou seja, $p_{1}=72 \%$ é significativamente maior que $p_{2}=17 \%$. 


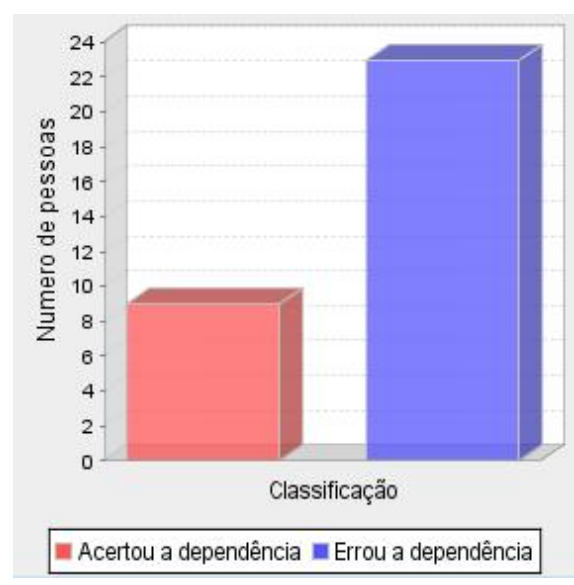

(a) Resultados obtidos na tarefa de análise de dependênica (Cor + Cor) da etapa 1.

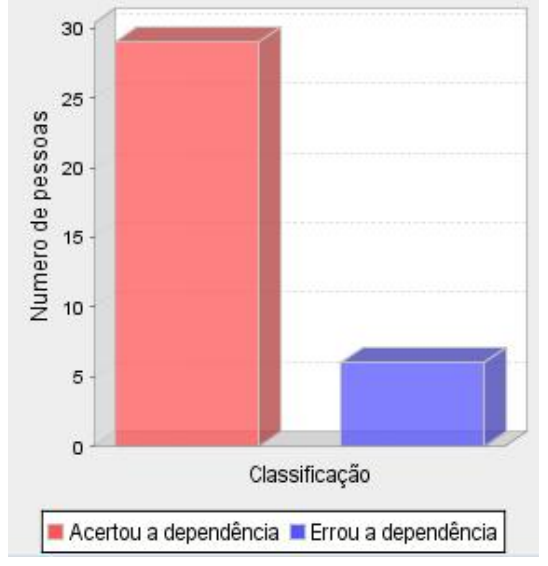

(b) Resultados obtidos na tarefa de análise de dependênica (Cor + Cor) da etapa 2.

Figura 5.10: Resultados obtidos na tarefa de análise de dependência utilizando cor.

\subsubsection{Tarefa de análise de densidades}

O tempo médio para realização dessa tarefa foi de 1 minuto e 40 segundos. As porcentagens de acertos e os intervalos de confiança (I.C) são apresentadas nas Tabelas 5.7 e 5.8.

Tabela 5.7: Tarefa de análise de densidade (maior densidade)

\begin{tabular}{|l|c|c|c|}
\hline Classificação & Nro. de pessoas & Porcentagem & I.C \\
\hline \hline Acertou a resposta & 30 & $94 \%$ & $86-100 \%$ \\
\hline Errou a resposta & 2 & $6 \%$ & $0-14 \%$ \\
\hline
\end{tabular}

Tabela 5.8: Tarefa de análise de densidade (menor densidade)

\begin{tabular}{|l|c|c|c|}
\hline Classificação & Nro. de pessoas & Porcentagem & I.C \\
\hline \hline Acertou a resposta & 30 & $94 \%$ & $86-100 \%$ \\
\hline Errou a resposta & 2 & $6 \%$ & $0-14 \%$ \\
\hline
\end{tabular}

Os resultados obtidos validam a aquisição de informações de um conjunto de dados através da sonificação gerada pelo Sonar 2D. As altas taxas de acerto (94\%) das perguntas presentes na tarefa confirmam que algumas características dos conjuntos de dados como "visão geral dos dados" e "existência de pontos específicos" (ver Seção 4.4.4), podem ser obtidas por meio da sonificação do sistema. A Figura 5.11 apresenta os gráficos dos resultados obtidos para a tarefa de análise de densidades.

\subsection{Considerações Finais}

Este capítulo descreveu os testes com usuários para avaliar e validar principalmente o uso de som como auxílio nas tarefas de investigação de dados em visualização interativa. As tarefas foram 


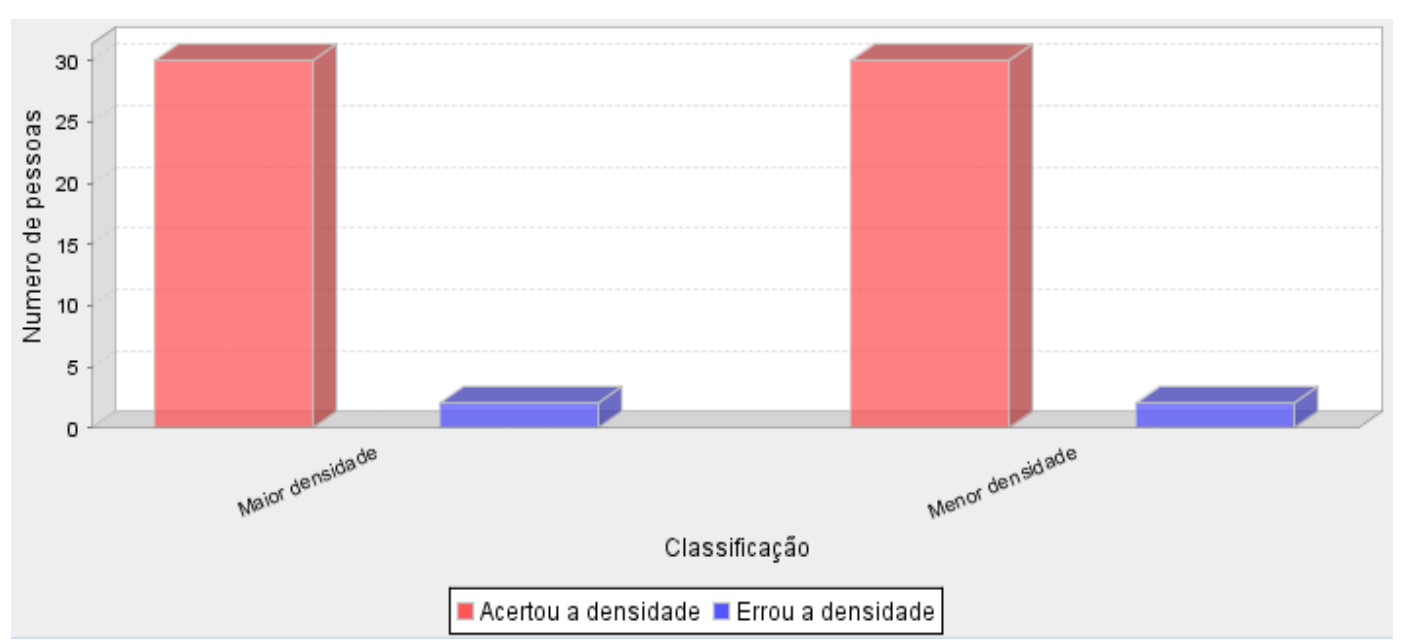

Figura 5.11: Resultados obtidos na tarefa de análise de densidades (Bar Chart).

realizadas utilizando um sistema interativo desenvolvido especificamente para o experimento e que contou com todas as características sonoras e visuais dos sistemas originais, Super Spider e Sonar 2D. As tarefas desempenhadas foram ordenação de regiões de uma visualização utilizando entoação sonora, análise de dependência entre atributos mapeados para cor e som, e quantificação de pontos utilizando sonificação.

Anteriormente à realização dos testes, foi realizado um teste piloto com colegas do departamento. O teste auxiliou a análise do tempo médio que os participantes levam para realizar as tarefas, a verificação da clareza e do conteúdo das instruções que são apresentadas na tela de cada tarefa e os testes de execução dos sistemas desenvolvidos e utilizados tanto para a realização do experimento quanto para a coleta e análise dos resultados.

Os resultados obtidos no experimento validaram a utilização de som em sistemas de visualização em todas as tarefas propostas no experimento. Os resultados também confirmam a hipótese que sonificação pode ser empregada para complementar a apresentação visual. O desempenho dos participantes reforçam a idéia de que o canal auditivo humano é tão eficiente quanto o canal visual na obtenção de informações.

No próximo capítulo são apresentadas as conclusões deste trabalho e algumas melhorias que podem ser realizadas futuramente. 



\section{CAPÍTULO \\ 6}

Conclusões

Este trabalho teve como principal objetivo estudar e desenvolver técnicas de sonificação em conjunto com visualização para auxiliar as tarefas de interpretação e entendimento de dados. Para isso, foi implementado no sistema Super Spider um módulo de sonificação pontual de dados que possibilita mapear valores escalares para sons com distintas propriedades sonoras: entoação, intensidade, inflexão da entoação, duração e timbre. Também foi desenvolvido o Sonar 2D, sistema integrado ao Super Spider que permite a sonificação de um conjunto de dados sem que seja necessário interagir com a visualização. O usuário define os itens sonoros que serão as representações sonoras dos pontos e o ponto central do Sonar. A sonificação é controlada por meio de controladores de um tocador musical.

Posteriormente ao desenvolvimento dessas ferramentas, foi realizado um experimento com usuários para avaliar e validar os mapeamentos sonoros e visuais utilizados nos sistemas. A principal motivação para este trabalho foi a perspectiva de utilização do canal auditivo como recurso alternativo num contexto onde o canal visual se encontra sobrecarregado.

Os estudos sobre uso de som para sistemas gráficos mostram que som tem colaborado tanto para reforçar as apresentações visuais quanto para representar dados. Experimentos têm sido realizados para avaliar o uso de som em sistemas gráficos para auxiliar o entendimento de informações e os resultados destes experimentos têm sido positivos. Os testes dos sistemas apresentados aqui foram realizados com o propósito de validar alguns dos mapeamentos sonoros utilizados, avaliar a eficiência do uso de sonificação em visualização interativa na realização de tarefas de ordenação, análise de dependência (correlação) de atributos e quantificação de registros.

Os resultados apresentados nos testes confirmam a utilidade de sonificação em sistemas de visualização principalmente na tarefa de ordenação de regiões de uma visualização utilizando en- 
toação sonora e na tarefa de análise de dependência de dois atributos de um conjunto de dados utilizando estímulos visuais e sonoros. Os testes também comprovaram que sonificação pode auxiliar no trabalho de quantificação (análise de densidade) de conjunto de registros categorizados pelos próprios valores.

Esses testes representam o início de um conjunto de testes que devem ser aplicados para avaliação completa do sistema Super Spider com o Sonar 2D. Outros testes para avaliação das ferramentas de interação e da utilidade dos métodos de sonificação e visualização disponíveis ainda devem ser realizados como continuação deste trabalho.

As principais contribuições deste trabalho são:

1. Implementação do módulo de sonificação da ferramenta Super Spider de modo a estender os recursos disponíveis para análise e exploração de visualizações. O módulo foi desenvolvido utilizando a API Java Sound e conta com um aparato de 128 timbres sonoros diferentes. Além disso, três propriedades sonoras parametrizáveis podem ser utilizadas no mapeamento dos dados: intensidade, entoação e inflexão da entoação.

2. Desenvolvimento de um novo sistema de sonificação de dados, o Sonar 2D, que permite ouvir as entidades de um conjunto de dados previamente categorizadas em propriedades sonoras distintas de acordo com seus valores escalares. O sistema está integrado ao sistema Super Spider e oferece um recurso alternativo na sonificação de dados. O Sonar 2D foi desenvolvido na linguagem Java utilizando as API's Java Sound e Java 3D.

3. Disponibilização dos sistemas para serem executados diretamente na $W e b$, bem como em diferentes sistemas operacionais, aproveitando a portabilidade da linguagem Java.

4. Avaliação do uso de sonificação como auxílio à visualização interativa por meio de testes com usuários para avaliar a utilidade do som em tarefas de interação com visualização e para validar os mapeamentos sonoros e visuais desenvolvidos nos sistemas.

\subsection{Trabalhos Futuros}

Duas ferramentas interativas de visualização e sonificação estão disponíveis até o presente momento, as quais possuem algumas funcionalidades interessantes como a fácil interação e os diferentes recursos para análise e exploração de dados nos aspectos visuais e sonoros. No entanto, algumas melhorias podem ser incorporadas para aumentar a interatividade e facilitar ainda mais a investigação dos dados. Algumas melhorias sugeridas para a ferramenta Super Spider são:

- A utilização de sons do dia-a-dia (ícones sonoros) deve ser avaliada e disponibilizada no sistema; 
- Estudo e implementação de novos mapeamentos visuais utilizando cor e realização de novos testes com usuários para validá-los;

- Novas técnicas de sonificação deverão ser desenvolvidas e incorporadas à ferramenta.

Algumas melhorias sugeridas para a ferramenta Sonar 2D são:

- Inclusão de sons do dia-a-dia no conjunto de sons produzido pelo sistema;

- Aplicação de novos testes com usuários para avaliar a identificação de outras informações de um conjunto de dados que são disponibilizadas através da sonificação gerada como (ver Seção 4.4.4): relação dos pontos com o ponto central e presença de cluster;

- Desenvolvimento de novas formas de percorrer e sonificar os pontos de um conjunto de dados, de modo que seja possível melhor identificar o posicionamento dos pontos na representação gráfica. 



\section{Referências Bibliográficas}

BARRASS, S.; Kramer, G. Using sonification. Secaucus, NJ, USA: Springer-Verlag New York, Inc., p. 23-31, 1999.

Berman, L. I.; Gallagher, K. B. Listening to program slices. In: Proceedings of the 2006 International Conference on Auditory Display, London, UK, 2006.

Disponível em http://www.dcs.qmul.ac.uk/research/imc/icad2006/ proceedings/papers / (Acessado em 17/01/2007)

Bonebright, T. L.; Miner, N. E.; Goldsmith, T. E.; Caudell, T. P. Data collection and analysis techniques for evaluating the perceptual qualities of auditory stimuli. In: Proceedings of the 1998 International Conference on Auditory Display, Glasgow, UK, 1998.

Disponível em www.icad.org/websiteV2.0/Conferences/ICAD98/papers/ BONEBRIG.PDF (Acessado em 16/02/2007)

Bonebright, T. L.; Nees, M. A.; Connerley, T. T.; McCain, G. R. Testing the effectiveness of sonified graphs for education: A programmatic research project. In: Proceedings of the 2001 International Conference on Auditory Display, Espoo, Finland, 2001.

Disponível em sonify.psych.gatech.edu/ mike/Nees\%20articles/ BonebrightNeesetal2001 ICAD.pdf (Acessado em 31/03/2007)

BRAZIL, E.; FERNSTRÖM, M. Investigating concurrent auditory icon recognition. In: Proceedings of the 2006 International Conference on Auditory Display, London, UK, 2006.

Disponível em http://www.dcs.qmul.ac.uk/research/imc/icad2006/ proceedings/papers / (Acessado em 31/03/2007)

Bregman, A. S. Auditory scene analysis: The perceptual organization of sound. The MIT Press, 1994.

Disponível em http://www.amazon.co.uk/exec/obidos/ASIN/0262521954/ citeulike-21 (Acessado em 16/02/2007) 
Brewster, S. A.; Wright, P. C.; Edwards, A. D. N. Auditory display: Sonification, audification, and auditory interfaces, cáp. A detailed investigation into the effectiveness of earcons. Addison-Wesley, p. 471-498, 1994.

Bussemakers, M. P.; Hann, A. D. When it sounds like a duck and it looks like a dog, auditory icons vs. earcons in multimedia environments. In: Proceedings of the 2000 International Conference on Auditory Display, Atlanta, GA, p. 184-189, 2000.

Disponível em http: //www. icad.org/websiteV2.0/Conferences/ICAD2000/ ICAD2 000 .html (Acessado em 05/07/2007)

de Campo, A.; Dayé, C.; Frauenberger, C.; Vogt, K.; Wallisch, A.; Eckel, G. Sonification as an interdisciplinary working process. In: Proceedings of the 2006 International Conference on Auditory Display, London, UK, 2006.

Disponível em http://www.dcs.qmul.ac.uk/research/imc/icad2006/ proceedings/papers / (Acessado em 17/01/2007)

ChILDS, E. Auditory graphs of real-time data. In: Proceedings of the 2005 International Conference on Auditory Display, Limerick, Ireland, 2005.

Disponível em http://sonify.psych.gatech.edu/ags2005/pdf/AGS05_ Childs.pdf (Acessado em 20/05/2007)

Cook, P. R.; Scavone, G. P. The synthesis toolkit (stk). Proceedings of 1999 Int. Computer Music Conf., p. 164-166, computer Music Association, Beijing, China, 1999.

CORPOHUMANO.HPG.IG.COM.BR Aparelhos sensoriais-ouvido. 2007.

Disponível em http://www.corpohumano.hpg.ig.com.br/apr_sensoriais/ ouvido/ouvido.html (Acessado em 09/02/2007)

Dieberger, A. A sonification enhanced navigation tool. In: Proceedings of the 2000 International Conference on Auditory Display, Atlanta, GA, p. 173-176, 2000.

Disponível em http://www.icad.org/websiteV2.0/Conferences/ICAD2000/ ICAD2 000 .html (Acessado em 17/01/2007)

FAloutsos, C.; Lin, K. Fastmap: A fast algorithm for indexing, datamining and visualization of traditional and multimedia databases. In: ACM SIGMOD Intl Conf. on Manag. of Data, San Jose-CA, USA: ACM Press: New York, p. 163-174, 1995.

Fitch, T.; Kramer, G. Auditory display: Sonification, audification, and auditory interfaces, cáp. Sonifying the body electric: Superiority of an auditory over a visual display in a complex multivariate system. Addison-Wesley, p. 307-325, 1994.

Frauenberger, C.; Stockman, T. Patterns in auditory menu design. In: Proceedings of the 2006 International Conference on Auditory Display, London, UK, 2006. 
Disponível em http://www.dcs.qmul.ac.uk/research/imc/icad2006/ proceedings/papers/ (Acessado em 16/05/2007)

GAVER, W. W. The sonicfinder: An interface that uses auditory icons. The Journal of HumanComputer Interaction, v. 4, n. 1, p. 67-94, 1989.

GAVER, W. W. Auditory display: Sonification, audification, and auditory interfaces, cáp. Using and creating auditory icons. Addison-Wesley, p. 417-446, 1994.

GAver, W. W.; SMITH, R. B.; O'SHEA, T. Effective sounds in complex systems: the arkola simulation. In: CHI '91: Proceedings of the SIGCHI conference on Human factors in computing systems, New York, NY, USA: ACM Press, p. 85-90, 1991.

DE HaAn, G.; KouteK, M.; Post, F. H. Towards intuitive exploration tools for data visualization in vr. In: VRST '02: Proceedings of the ACM symposium on Virtual reality software and technology, New York, NY, USA: ACM Press, p. 105-112, 2002.

Hansen, M. D.; Charp, E.; Lodha, S. K.; Meads, D.; Pang, A. Promuse: A system for multi-media data presentation of protein structural alignments. In: Proceedings of the 4th Pacific Symposium on Biocomputing (PSB'99), Big Island of Hawaii, USA, p. 368-379, 1999.

Disponível em http://helix-web. stanford.edu/psb99/Hansen.pdf (Acessado em 04/01/2007)

Hastie, T.; Stuetzle, W. Principal curves. Journal of the American Statistical Association, v. 84, p. 502-516, 1989.

HAYWARD, C. Auditory display: Sonification, audification, and auditory interfaces, cáp. Listening to the Earth Sing. Addison-Wesley, p. 369-404, 1994.

Hermann, T. Sonification for exploratory data analysis. Tese de Doutoramento, Universität Bielefeld, 2002.

Hermann, T.; Drees, J. M.; H., R. Broadcasting auditory weather reports - a pilot project. In: Proc. International Conference on Auditory Display (ICAD 2003), Boston, MA, USA, p. 208-211, 2003a.

Disponível em http://www.icad.org/websiteV2.0/Conferences/ICAD2003/ paper $/ 51 \% 20$ Hermann 1-20weather.pdf (Acessado em 17/01/2007)

Hermann, T.; Hunt, A. Guest editors' introduction: An introduction to interactive sonification. IEEE MultiMedia, Los Alamitos, CA, USA, v. 12, n. 2, p. 20-24, 2005.

Hermann, T.; Meinicke, P.; Ritter, H. Principal curve sonification. In: Proceedings of the 2000 International Conference on Auditory Display, Atlanta, Georgia, USA, p. 81-86, 2000. Disponível em http://www. icad.org/websiteV2.0/Conferences/ICAD2000/ ICAD 2000. html (Acessado em 07/01/2007) 
Hermann, T.; Niehus, C.; RitTer, H. Interactive visualization and sonification for monitoring complex processes. In: Proceedings of the 2003 International Conference on Auditory Display, Boston, USA, p. 247-250, 2003b.

Disponível em www.icad.org/websiteV2.0/Conferences/ICAD2003/paper/ $60 \% 20$ Hermann2-\%20 complex.pdf (Acessado em 17/01/2007)

Hermann, T.; Ritter, H. Listen to your data: Model-based sonification for data analysis. In: Proceedings of Advances in Intelligent Computing and Multimedia Systems (AICMS) 1999, Baden-Baden, Germany, p. 189-194, 1999.

Hermann, T.; Ritter, H. Crystallization sonification of high-dimensional datasets. In: Proceedings of the 2002 International Conference on Auditory Display, Kyoto, Japan, p. 76-81, 2002.

Disponível em http://www.icad.org/websiteV2.0/Conferences/ICAD2002/ proceedings / (Acessado em 17/01/2007)

Hinterberger, T.; Baier, G. Parametric orchestral sonification of eeg in real time. IEEE MultiMedia, Los Alamitos, CA, USA, v. 12, n. 2, p. 70-79, 2005.

Holmes, J. Interacting with an information space using sound: Accuracy and patterns. In: Proceedings of the 2005 International Conference on Auditory Display, Limerick, Ireland, 2005.

Disponível em http://www.idc.ul.ie/icad2005/downloads/f91.pdf (Acessado em 17/01/2007)

JanAtA, P.; ChIlds, E. Marketbuzz: Sonification of real-time financial data. In: Proceedings of the 2004 International Conference on Auditory Display, Sydney, Australia, 2004.

Disponível em www.icad.org/websiteV2.0/Conferences/ICAD2004/papers/ janata_childs.pdf (Acessado em 09/01/2007)

JosePh, A. J.; LodhA, S. K. Musart: Musical audio transfer function real-time toolkit. In: Proceedings of the 2002 International Conference on Auditory Display, Kyoto, Japan, 2002.

Disponível em www.icad.org/websiteV2.0/Conferences/ICAD2002/ proceedings/01_AbigailJoseph.pdf (Acessado em 11/01/2007)

KrAMER, G. Auditory display: Sonification, audification, and auditory interfaces, cáp. An introduction to auditory display. Addison-Wesley, p. 1-79, 1994.

Lodha, S. K.; Beahan, J.; Heppe, T.; Joseph, A.; Zane-Ulman, B. Muse: A musical data sonification toolkit. In: Proceedings of the 1997 International Conference on Auditory Display, Palo Alto, USA., p. 36-40, 1997.

Disponível em http://www.santafe.edu/ icad/websiteV2.0/Conferences/ ICAD 97 /ABSTR97.html (Acessado em 04/01/2007) 
Lodha, S. K.; Sheehan, B.; Pang, A. T.; Wittenbrink, C. M. Visualizing geometric uncertainty of surface interpolants. In: DAVIS, W. A.; BARTELS, R., eds. Graphics Interface '96, Canadian Human-Computer Communications Society, p. 238-245, 1996.

Disponível em citeseer.ist.psu.edu/lodha96visualizing.html (Acessado em 31/03/2007)

MCCABE, K.; RAngwalla, A. Auditory display: Sonification, audification, and auditory interfaces, cáp. Auditory display of computational fluid dynamics data. Addison-Wesley, p. 327-340, 1994.

MeIJer, P. The voice - seeing with sound. 2003.

Disponível em http: / / www.artificialvision.com/ (Acessado em 31/03/2007)

Minghim, R.; FORREST, A. R. An illustrated analysis of sonification for scientific visualisation. In: Proc. of IEEE Visualization'95, Atlanta, USA: IEEE CS Press, p. 110-117, 1995.

Minghim, R.; Levkowitz, H.; Nonato, L. G.; Watanabe, L.; Salvador, V.; Lopesk, H.; Pesco, S.; TAVARES., G. Spider cursor: A simple versatile exploration tool for data visualization . GRAPHITE'05 - 3rd International Conference on Computer Graphics and Interactive Techniques in Australasia and Southeast Asia. Proceedings of Graphite 2005, ACM Press, p. 307-313, 2005.

Minghim, R.; Oliveira, M. C. F. Uma introdução à visualização computacional. In: JAI Jornadas de Atualização em Informática, Brasília - DF, Brasil: SBC, p. 45, 1997.

Minghim, R.; Paulovich, F. V.; Lopes, A. A. Content-based text mapping using multidimensional projections for exploration of document collections. In: IS\&T/SPIE Symposium on Electronic Imaging - Visualization and Data Analysis, San Jose, California, 2006.

MoOre, F. R. Elements of computer music. Prentice Hall, 1990.

NAKatani, T.; Miyoshi, M. Blind dereverberation of single channel speech signal based on harmonic structure. In: Proc. IEEE Int. Conf. Acoust. Speech, Signal Processing, HongKong, China, p. 92-95, 2003.

NeSBitT, K. V.; BARRASS, S. Evaluation of a multimodal sonification and visualization of depth of market stock data. In: Proceedings of the 2002 International Conference on Auditory Display, Kyoto, Japan, p. 233-238, 2002.

Disponível em http://www.icad.org/websiteV2.0/Conferences/ICAD2002/ proceedings/51_KeithNesbitt.pdf (Acessado em 17/01/2007)

Neuhoff, J. G.; Kramer, G.; Wayand., J. Sonification and the interaction of perceptual dimensions, can the data get lost in the map? In Proceedings of the 2000 International Conference on Auditory Display. Atlanta, Georgia,USA, p. 93-98, 2000. 
Disponível em http://www.icad.org/websiteV2.0/Conferences/ICAD2000/ ICAD 2000 . html (Acessado em 05/07/2007)

Nonato, L. G.; Minghim, R.; F., O. M. C.; Tavares, G. A novel approach for delaunay 3d reconstruction with a comparative analysis in the light of applications. In: Computer Graphics Forum, p. 161-171, 2001.

Papp, A. L.; Blattner, M. M.; Glinert., E. P. Auditory display: Sonification, audification, and auditory interfaces, cáp. Sonic enhancement of twodimensional graphics displays. AddisonWesley, p. 447-470, 1994.

PATTERSON, R. D. Guidelines for auditory warning systems on civil aircraft. Relatório Técnico, Civil Aviation Authority, London, UK, 1982.

Pauletto, S.; Hunt, A. A toolkit for interactive sonification. In: Proceeding of the 2004 International Conference on Auditory Display, Sydney, Australia, 2004.

Disponível em www.icad.org/websiteV2.0/Conferences/ICAD2004/papers/ pauletto_hunt.pdf (Acessado em 09/01/2007)

Pauletto, S.; Hunt, A. A comparison of audio \& visual analysis of complex time-series data sets. In: Proceedings of the 2005 International Conference on Auditory Display, Limerick, Ireland, 2005.

Disponível em http://www.idc.ul.ie/icad2005/downloads/£30.pdf (Acessado em 17/01/2007)

Paulovich, F.; De Oliveira, M.; Minghim, R. The projection explorer: A flexible tool for projection-based multidimensional visualization (to appear). In: Proceedings of XX Brazilian Symposium on Computer Graphics and Image Processing - SIBIGRAPI 2007, Belo Horizonte, Brazil: IEEE CS Press, 2007.

Peres, S. C.; Lane, D. M. Sonification of statistical graphs. In: Proceedings of the 2003 International Conference on Auditory Display, Boston, MA, USA, p. 157-160, 2003.

Disponível em www.icad.org/websiteV2.0/Conferences/ICAD2003/paper/ $38 \% 20$ Peres.pdf (Acessado em 17/01/2007)

PNUD Desenvolvimento humano e idh. (Programa das Nações Unidas para o Desenvolvimento), 2007.

Disponível em http: / /www.pnud.org.br/idh/ (Acessado em 04/07/2007)

Ramaswamy, L.; Hutchinson, T.; Kuester, F. Towards enhancing earthquake response interpretation using sonification. In: Proceedings of the 2004 International Conference on Auditory Display, Sydney, Australia, 2004.

Disponível em Www.icad.org/websiteV2.0/Conferences/ICAD2004/ posters/ramaswamy_hutchinson_kuester.pdf (Acessado em 09/01/2007) 
Roth, P.; Petrucci, L.; Assimacopoulos, A.; Pun, T. Ab-web: Active audio browser for visually impaired and blind users. In: Proceedings of the 1998 International Conference on Auditory Display, Glasgow, UK, p. 16, 1998.

Salvador, V.; Minghim, R.; PACheco, M. Sonification to support visualization tasks. In: SIBGRAPHI '98: Proceedings of the International Symposium on Computer Graphics, Image Processing, and Vision, Washington, DC, USA: IEEE Computer Society, p. 150, 1998.

SALVADOR, V. C. L. Development of a model for exploration in distributed scientific visualization using sound (in portuguese). Tese de Doutoramento, USP - Inst. Math.Comput., São Carlos - SP, Brazil, 2003.

SAlvador, V. C. L.; Minghim, R. An interaction model for scientific visualization using sound. In: SIBGRAPI, Los Alamitos, CA, USA: IEEE Computer Society, p. 132, 2003.

Salvador, V. C. L.; Minghim, R.; Levkowitz, H. Dsvol ii - a distributed visualization and sonification application communicating via an xml-based protocol. In: SIBGRAPI '02: Proceedings of the 15th Brazilian Symposium on Computer Graphics and Image Processing, Washington, DC, USA: IEEE Computer Society, p. 35-42, 2002.

SAlvador, V. C. L.; Minghim, R.; LeVkowitz., H. User evaluations of interactive multimodal data presentation. 9th International Conference on Information Visualization, London, UK, IEEE CS Press., p. 11-16, 2005.

SAuE, S. A model for interaction in exploratory sonification displays. In: Proceedings of the 2000 International Conference on Auditory Display, Atlanta, Georgia, USA, p. 105-110, 2000. Disponível em http: //www. icad.org/websiteV2.0/Conferences/ICAD2000/ ICAD2000.html (Acessado em 17/01/2007)

Scaletti, C. Auditory display: Sonification, audification, and auditory interfaces, cáp. Sound Synthesis Algorithms for Auditory Data Representations. Addison-Wesley, p. 223-252, 1994.

Schroeder, W. J.; Martin, K.; Lorensen, W. Vtk, the visualization toolkit, 3rd edition. Prentice-Hall, 2003.

Smith, D. R.; WALKer, B. N. Tick-marks, axes, and labels: The effects of adding context to auditory graphs. In: Proceedings of the 2002 International Conference on Auditory Display, Kyoto, Japan, p. 362-367, 2002.

Disponível em http://www. icad.org/websiteV2.0/Conferences/ICAD2002/ proceedings / (Acessado em 11/01/2007)

Smith, S.; Picket, R. M.; Williams, M. G. Auditory display: Sonification, audification, and auditory interfaces, cáp. Environments for Exploring Auditory Representations of Multidimensional Data. Addison-Wesley, p. 167-184, 1994. 
Stevens, C.; Brennan, D.; PARKer, S. Simultaneous manipulation of parameters of auditory icons to convey direction, size, and distance: Effects on recognition and interpretation. In: Proceedings of the 2004 International Conference on Auditory Display, Sydney, Australia, 2004. Disponível em www.icad.org/websiteV2.0/Conferences/ICAD2004/papers/ stevens_brenna_parker.pdf (Acessado em 31/03/2007)

Thomas, T. Sonifikation von borsendaten. Dissertação de Mestrado, Bielefeld University, 2001.

Walker, B. N.; Cothran, J. T. Sonification sandbox: A graphical toolkit for auditory graphs. In: Proceedings of the 2003 International Conference on Auditory Display, Boston, MA, USA, p. 161-163, 2003.

Disponível em www.icad.org/websiteV2.0/Conferences/ICAD2003/paper/

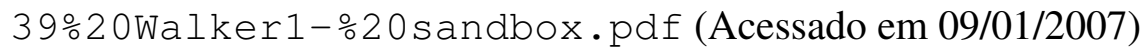

WALKER, B. N.; LindSAY, J.; Godfrey, J. The audio abacus: Representing a wide range of values with accuracy and precision. In: Proceedings of the 2004 International Conference on Auditory Display, Sydney, Australia, 2004.

Disponível em http: //www.icad.org/websiteV2.0/Conferences/ICAD2004/ papers/walker_lindsay_godfrey.pdf (Acessado em 31/03/2007)

WAlker, B. N.; NANCE, A.; Lindsay, J. Spearcons: Speech-based earcons improve navigation performance in auditory menus. In: Proceedings of the 2006 International Conference on Auditory Display, London, UK, 2006.

Disponível em http://www.dcs.qmul.ac.uk/research/imc/icad2006/ proceedings/papers / (Acessado em 17/01/2007)

Walpole, R.; Myers, R.; Myers, S.; Ye, K. Probability \& statistics for engineers \& scientists. New Jersey, USA: Prentice Hall, 2002.

WATANABE, L. Super spider: uma ferramenta versátil para exploração de dados multidimensionais representados por malhas de triângulos. Dissertação de Mestrado, Universidade de São Paulo, Instituto de Ciências Matemáticas e Computação, São Carlos, Brasil, 2007.

Watson, M. Scalable earcons: Bridging the gap between intermittent and continuous auditory displays. In: Proceedings of the 2006 International Conference on Auditory Display, London, UK, 2006.

Disponível em http://www.dcs.qmul.ac.uk/research/imc/icad2006/ proceedings/papers/ (Acessado em 17/01/2007)

WIKIPEDIA Wikipedia sonido. 2007.

Disponível em http: / /es.wikipedia.org/wiki/Sonido (Acessado em 09/02/2007)

Williams, S. M. Auditory display: Sonification, audification, and auditory interfaces, cáp. Perceptual principles in sound grouping. Addison-Wesley, p. 95-126, 1994. 
Wilson, C. M.; Lodha, S. K. Listen: A data sonification toolkit. In: Proceedings of the 1996 International Conference on Auditory Display, Palo Alto, CA, USA, p. 35-40, 1996.

Disponível em http://www.santafe.edu/ icad/ICAD96/proc96/lodha.htm (Acessado em 04/01/2007)

Yeo, W. S.; Berger, J.; LeE, Z. Sonart: A framework for data sonification, visualization and networked multimedia applications. In: Proceedings of the 2004 International Computer Music Conference (ICMC 2004), Miami, USA, p. 180-184, 2004.

YEUng, E. S. Pattern recognition by audio representation of multivariate analytical data. Analytical Chemistry, v. 52, n. 7, p. 1120-1123, 1980.

Zhao, H.; Smith, B. K.; Norman, K.; Plaisant, C.; Shneiderman, B. Interactive sonification of choropleth maps. IEEE MultiMedia, Los Alamitos, CA, USA, v. 12, n. 2, p. 26$35,2005$. 

APÊNDICE

\section{$A$}

Resultados dos testes aplicados 
Tabela A.1: Resultados de cada participante na tarefa de ordenação - Etapa 1 \begin{tabular}{|l|l|l|}
\hline Participante & Tarefa de ordenação $(4,1,2,3)$ & Tempo min. \\
\hline
\end{tabular}

\begin{tabular}{|c|c|c|}
\hline 1 & $(4,1,2,3)$ & $00: 43$ \\
\hline 2 & $(4,1,2,3)$ & $00: 49$ \\
\hline 3 & $(4,1,2,3)$ & $00: 54$ \\
\hline 4 & $(4,1,2,3)$ & $00: 36$ \\
\hline 5 & $(4,1,2,3)$ & $00: 45$ \\
\hline 6 & $(4,1,2,3)$ & $00: 44$ \\
\hline 7 & $(1,4,3,2)$ & $01: 29$ \\
\hline 8 & $(4,1,2,3)$ & 01:03 \\
\hline 9 & $(4,1,3,2)$ & $00: 37$ \\
\hline 10 & $(2,3,4,1)$ & $00: 45$ \\
\hline 11 & $(4,2,3,1)$ & $00: 53$ \\
\hline 12 & $(4,1,3,2)$ & $00: 52$ \\
\hline 13 & $(4,1,2,3)$ & $00: 59$ \\
\hline 14 & $(4,1,2,3)$ & $00: 51$ \\
\hline 15 & $(4,1,3,2)$ & $00: 39$ \\
\hline 16 & $(4,1,2,3)$ & $00: 31$ \\
\hline 17 & $(4,1,2,3)$ & $00: 54$ \\
\hline 18 & $(4,1,2,3)$ & $00: 56$ \\
\hline 19 & $(4,1,2,3)$ & $00: 21$ \\
\hline 20 & $(4,1,2,3)$ & $00: 30$ \\
\hline 21 & $(4,1,2,3)$ & 01:07 \\
\hline 22 & $(4,1,2,3)$ & 01:00 \\
\hline 23 & $(4,1,2,3)$ & $00: 48$ \\
\hline 24 & $(4,1,2,3)$ & $00: 44$ \\
\hline 25 & $(4,1,2,3)$ & $00: 40$ \\
\hline 26 & $(4,1,2,3)$ & $01: 03$ \\
\hline 27 & $(4,1,2,3)$ & $01: 50$ \\
\hline 28 & $(4,1,2,3)$ & $00: 32$ \\
\hline 29 & $(4,1,2,3)$ & $00: 27$ \\
\hline 30 & $(4,1,2,3)$ & $00: 34$ \\
\hline 31 & $(4,1,2,3)$ & $00: 36$ \\
\hline 32 & $(4,1,2,3)$ & $02: 10$ \\
\hline
\end{tabular}


Tabela A.2: Resultados da tarefa de análise (Som + Cor) e (Cor + Cor) - Etapa 1

\begin{tabular}{|c|c|c|c|c|}
\hline Participante & Tarefa (Som + Cor) (Alta) & Tempo min. & Tarefa (Cor + Cor) (Alta) & Tempo min. \\
\hline 1 & Alta Dep. & $00: 51$ & Baixa Dep. & 00:56 \\
\hline 2 & Alta Dep. & $00: 35$ & Baixa Dep. & $00: 16$ \\
\hline 3 & Alta Dep. & $00: 35$ & Baixa Dep. & $00: 35$ \\
\hline 4 & Alta Dep. & $00: 21$ & Baixa Dep. & $00: 54$ \\
\hline 5 & Alta Dep. & $01: 17$ & Baixa Dep. & $00: 23$ \\
\hline 6 & Alta Dep. & $00: 28$ & Alta Dep. & $00: 31$ \\
\hline 7 & Baixa Dep. & $00: 43$ & Baixa Dep. & $00: 41$ \\
\hline 8 & Alta Dep. & $01: 39$ & Baixa Dep. & $01: 44$ \\
\hline 9 & Alta Dep. & $01: 37$ & Baixa Dep. & $01: 11$ \\
\hline 10 & Alta Dep. & $00: 34$ & Baixa Dep. & 00:40 \\
\hline 11 & Alta Dep. & 00:08 & Alta Dep. & $00: 13$ \\
\hline 12 & Alta Dep. & $00: 54$ & Baixa Dep. & $00: 34$ \\
\hline 13 & Baixa Dep. & $00: 25$ & Baixa Dep. & $00: 49$ \\
\hline 14 & Baixa Dep. & $00: 48$ & Alta Dep. & $00: 55$ \\
\hline 15 & Alta Dep. & $00: 32$ & Baixa Dep. & $00: 32$ \\
\hline 16 & Baixa Dep. & $00: 30$ & Alta Dep. & $00: 24$ \\
\hline 17 & Alta Dep. & $00: 38$ & Alta Dep. & $00: 31$ \\
\hline 18 & Alta Dep. & $00: 52$ & Baixa Dep. & 01:04 \\
\hline 19 & Alta Dep. & 00:02 & Baixa Dep. & $00: 33$ \\
\hline 20 & Alta Dep. & $00: 22$ & Baixa Dep. & $00: 24$ \\
\hline 21 & Alta Dep. & $00: 49$ & Baixa Dep. & 01:00 \\
\hline 22 & Alta Dep. & $00: 28$ & Alta Dep. & 02:05 \\
\hline 23 & Alta Dep. & 01:08 & Baixa Dep. & $00: 41$ \\
\hline 24 & Baixa Dep. & $00: 24$ & Alta Dep. & $00: 30$ \\
\hline 25 & Alta Dep. & 01:01 & Baixa Dep. & $00: 38$ \\
\hline 26 & Alta Dep. & $01: 23$ & Baixa Dep. & $00: 55$ \\
\hline 27 & Alta Dep. & $00: 54$ & Baixa Dep. & $02: 10$ \\
\hline 28 & Baixa Dep. & $00: 40$ & Baixa Dep. & $00: 18$ \\
\hline 29 & Baixa Dep. & $00: 28$ & Baixa Dep. & $00: 18$ \\
\hline 30 & Alta Dep. & $00: 44$ & Alta Dep. & $01: 53$ \\
\hline 31 & Baixa Dep. & $01: 45$ & Baixa Dep. & 01:03 \\
\hline 32 & Baixa Dep. & $00: 57$ & Alta Dep. & 01:29 \\
\hline
\end{tabular}


Tabela A.3: Resultados da tarefa de análise de densidades com o Sonar - Etapa 1

\begin{tabular}{|l|c|c|c|}
\hline Participante & Maior densidade (IDH Medio) & Menor densidade (IDH Alto) & Tempo min. \\
\hline \hline 1 & IDH Medio & IDH Alto & $02: 17$ \\
\hline 2 & IDH Medio & IDH Alto & $01: 03$ \\
\hline 3 & IDH Medio & IDH Alto & $01: 25$ \\
\hline 4 & IDH Medio & IDH Alto & $00: 55$ \\
\hline 5 & IDH Medio & IDH Alto & $03: 32$ \\
\hline 6 & IDH Medio & IDH Alto & $01: 00$ \\
\hline 7 & IDH Medio & IDH Alto & $02: 09$ \\
\hline 8 & IDH Medio & IDH Alto & $01: 43$ \\
\hline 9 & IDH Medio & IDH Alto & $03: 10$ \\
\hline 10 & IDH Medio & IDH Alto & $01: 07$ \\
\hline 11 & IDH Medio & IDH Alto & $00: 51$ \\
\hline 12 & IDH Medio & IDH Baixo & $01: 06$ \\
\hline 13 & IDH Medio & IDH Alto & $01: 30$ \\
\hline 14 & IDH Medio & IDH Baixo & $01: 11$ \\
\hline 15 & IDH Alto & $01: 42$ \\
\hline 16 & IDH Medio & IDH Alto & $01: 00$ \\
\hline 17 & IDH Medio & IDH Alto & $00: 56$ \\
\hline 18 & IDH Medio & IDH Alto & $02: 18$ \\
\hline 19 & IDH Medio & IDH Alto & $01: 43$ \\
\hline 20 & IDH Medio & IDH Alto & $03: 10$ \\
\hline 21 & IDH Medio & IDH Alto & $01: 39$ \\
\hline 22 & IDH Medio & IDH Alto & $01: 10$ \\
\hline 23 & IDH Medio & IDH Alto & $00: 59$ \\
\hline 24 & IDH Baixo & IDH Alto & $01: 45$ \\
\hline 25 & IDH Medio & IDH Alto & $01: 44$ \\
\hline 26 & IDH Medio & IDH Alto & $01: 59$ \\
\hline 27 & IDH Medio & IDH Alto & $01: 21$ \\
\hline 28 & IDH Medio & IDH Alto & $01: 13$ \\
\hline 29 & IDH Medio & IDH Alto & $02: 11$ \\
\hline 30 & IDH Medio & & $01: 45$ \\
\hline 31 & IDH Baixo & & \\
\hline 32 & IDH Medio & & \\
\hline
\end{tabular}


Tabela A.4: Resultados da tarefa de análise (Cor + Cor) e (Som + Cor) - Etapa 2

\begin{tabular}{|c|c|c|c|c|}
\hline Participante & Tarefa (Cor + Cor) (Alta) & Tempo min. & Tarefa (Som + Cor) (Alta) & Tempo min. \\
\hline 1 & Alta Dep. & $01: 22$ & Alta Dep. & 01:00 \\
\hline 2 & Alta Dep. & $00: 23$ & Alta Dep. & $01: 13$ \\
\hline 3 & Alta Dep. & $00: 34$ & Alta Dep. & 01:06 \\
\hline 4 & Alta Dep. & 01:00 & Alta Dep. & $00: 54$ \\
\hline 5 & Alta Dep. & $00: 13$ & Alta Dep. & $02: 38$ \\
\hline 6 & Alta Dep. & 00:09 & Alta Dep. & $00: 29$ \\
\hline 7 & Baixa Dep. & $00: 26$ & Baixa Dep. & $00: 21$ \\
\hline 8 & Alta Dep. & 00:06 & Alta Dep. & $00: 14$ \\
\hline 9 & Alta Dep. & $00: 24$ & Alta Dep. & $00: 33$ \\
\hline 10 & Alta Dep. & $00: 13$ & Alta Dep. & $00: 14$ \\
\hline 11 & Alta Dep. & $00: 44$ & Alta Dep. & 01:04 \\
\hline 12 & Alta Dep. & $00: 20$ & Alta Dep. & $00: 25$ \\
\hline 13 & Alta Dep. & $00: 51$ & Alta Dep. & $00: 31$ \\
\hline 14 & Baixa Dep. & 01:04 & Alta Dep. & $00: 51$ \\
\hline 15 & Alta Dep. & $00: 25$ & Alta Dep. & $00: 37$ \\
\hline 16 & Alta Dep. & $01: 24$ & Alta Dep. & 01:00 \\
\hline 17 & Alta Dep. & $00: 14$ & Alta Dep. & $00: 31$ \\
\hline 18 & Alta Dep. & $00: 49$ & Alta Dep. & $01: 35$ \\
\hline 19 & Alta Dep. & $00: 28$ & Alta Dep. & $00: 52$ \\
\hline 20 & Baixa Dep. & $00: 10$ & Baixa Dep. & $00: 53$ \\
\hline 21 & Alta Dep. & $00: 19$ & Alta Dep. & 01:08 \\
\hline 22 & Alta Dep. & $00: 30$ & Baixa Dep. & $00: 59$ \\
\hline 23 & Alta Dep. & 00:06 & Alta Dep. & $00: 47$ \\
\hline 24 & Baixa Dep. & $00: 15$ & Alta Dep. & $00: 19$ \\
\hline 25 & Alta Dep. & $00: 02$ & Alta Dep. & 01:00 \\
\hline 26 & Alta Dep. & 01:09 & Alta Dep. & $00: 46$ \\
\hline 27 & Baixa Dep. & $00: 17$ & Alta Dep. & $00: 54$ \\
\hline 28 & Alta Dep. & $00: 06$ & Alta Dep. & 01:02 \\
\hline 29 & Alta Dep. & $00: 31$ & Baixa Dep. & $04: 29$ \\
\hline 30 & Alta Dep. & $00: 49$ & Alta Dep. & 01:05 \\
\hline 31 & Alta Dep. & $00: 29$ & Alta Dep. & $00: 32$ \\
\hline 32 & Baixa Dep. & $00: 35$ & Alta Dep. & $00: 50$ \\
\hline 33 & Alta Dep. & 01:03 & Alta Dep. & $00: 32$ \\
\hline 34 & Alta Dep. & $00: 37$ & Alta Dep. & $00: 37$ \\
\hline 35 & Alta Dep. & $00: 56$ & Alta Dep. & $00: 16$ \\
\hline
\end{tabular}

